Assessment of Very High-Temperature Reactors in Process Application

\title{
Appendix I-Evaluation of the
} Reactor System

John E. Jones, Jr. Irving Spiewak

\section{MASTER}

\section{OAK RIDGE NATIONAL LABORATORY}

OPERATED BY UNION CARBIDE CORPORATION FOR THE FNFRGY RFSFARIH ANII IIFVELOPMENT ADMINISTRATION 


\section{DISCLAIMER}

This report was prepared as an account of work sponsored by an agency of the United States Government. Neither the United States Government nor any agency Thereof, nor any of their employees, makes any warranty, express or implied, or assumes any legal liability or responsibility for the accuracy, completeness, or usefulness of any information, apparatus, product, or process disclosed, or represents that its use would not infringe privately owned rights. Reference herein to any specific commercial product, process, or service by trade name, trademark, manufacturer, or otherwise does not necessarily constitute or imply its endorsement, recommendation, or favoring by the United States Government or any agency thereof. The views and opinions of authors expressed herein do not necessarily state or reflect those of the United States Government or any agency thereof. 


\section{DISCLAIMER}

Portions of this document may be illegible in electronic image products. Images are produced from the best available original document. 
Printed in the United States of America. Available from National Technical Information Service

U.S. Department of Commerce

5285 Port Royal Road, Springfield, Virginia 22161

Price: Printed Copy $\$ 6.75$; Microfiche $\$ 3.00$

This report was prepared as an account of work sponsored by the United States Government. Neither the United States nor the Energy Research and Development Administration/United States Nuclearr Regulatory Commission, nor any of their employees, nor any of their contractors, subcontractors, or their employees, makes any warranty, express or implied, or assumes any legal liability or responsibility for the accuracy, completeness or usefulness of any information, apparatus, product or process disclosed, or represents that its use would not infringe privately owned rights. 
ORNL/TM-5409

(Appendix I of ORNL/TM-5242)

Contract No. W-7405-eng-26

ENGINEERING TECHNOLOGY DIVISION

ASSESSMENT OF VERY HIGH-TEMPERATURE REACTORS

IN PROCESS APPLICATION

APPENDIX I - EVALUATION OF THE REACTOR SYSTEM

Date Published: December 1976

John E. Jones, Jr. Irving Spiewak

This report was prepared as an account of work sponsored by the United States Government. Neither Research ond Developere the their employces, not any of their contractors, subcontractors, or their employees, makes any warranty, express or implied, or assumes any legal

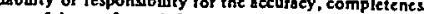
of userulness of any information, apparatus, product or process disclosed, or represents that its use would not
infringe privately owned rights.

Prepared by

OAK RIDGE NATIONAL LABORATORY

Oak Ridge, Tennessee 37830 operated by UNION CARBIDE CORPORATION for the ENERGY RESEARCH AND DEVELOPMENT ADMTNISTRATION 
The complete report is composed of the following:

ORNL/TM-5242 - Assessment of Very High-Temperature Reactors in Process Applications

ORNL/TM-5409 - Evaluation of the Reactor System

(Appendix I)

ORNL/TM-5410 - Very High-Temperature Reactor Process Application Studies (Appendix II)

ORNL/TM-5411 - Engineering Evaluation of Process Heat Applications for Very High-Temperature Reactors 
G. Samuels, ORNL

P. L. Rittenhouse, ORNL

A. E. Pasto, ORNL

A. P. Malinauskas, ORNL

E. L. Compere, ORNL

R. K. Nanstad, ORNL

D. A. Canonico, ORNL

F. J. Homan, ORNL

E. L. Long, ORNL

W. L. Greenstreet, ORNL

PROCESS HEAT COST ANALYSIS

L. C. Fuller, ORNL

FUEL CYCLE COST ANALYSIS

J. G. Delene, ORNL

CAPITAL AND OPERATING AND

MAINTENANCE (O\&M) COST

ANALYSIS

J. B. Newman, United Engineers \& Constructors

M. F. Chamow, United Engineers \& Constructors

W. E. Dahme, United Engineers \& Constructors

A. L. Garrett, United Engineers \& Constructors

S. W. Kight, United Engineers \& Constructors

D. D. Ray, United Engineers \& Constructors 


\section{THIS PAGE \\ WAS INTENTIONALLY \\ LEFT BLANK}


FOREWORD . . . . . . . . . . . . . . . . . . . . . vii

ABSTRACT . . . . . . . . . . . . . . . . . . . ix

1. SUMMARY . . . . . . . . . . . . . . . . . . . 1

1.1 Introduction . . . . . . . . . . . . . . . . 1

1.1.I Scope ...................... 1

1.2 Conclusions and Recommendations ........... 1

1.2.1 Conclusions ................. . 1

1.2.2 Recommendations for R\&D program . . . . . . . 3

1.3 Summary of Technology .. . . . . . . . . . . . 4

1.3.1 Concepts and components.......... . 5

1.3.2 Safety . . . . . . . . . . . . . 7

1.3.3 Materials . . . . . . . . . . . 7

1.4 Summary of Costs . . . . . . . . . . . . . . 10

1.4.1 Capital and operating and maintenance

(O\&M) costs ................ 10

1.4.2 Fuel cycle costs . . . . . . . . . . . . 12

1.4.3 Process heat cost ............. . 16

2. EVALUATION OF VHTR TEChNOLOGY . . . . . . . . . . . . . 21

2.1 Concepts and Components .............. . 21

2.1.1 Reactor core ................. 22

2.1.2 Process and power generation systems . . . . 26

2.1.3 Reactor vessels... . . . . . . . . . 28

2.1.4 Ducting and insulation ........... . 30

2.1.5 Heat exchangers . . . . . . . . . . . . 31

2.1 .6 Valves ................... 31

2.1 .7 Safety . . . . . . . . . . . . . 32

2.2 Materials (alloys) . . . . . . . . . . . . 32

2.2.1 Status of technology . . . . . . . . . 32

2.2.2 Alloys for the reference system . . . . . . . . 38

2.2.3 Advanced materials .............. . 41

2.2.4 Research and development needs ........ . 43

2.2.5 Structural design technology for high-temperature applications . . . . . . . . . . . 47

2.3 Materials (Ceramic) . ............. . 51

2.4 Fission Product Behavior Aspects . . . . . . . . . . 53

2.4.1 The General Atomic Company concept . . . . . . 55

2.4.2 The General Electric Company concept . . . . . 57

2.4.3 The Westinghouse Astronuclear Laboratory concept . . . . . . . . . 59

2.4:4 Summary ................. . . 60

2.5 Steam Ingress Considerations . . . . . . . . . . . 61

2.5.1 The Westinghouse proposal concept . . . . . . 62

2.5.2 The General Electr1c proposal concept . . . . . 63

2.5.3 The General Atomic proposal concept . . . . . 63

2.5 .4 Summary . . . . . . . . . . . . . 64 
3. FUEL CYCLE COST ANALYSIS . . . . . . . . . . . . 67

3.1 Introduction .................. 67

3.2 Evaluation Methods ................ 69

3.3 Mass Balances .. . . . . . . . . . . . . 71

3.4 Economic Assumptions .. . . . . . . . . . . 72

3.5 Fuel-Cycle Cost . . . . . . . . . . . . . . 74

3.6 Sensitivity Studies . . . . . . . . . . . 76

4. CAPITAL AND OPERATING AND MAINTENANCE (O\&M) COST ANALYSIS • - 87

4.1 Introduction . . . . . . . . . . . . . . . . . . 87

4.1.1 Scope . . . . . . . . . . . . . . 87

4.1.2 UE\&C cost estimation methods . . . . . . . . 87

4.1.3 General Atomic/UE\&C plant description and

cost summary . . . . . . . . . . . . 88

4.1.4 Comparison summary . . . . . . . . . . . . 90

4.1.5 Interfaces with the chemical plant . . . . . 90

4.1.6 General comments . . . . . . . . . . . 92

4.2 Description and Cost of General Atomic/UE\&C Plant . . 94

4.2.1 Introduction . . . . . . . . . . . . . . 94

4.2.2 Base plant . . . . . . . . . . . . . . . 95

4.2.3 Intermediate heat transfer loop . . . . . . . 108

4.2.4 Power generation . . . . . . . . . . . 118

4.2.5 Operating and maintenance... . . . . . . 125

4.2.6 Comparison plant .............. 127

4.3 Description and Costs of General Electric and

Westinghouse Plants . . . . . . . . . . . 127

4.3.1 GE description and cost . . . . . . . . . . 127

4.3.2 Westinghouse description and cost . . . . . . 131

4.4 Summary of Scope and Costs of General Atomic/UE\&C,

General Electric, and Westinghouse Conceptual

Designs . . . . . . . . . . . . . . . . 137

4.4.1 Bases for sumary . . . . . . . . . . . . 137

4.4.2 Plant cost and scope ............. . 142

4.4.3 Summary of operating and maintenance costs . . 148

REFERENCES . . . . . . . . . . . . . . . . . 151

ATTACHMENT A - PROCESS PLANT INTERFACES . . . . . . . . . 153 
This is one of a series of reports on nuclear process heat. The overall summary is Assessment of Very High-Temperature Reactors in Process Applications (ORNL/TM-5242). Details and background information are presented in Appendix I - Evaluation of the Reactor System (ORNL/TM-5409); Appendix II - VHTR Process Application Studies (ORNL/TM-5410); and Appendix III - Engineering Evaluation of Process Heat Applications for VHTRS (ORNL/TM-5411). 
THIS PAGE

WAS INTENTIONALLY

LEFT BLANK 
In April 1974, the U.S. Atomic Energy Commission [now the Energy Research and Development Administration (ERDA)] authorized General Atomic Company, General Electric Company, and Westinghouse Electric Corp., Astronuclear Laboratory, to assess the available technology for producing heat using very high-temperature nuclear reactors.

An evaluation of these studies and of the technical and economic potential of very high-temperature reactors (VHTR) is presented. The VHTR is a helium-cooled graphite-moderated reactor. The concepts and technology are evaluated for producing process stream temperatures of $649,760,871$, 982 , and $1093^{\circ} \mathrm{C}\left(1200,1400,1600,1800\right.$, and $\left.2000^{\circ} \mathrm{F}\right)$. There are a number of large industrial process heat applications that could utilize the VHTR. 


\section{SUMMARY}

\subsection{Introduction}

\section{1 .1 Scope}

In April 1974, the U.S. Atomic Energy Commission [now the Energy Research and Development Administration (ERDA)] authorized General Atomic Company (GA), General Electric Company (GE), and Westinghouse Electric Corporation, Astronuclear Laboratory (WANL), to assess the available technology for producing process heat utilizing very high temperature nuclear reactors. 1-3 General Electric and Westinghouse produced concepts for the entire nuclear system, including the balance of plant. The General Atomic Company's assessment includes only the nuclear reactor portion of the nuclear plant. Draft reports of this work were submitted to ERDA in September 1974, and the final reports were submitted in December 1974.

The purpose of the effort reported herein is to evaluate existing data and to make program recommendations to ERDA on the development of very high-temperature nuclear reactor (VHTR) systems for high-temperature industrial processes. This report represents the first major milestone in the ORNL effort, that is, evaluation of the VHTR studies from the standpoint of economics and technology. The report is divided into four sections and an Attachment: Sect. 1-Summary; Sect. 2 - Evaluation of VHTR Technology; Sect. 3 - Fuel Cycle Cost Analysis; and Sect. 4 - Capital and O\&M Cost Analysis. [Section 4 was prepared by United Engineers \& Constructors, Inc. (UE\&C).] The Attachment deals with process plant interfaces.

\subsection{Conclusions and Recommendations}

\subsubsection{Conclusions}

1. Process temperatures up to the 1400 to $1500^{\circ} \mathrm{F}$ range are achievable with near-term technology. Process temperatures up to $1600^{\circ} \mathrm{F}$ are somewhat more difficult and will require an expanded materials program and probably more time. Many elements of the high-temperature gas-cooled reactor (HTGR) component and design technology can be utilized. The major incremental development considerations are high-temperature materials, the safety questions (in particular regarding the isolation loop), and the reformer or process heat exchanger.

2. Process temperatures in the range of 1600 to $2000^{\circ} \mathrm{F}$ are potentially achievable but would require a much larger development program over a longer period of timc.

Some major uncertainties in this higher temperature range include heat exchanger design and materials (possibly ceramics), ducting and vessel insulation, fission product release and transport, safety, and possibly advanced fuel particles design. 
3. Certain unique features of the VHTR concepts appear to require specific comment:

a. An isolation loop appears to be desirable from the standpoint of safety and may be required for certain applications. The typical process fluids appear to have the potential for creating hazardous and damaging reactions in the primary reactor loop. An isolation loop would provide an opportunity to clean up contaminants from both the process and the reactor and would avoid the introduction of process fluids into the reactor system and likewise would avoid the potential release of radioactive contaminants. A purification system must be assumed as a part of the isolation loop.

A systematic evaluation of all aspects of an intermediate loop vs no intermediate loop should be undertaken.

b. There appears to be some doubt that the WANL fuel concept, as presented in ref. 3, would be adequate for long life and high burnup. The questions center around potential shrinkage and debonding, which in this concept could lead to coolant-induced vibration, particles and dust breakoff into the coolant stream, and possibly flow blockage. However, we believe that fuel elements of this generic type could be developed.

The GA fuel concept appears adequate for the 1400 to $1600^{\circ} \mathrm{F}$ maximum process temperature range, but beyond this range advanced fuel particle development may be required.

The pebble-bed fuel concept presented by GE appears capable of higher process temperatures than the GA prismatic fuel concept. The once-throughthen-out (OTTO) cycle has not been demonstrated but does not involve new exposure conditions.

Materials for ducting and interface heat exchangers will probably dictate the practical temperature limits rather than fuels.

c. The prestressed cast iron vessel (PCIV) proposed by WANL could be very worthwhile and is recommended for additional study. This concept could save considerable cost and onsite construction time if remotely fabricated in a factory and assembled onsite. The application of the PCIV is not limited to the VHTiR concept; therefore, it is recommended that the PCIV be evaluated promptly as a part of the overall Gas-Cooled Reactor Program.

d. The use of gas turbines in the VHTR concept as proposed by WANL is not recommended. This item alone would appreciably increase the cost and time required for the research and development ( $R \& D$ ) program. It would provide perhaps the most severe problems from the standpoint of materials and safety and is not necessary for the successful development of the VH'IR in process applications. 
e. If an isolation loop is required and if steam generators are located only in the intermediate loop, significant cost savings in prestressed concrete reactor vessel (PCRV) or PCIV and containment buildings costs may be realized. Also, this would minimize the potential for steam ingress. In view of the higher temperature of the graphite moderator, which is inherent in the VHTR concept, minimizing potential steam ingress could result in advantages in reactor safety.

4. Representative costs of process heat from a VHTR are presented. It is premature at this time to draw a conclusion about cost-benefit tradeoffs. Continuing work on process applications w1ll provide a comparison of cost of end products using VHTR process heat vs conventional fossil fuels. This comparison will be drawn for a number of potential process applications.

\subsubsection{Recommendations for R\&D program}

Each vendor's study considered an R\&D program to develop the concept. Table 1 presents a very preliminary estimate (based on a review of the vendor estimates) of the R\&D program costs required to achieve a process temperature of 1400 to $1500^{\circ} \mathrm{F}$. Such a program could be completed in 6 to 10 years. Several R\&D priority areas are outlined below.

Table 1. Preliminary estimates of R\&D program costs

\begin{tabular}{lc}
\multicolumn{1}{c}{ Item } & $\begin{array}{c}\text { Millions of } \\
\text { dollars }\end{array}$ \\
\hline Intermediate heat exchanger & 25 \\
Steam reformer & 25 \\
Materials & 15 \\
Design technology development & 20 \\
Components and systems layout & 35 \\
Fuel and core components & 18 \\
Pressurc veesel & 11 \\
Component development & 16 \\
Safety & 16 \\
Contingency & 39 \\
& 220 \\
\hline
\end{tabular}

The VHTR safety and safety-related technology should be assessed promptly in order to identify and hopefully resolve key concerns of importance to public safety. Background information presented in the vendor reports provides a starting point. Preliminary results indicate that fission product, primary coolant, and primary system materials technology are areas in which safety studies should be initiated first. 
The first area of development work is the intermediate heat exchanger (IHX) and the second area is materials development.

Additional work is needed to determine in a more definitive manner whether or not the IHX is required, and, if so, to look into alternative design approaches to reduce cost. A better answer regarding the IHX is needed as soon as possible because of its strong effect on the economics of the VHTR.

Regarding materials, the early results of a program to screen, select, and qualify alloys for service in VHTR process heat system would have very broad application even if the VHTR concept was abandoned. Therefore a materials R\&D program is suggested as shown in Sect. 2.2.4.1.

\subsection{Summary of Technology}

In the evaluation of VHTR technology, the relative merits of the concepts prepared by GA, WANL, and GE are reviewed in terms of concepts and components and also in terms of special problem areas concerning materials and safety.

The concepts and technology are evaluated for producing process stream temperatures of $1200,1400,1600,1800$, and $2000^{\circ} \mathrm{F}$. The current technology limits to the process temperature that can be obtained from VHTR systems are in the fields of materials and safety. The basic limitation is the temperature at which the fuel and structural materials can operate, whereas the temperature required of the fuel and materials depends on what process temperature is desired, whether an IHX is required between the reactor coolant (helium) and the process heat exchanger (PHX), and to some extent which concept is selected.

Preliminary information on process applications indicates a range of process temperature requirements as shown in Table 2 . These are by no means the only applications of VHTRs, but they are among the major applications and they do reflect the range of temperatures that are of interest.

Table 2. Process temperature requirements

\begin{tabular}{|c|c|}
\hline Process & $\begin{array}{c}\text { Process temperature } \\
\left({ }^{\circ} \mathrm{F}\right)\end{array}$ \\
\hline Refinery process heat & 1000 \\
\hline Methane or light HC reforming & 1400 to 1600 \\
\hline Thermochemical water splitting & 1600 to 2000 \\
\hline Steam carbon reaction & \\
\hline $\mathrm{C}+\mathrm{H}_{2} \mathrm{O} \rightarrow \mathrm{CO}+\mathrm{H}_{2}$ & 1800 to 2000 \\
\hline
\end{tabular}


Three levels of technology can be identified as a function of process temperature. First, process temperatures in the range of 1000 to $1200^{\circ} \mathrm{F}$ can be achieved with current high-temperature gas-cooled reactor (HTGR) technology within perhaps 10 to 12 years. Process temperatures from 1200 to $1600^{\circ} \mathrm{F}$ represent near-term technology; that is, commercial application, allowing 7 to 10 years for R\&D, could be achieved within 15 to 18 years. These schedules are based on use of, or extrapolation of, HTGR component technology. Finally, process application from 1600 to $2000^{\circ} \mathrm{F}$ appears to represent long-term technology that would require in the order of 15 to 25 years of $R \& D$ and perhaps 25 to 35 years for commercialization.

\subsubsection{Concepts and components}

In comparing the different concepts, the systems are first considered on the basis of the temperature that can be obtained from the reactor core, which depends on fuel temperature limitations and the core design, and second, on the manner in which the concepts accommodate and utilize the high-temperature helium. Table 3 presents a comparison of concepts for the $1600^{\circ} \mathrm{F}$ process temperature.

\subsubsection{Intermediate heat exchanger}

The process involved will have an important impact on the safety of the reactor system if one attempts to avoid the use of an intermediate heat exchanger between the reactor coolant and the process stream. Most hightemperature processes of interest involve hydrogen and/or hydrocarbons, and without an IHX, they would bring a combustible mixture into the containment building. Also, the elimination of the IHX would introduce additional problems such as hydrogen diffusion into the primary coolant, tritium into the process stream, and, in the case of a failure of the primary heat exchanger, could $\mathrm{mix}$ the primary coolant and process stream. This latter accident could cause severe damage to the reactor core and other primary system components.

The GA design was the only one not to use an IHX, but it was stated that the need for an IHX had not been ruled out. General Electric included an IHX, with implications of some hope that additional studies would show that it could be eliminated. WANL made a rather strong case for the necessity of the IHX. Since there does not appear to be any basic design feature or innovation that would allow one concept only to use the direct system, it is assumed that this difference is one of philosophy and that, for comparison purposes, all systems should be compared on the bases of an equal degree of optimism or conservatism. 
Table 3. Comparison of concepts for $1600^{\circ} \mathrm{F}$ process temperature

\begin{tabular}{|c|c|c|c|}
\hline Parameter & General Atomic Company & General Electric Company & Westinghouse Electric Corp. \\
\hline $\begin{array}{l}\text { Basis of very high temperature } \\
\text { nuclear reactor design }\end{array}$ & Modification of HTGR concept & $\begin{array}{l}\text { Pebble-bed concept based on German } \\
\text { technology }\end{array}$ & $\begin{array}{l}\text { Prismat1c fuel concept based on } \\
\text { nuclear rocket technology }\end{array}$ \\
\hline Reactor core type & $\begin{array}{l}\text { Hexagonal graphite blocks; } \\
\text { solld, cyllndrical fuel } \\
\text { rods }\end{array}$ & $\begin{array}{l}\text { Pebble-bed core; graphite sphere } \\
\text { fuel element }\end{array}$ & $\begin{array}{l}\text { Hexagonal graphite blocks; } \\
\text { hollow, cylindrical fuel rods } \\
\text { with central-control coolant } \\
\text { channel }\end{array}$ \\
\hline Reactor coolant & Hellum & Helium & Helium \\
\hline Reference thermal power & $3000 \mathrm{MW}(t)$ & $3000 \mathrm{MW}(\mathrm{t})$ & $3000 \mathrm{MW}(\mathrm{t})$ \\
\hline Pressure vessel concept & PCRV & PCRV & PCIV \\
\hline Fuel composition & $\begin{array}{l}\text { Fully enriched } \mathrm{U} \text { feed }\left(\mathrm{UC}_{2}\right) \\
\text { with thorium }\left(\mathrm{ThO}_{2}\right) \text { fertile } \\
\text { material; } \\
\text { No recycle of } 233 \mathrm{U} \text {; } \\
\text { TRIso coating for both } \\
\text { f1ssile and fertile } \\
\text { particles; } \\
\text { Carbon-to-thorium ratio }=200\end{array}$ & $\begin{array}{l}\text { Low-enriched }(9.01 \%) 235 \mathrm{U} \text { fuel } \\
\text { No recycle of bred pluton1um } \\
\text { TRISO-coated } \mathrm{UO}_{2} \text { fuel particles } \\
\text { Graphite sphere fuel element } \\
\text { Carbon-to-heavy-metal ratio }=350\end{array}$ & $\begin{array}{l}\text { Fully enriched } \mathrm{U} \text { feed }\left(\mathrm{UC}_{2}\right) \\
\text { with thorlum }\left(\mathrm{ThO}_{2}\right) \text { material } \\
\text { Recycle of } 233_{\mathrm{U}} \\
\text { TRISO-coated fissile particle } \\
\text { BISO-coated fertile particle } \\
\text { Carbon-to-thorium rat1o }=206\end{array}$ \\
\hline Average fuel residence time & $\sim 4$ years. & 3.8 years & 4 years \\
\hline Power density & $8.4 \mathrm{~W} / \mathrm{cm}^{3}$ & $5 \mathrm{~W} / \mathrm{cm}^{3}$ & $10 \mathrm{w} / \mathrm{cos}^{3}$ \\
\hline System pressure & $725 \mathrm{lb} /$ in. $^{2}$ & $600 \mathrm{lb} / \mathrm{ln} .^{2}$ & $1000 \mathrm{1b} / \mathrm{An} .^{2}$ \\
\hline Core Inlet temperature & $932^{\circ} \mathrm{F}$ & $482^{\circ} \mathrm{F}$ & $807^{\circ} \mathrm{F}$ \\
\hline Core outlet remperature & $1800^{\circ} \mathrm{F}$ & $1742^{\circ} \mathrm{F}$ & $1850^{\circ} \mathrm{F}$ \\
\hline Maximum fuel temperature & $2562^{\circ} \mathrm{F}$ & $2030^{\circ} \mathrm{F}$ & $2158^{\circ} \mathrm{F}$ \\
\hline
\end{tabular}




\subsubsection{Reactor core}

All three reactor core concepts are based on coated fuel particles, either all TRISO or a combination of TRISO-coated fissile and BISO-coated fertile particles, and graphite for the moderator and reflector. Both GA and WANL use prismatic fuel blocks, while GE uses the pebble-bed concept.

All of the core concepts are capable of producing coolant temperatures $\left(\sim 1800^{\circ} \mathrm{F}\right.$ ) sufficient to meet the reference 1400 to $1600^{\circ} \mathrm{F}$ process temperature with current technology. The GE and WANL designs have a smaller temperature difference between the peak fuel temperature and the core outlet gas temperatures than does the GA design, are capable of producing reactor coolant temperatures greater than $2000^{\circ} \mathrm{F}$, and are possibly sufficient to meet the requirements for a $2000^{\circ} \mathrm{F}$ process temperature. Several alternatives are available for increasing the helium outlet temperature from the GA design. However, development of a higher temperature fuel particle may be required for core coolant outlet temperatures much above $1800^{\circ} \mathrm{F}$.

The GA design is the most developed of the proposed systems. Although the Arbeitsgemeinschaft Versuchsreactor (AVR) has proved the technical feasibility of the pebble-bed concept, this has not been accomplished on a commercial basis. The once-through-then-out (OTTO) cycle is new and untried but does not involve new technology. It should also be noted that the GE core has a lower power density relative to the other two and thus requires a larger core and reactor vessel.

There are rather serious questions as to the structural integrity of WANL fuel elements for long-time, high-burnup operation. Irradiation experience has shown that severe debonding of the particles within the graphite matrix can occur and that the fuel elements will undergo shrinkage during irradiation. The shrinkage of the elements will lead to difficulties in ensuring an adequate bond between the elements and the moderator block during their life. Loose elements would be subjected to coolant-induced vibrations that could accelerate the debonding problem.

\subsubsection{Gas turbines}

The inclusion of gas turbines will appreciably add to the cost, time, and difficulty of developing the VITR concept. The additional problems related to the consideration of gas turbines along with the VHTR process heat applications appear to far outweigh the advantages that could be achieved.

Both the direct Brayton cycle and the VHTR are advanced applications of gas-cooled reactor technology. Both have significant advantages and significant problems. Wrapping the two in a single package compounds the problems but does not appear to yield significant new advantages. It is recommended that each alternative be pursued independently based on its merit in the context of the national goals. Once each alternative is saticfactorily demonstrated, it may be worthwhile to consider their combined application. 


\subsubsection{Reactor vessels}

The GA and GE concepts use large conventional PCRVs that are typical of those currently being designed for gas-cooled reactors.

The WANL concept specifies a developmental PCIV concept.

The concept of the PCIV offers some potential advantages for power reactors which are worthy of further study. The potential advantages apply to large pressure vessels in general and are not restricted to the VHTR.

\subsubsection{Safety}

With the inclusion of the IHX, the safety-related problems for the VHTR are similar to those of the current U.S. gas-cooled reactors for steam plants. There will be some additional requirements for the VHTR, such as isolation valves for the intermediate loop. Also, the margin of safety, in regard to temperature, between the normal operating conditions and those that may cause failure of safety related components, will be reduced. However, the basic problems and the design approaches are quite similar.

The questions of fission product release and transport and also of steam ingress are potentially aggravated by the higher temperature of the VHTR core. Adequate safety requires a very careful analysis of these problems as a function of the higher temperatures.

The use of gas turbines will have a number of safety-related problems in addition to those of the process heat designs. A list of those problems associated with the turbomachinery that will require further evaluation and/or specific safety design features are (1) the effect of transients induced by a failure of a component or duct separating the high- and lowpressure parts of the system; (2) the effects of a loss-of-electrical load on turbomachinery speed; (3) the effects of a failure of the turbomachinery components such as blades, rotors, or generator or of a seizure of the machinery; and (4) the question of whether a depressurization incident in the low-pressure part of the primary system would drive the compressor into surge.

\subsubsection{Materials}

One of the most important considerations for the VHTR concept is the availability of materials to withstand the difficult temperature and environment requirements. For discussion, materials can usefully be broken into three classes of service as a function of temperature, and they will be discussed in that order: (1) less than $1500^{\circ} \mathrm{F}$, (2) 1500 to $1800^{\circ} \mathrm{F}$, and (3) greater than $1800^{\circ} \mathrm{F}$. 


\subsubsection{Less than $1500^{\circ} \mathrm{F}$}

In general, it can be stated that alloys are available for construction of VHTR system components that will operate at temperatures below $\sim 1500^{\circ} \mathrm{F}$. The general classes of alloys available in this temperature range are listed below in qualitatively increasing order of temperature capability.

Estimate of temperature limit

1. Carbon and low-alloy steels

2. High-alloy ferritic steels

3. Ferritic stainless steels

4. Austenitic stainless steels

5. Fe-Ni-base alloys

6. Ni-base alloys $\leqslant 1000^{\circ} \mathrm{F}$

$\$ 1200^{\circ} \mathrm{F}$

$\leqslant 1200^{\circ} \mathrm{F}$

$\leqslant 1500^{\circ} \mathrm{F}$

$\leqslant 1500^{\circ} \mathrm{F}$

$>1500^{\circ} \mathrm{F}$

Some materials in this class are qualified for nuclear service whereas others would have to be qualified before use. Existing alloys appear to be applicable.

\section{$1.3 .3 .2 \quad 1500$ to $1800^{\circ} \mathrm{F}$}

There appears to be a reasonable prospect for the use of various metallic materials in this temperature range. It is possible that modifications to existing nickel-base alloys (e.g., Inconel 617) or the development of new nickel-base alloys may extend the range of their use for the VHTR system to temperatures approaching $1800^{\circ} \mathrm{F}$. The development of such alloys should include minimization of alloying elements that could cause radioactive contamination problems (e.g., cobolt and tantalum) and alloying elements that oxidize selectively in gas-cooled reactor helium (e.g., titanium and aluminium). Efforts directed at alloying element substitutions or new alloy developments will likely benefit from consideration of the strengthening potential of elements such as molybdenum, tungsten, and niobium (columbium).

A new class of solid-colution-strengthened nickel alloys that may hold promise are the long-range-ordered alloys based on the $A_{3} B$ structure. These alloys offer good potential for high-temperature creep resistance, contain no precipitated phases or segregation that might aggravate selective gas-metal reactions, and do not overage or decarburize.

Of course, the ultimate use of any alloys developed would require their qualification for nuclear service.

\subsubsection{Over $1800^{\circ} \mathrm{F}$}

Oxide-dispersion-strengthened nickel alloys offer the potential for use at temperatures in excess of $1800^{\circ} \mathrm{F}$. These alloys (e.g., TDNi and MA-753) receive their strengthening from careful control of the oxide - thoria 
and yttria, respectively - particle size and interparticle spacing. Anisotropy of properties could be a problem with these materials, as well as questions related to their environmental compatibility.

Molybdenum-base alloys may be very good choices for use at temperatures in the 1700 to $2200^{\circ} \mathrm{F}$ range. However, considerable development will be required for these materials. The only current commercial alloy, TZM, is a carbide-strengthened material (50\% titanium, $8 \%$ zirconium, $3 \%$ carbon, and balance molybdenum) which could suffer some degeneration through selective oxidation of titanium and zirconium. However, preliminary testing of TZM in a simulated gas-cooled reactor environment in Europe has shown excellent compatibility.

The application of ceramics may be considered in this higher temperature range. Many nonmetallic materials possessing outstanding thermal stability and resistance to harsh gaseous environments can be utilized in designs that minimize the tensile loads the components must bear.

\subsection{Summary of Costs}

\subsubsection{Capital and operating and maintenance (O\&M) costs}

United Engineers \& Constructors, Inc. (UE\&C) prepared an economic comparison of capital and $O \& M$ costs of the three conceptual plants. General Electric and WANL produced concepts for the entire nuclear system, including the balance of plant. The GA assessment includes only the nuclear reactor portion of the nuclear plant. Costs for the balance of plant for the GA concept provided by UE\&C are based on or are derived from the most recent estimates of similar costs for the HTGR. Costs due to changes in design are added where appropriate.

As a result, the costs presented for the VHTR concept are much more realistic than would be anticipated for a new reactor concept. The GA/UE\&C and GE costs are within $10 \%$ of each other in most cases, which is very good agreement. The WANL costs are substantially less, which probably results in part from the fact that the design is not as fully developed as the GA concept or the pebble-bed concept presented by GE.

The most disappointing aspect of the costs is the very high cost of the IHX and associated loop and equipment. It appears that the GE costs could be reduced by a better design layout. A systematic evaluation of all aspects of an intermediate loop vs no intermediate loop should be undertaken.

Table 4 summarizes the capital costs with an IHX, and Table 5 summarizes the capital costs without an IHX. The GE plant costs are similar to those for the GA/UE\&C plant. The cost difference between the two concepts is not significant, given the uncertainties involved. The WANL plant costs are consistently lower than either of the other estimates. Although differences in some accounts can be explained by different scopes or 
Table 4. Summary of costs (July 1974) with IHX $^{a}$

\begin{tabular}{|c|c|c|c|c|}
\hline \multirow[b]{2}{*}{ Account } & \multirow[b]{2}{*}{ Description } & \multicolumn{3}{|c|}{ Total costs (thousands of dollars) } \\
\hline & & GA/UE\&C & GE & WANL \\
\hline \multicolumn{5}{|l|}{ Direct costs } \\
\hline 20 & Land and land rights & 1,000 & 1,000 & 1,000 \\
\hline 21 & Structures and site facilities & 75,400 & 81,800 & 58,000 \\
\hline 22 & Reactor plant equipment & 335,800 & 371,700 & 178,600 \\
\hline 24 & Electric plant equipment & 26,500 & 21,900 & 16,700 \\
\hline 25 & Miscellaneous plant equipment & 8,800 & 10,100 & 6,800 \\
\hline 26 & SFecial materials & 1,000 & 1,200 & 1,000 \\
\hline Subtotal direct costs & & 448,500 & 487,700 & 262,100 \\
\hline \multicolumn{5}{|l|}{ Indirect costs } \\
\hline 91 & Engineering and construction costs & 107,100 & 64,100 & 57,200 \\
\hline 99 & Other costs & 34,300 & 82,800 & 47,800 \\
\hline $\begin{array}{l}\text { Subtotal direct and } \\
\text { indirect costs }\end{array}$ & & 589,900 & 634,600 & 367,100 \\
\hline $\begin{array}{l}\text { Interest during } \\
\text { construction }\end{array}$ & & 187,000 & 201,000 & 116,400 \\
\hline Total & & 776,900 & 835,600 & 483,500 \\
\hline
\end{tabular}

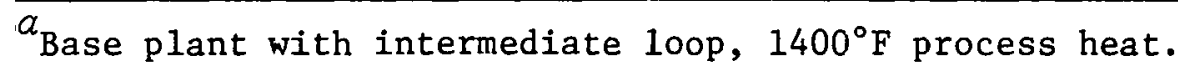


Table 5. Summary of costs (July 1974) without IHX

\begin{tabular}{|c|c|c|c|}
\hline \multirow[b]{2}{*}{ Costs } & \multicolumn{3}{|c|}{ Total costs (thousands of dollars) } \\
\hline & GA/UE\&C & $\mathrm{GE}$ & WANL \\
\hline Direct costs & 448,500 & 487,700 & 262,100 \\
\hline Minus IHX costs & 96,100 & $107 ; 600$ & 71,400 \\
\hline Direct cost without IHX & 352,400 & 380,100 & 190,700 \\
\hline Indirect costs & 111,100 & 114,500 & 72,700 \\
\hline $\begin{array}{l}\text { (Scaled in proportion to } \\
\text { direct costs) }\end{array}$ & 463,500 & 494,600 & 263,400 \\
\hline $\begin{array}{l}\text { Interest during construction } \\
\quad(0.317)\end{array}$ & 146,900 & 156,800 & 83,500 \\
\hline Total & 610,400 & 651,400 & 346,900 \\
\hline
\end{tabular}

different structure sizes, WANL estimates of equipment, labor, and material costs for the reactor containment building, the administration building, and the heat transfer system are lower than would be expected if comparable base costs were used.

Table 6 summarizes O\&M costs developed by UE\&C for the GA concept and those presented by GE and WANL.

\subsubsection{Fuel cycle costs}

Ground rules for fuel cycle cost evaluation were revised from the original ground rules provided to the vendors by ERDA. Table 7 presents a comparison of the original and revised ground rules. The revised ground rules were chosen as reasonably expected values once the current supply and demand imbalance levels out. With rapidly changing market conditions, there is certainly room for debate over many of these cost parameters. 'lherefore, the detailed fuel-cycle cost analysis (Sect. 3) presents a number of figures showing the sensitivity of fuel cycle cost vs various. parameters.

The three high-temperature $\left(>1600^{\circ} \mathrm{F}\right)$ process heat designs have similar direct costs. The differences in the fuel cycle costs arise mainly from the indirect charges. Table 8 gives some mass balance information as used in the comparison study. The net resource consumption does not differ appreciably for the various system designs. This is consistent with their similar direct costs. The indirect cost is a function of the 
Tajle 6. Summary of annual direct $0 \& M \operatorname{costs}^{a}$

(without electrical generation)

(July 1974)

\begin{tabular}{|c|c|c|c|}
\hline \multirow[b]{2}{*}{ Item } & \multicolumn{3}{|c|}{ Annual direct costs (thousands of dollars) } \\
\hline & GA/UE\&C & $\mathrm{GE}$ & WANL \\
\hline Station staffing & 1,960 & 1,544 & 1,698 \\
\hline $\begin{array}{l}\text { Materials, supplies, and } \\
\text { outside services }\end{array}$ & 160 to 820 & 1,160 & 520 \\
\hline Coolant makeup purchases & 125 & 120 & 135 \\
\hline Electric power purchases & 2,080 & & 2,920 \\
\hline Fixed maintenance & 2,500 to 4,000 & & \\
\hline $\begin{array}{l}\text { Variable maintenance } \\
\quad \text { (including catalyst costs) }\end{array}$ & 1,320 & & \\
\hline General and administrative & 260 & 174 & 332 \\
\hline $\begin{array}{l}\text { Nuclear liability insurance } \\
\text { (including commercial and } \\
\text { government) }\end{array}$ & 390 & 390 & 390 \\
\hline Annual licerse fee & 200 & & \\
\hline Total annual costs ${ }^{\alpha}$ & 8,995 to 11,155 & 3,398 & 5,996 \\
\hline
\end{tabular}

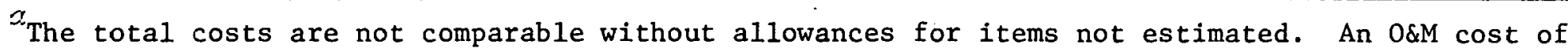
$\$ 9,000,000$ was assumed for all plants in determining process heat cost. 
Table 7. Comparison of original and revised ground rules for fuel cycle cost evaluation

\begin{tabular}{lcc}
\hline & \multicolumn{2}{c}{ Fissile material value } \\
\cline { 2 - 3 } Item & Original ground rules & Revised ground rules \\
\hline $\mathrm{U}_{3} \mathrm{O}_{8}, \$ / 1 \mathrm{~b}$ & 10.0 & 30.0 \\
$\begin{array}{l}\text { Enrichment, } \\
\begin{array}{l}\text { \$/separative work } \\
\text { unit (SWU) }\end{array}\end{array}$ & 40.0 & 75.0 \\
$233_{\mathrm{U}, ~} / \mathrm{g}$ & 17.0 & 38.0 \\
$239,24 \mathrm{Pu}, \$ / \mathrm{g}$ & 6.90 & 27.0 \\
\hline
\end{tabular}

Table 8. Fuel cycle mass balance information

\begin{tabular}{lrrrr}
\hline \multicolumn{1}{c}{ Item } & \multicolumn{1}{c}{ GA } & GA & GE & WANL \\
\hline Lifetime resource consumption, ${ }^{\circ} \mathrm{F}$ & $<1600$ & $>1600$ & & \\
Net $\mathrm{U}_{3} \mathrm{O}_{8}$, tons & 5031 & 5315 & 4952 & 4992 \\
Net separative work, $10^{3} \mathrm{SWU}$ & 5060 & 5356 & 4425 & 5033 \\
Net fissile material produced, $\mathrm{kg}$ & 7093 & 8765 & 2436 & 3091 \\
Fissile material loadings & & & & \\
Initial core, kg & 1768 & 1564 & 1267 & 3223 \\
Equilibrium charge, kg/year & 726 & 959 & 782 & 990 \\
Equilibrium discharge, kg/year & 302 & 578 & 219 & 449 \\
\hline
\end{tabular}

time displacement between when money is paid for an item and when money is recelved for the produced power. A higher loading of fissile material will result in a higher money payment and therefore a higher indirect charge. Similarly, continuous fueling will result in a shorter average time displacement between outlays and income and will thus reduce the indirect charge compared with another system that is fueled annually.

The GE system has the smaller indirect charge since it is both continuously fueled and since it needs a lower charge of fissile material. The lower fissile loading is also an effect of the continuous fueling since less control rod poisoning is required here than in the cases where the reactor is fueled annually.

For the annually fueled, prismatic fuel cases (GA and WANL), the WANL design has higher fissile loadings than the GA designs. The reason for this can be partially explained by the zonal fuel loading in the WANL design for power flattening purposes. Also, the WANL design is not fully optimized. The net effect is that the WANL system has higher indirect costs than either the GA systems or the GE system. Estimated fuel cycle costs based on the revised ground rules are shown in Table 9. 
Table 9. Fuel cycle costs, c/MBtu (revised ground rules)

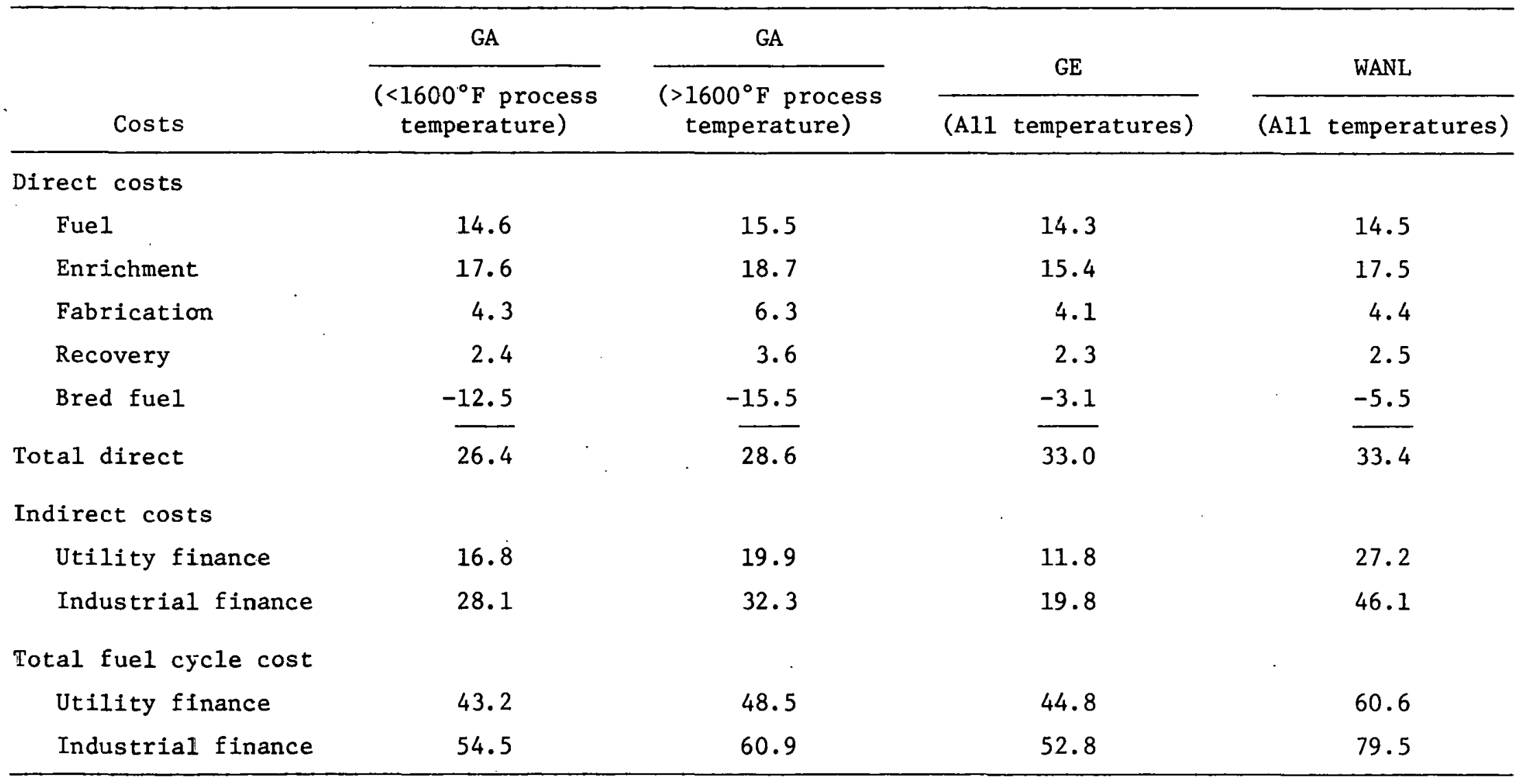


Based on utility-financing ground rules, it is our judgment that a fuel cycle cost of approximately $50 c / 10^{6}$ Btu could be achieved with the WANL design, if it were fully optimized.

\subsubsection{Process heat cost}

The cost of value of process heat from the VHTR can be evaluated in a number of ways. For the reformer application, one value could be placed on heat to the reformer and another on heat to steam. If by-product power is produced, still another product cost could be introduced.

For the purposes of this evaluation, it is assumed that the cost of process heat from the VHTR is independent of the form of the energy or how it is used; that is, all energy from the VHTR is assumed to have the same value.

The process heat cost (expressed in cents per million Btu) calculated for the three concepts at $1400^{\circ} \mathrm{F}$ maximum process temperature is presented in Table 10. Similar calculations were made for each temperature and financing condition, both with and without the IHX.

The three concepts did not present a consistent assessment of the effect of temperature on cost. The base case for each concept was a core outlet temperature near $1800^{\circ} \mathrm{F}$. This would allow a process maximum temperature of $1600^{\circ} \mathrm{F}$ without an IHX and about $1400^{\circ} \mathrm{F}$ with an IHX (assuming $200^{\circ} \mathrm{F} \Delta T$ per heat exchanger). For higher core outlet temperatures, much high-cost materials, heavier insulation, possibly new fuels, and more complex designs will be required. The total cost of higher temperatures cannot be well defined based on current studies. For the purpose of this evaluation, it has been projected that the cost of process heat is $20 \%$ higher for process temperatures of $1800^{\circ} \mathrm{F}$ without an IHX and for process temperatures of $1600^{\circ} \mathrm{F}$ with an IHX.

This large step change in cost is based on the assumption that for helium temperatures above $\sim 1800^{\circ} \mathrm{F}$ core outlet, entirely new designs would be required for many primary loop components, possibly involving ceramic materials.

For all temperature levels, a $5 \%$ increase in process heat cost has been projected for each $200^{\circ} \mathrm{F}$ increment of increase in maximum process temperature. As the temperature increases, additional components require more exotic and expensive materials and designs.

Figures 1 and 2 present the process heat costs as a function of temperature. The highest cost from the three concepts is taken as a maximum in each case. The range of costs is shown to be $10 \%$ less than the maximum projected for each temperature. In most cases, this range includes the costs projected by GE and GA. The WANL capital costs are consistently lower.

Figure 3 presents the process heat costs as a function of power output (in megawatts thermal). 
Table 10. Process heat cost ( $C / \mathrm{MBtu}$ )

[ $1400^{\circ} \mathrm{F}$ maximum process temperature, $3000 \mathrm{MW}(\mathrm{t})$ plant rating]

\begin{tabular}{lcccccc}
\hline & \multicolumn{3}{c}{ GA } & \multicolumn{2}{c}{1974 dollars } \\
\cline { 2 - 7 } Financing & $\begin{array}{c}\text { Without IHX } \\
\text { loop }\end{array}$ & $\begin{array}{c}\text { With IHX } \\
\text { loop }\end{array}$ & $\begin{array}{c}\text { Without IHX } \\
\text { loop }\end{array}$ & $\begin{array}{c}\text { With IHX } \\
\text { loop }\end{array}$ & $\begin{array}{c}\text { Without } \\
\text { loop }\end{array}$ & $\begin{array}{c}\text { IHX } \\
\text { WANL } \\
\text { loop }\end{array}$ \\
\hline Utility & 183 & 221 & 194 & 235 & 146 & 177 \\
Industrial & 280 & 340 & 292 & 359 & 213 & 263 \\
\hline
\end{tabular}




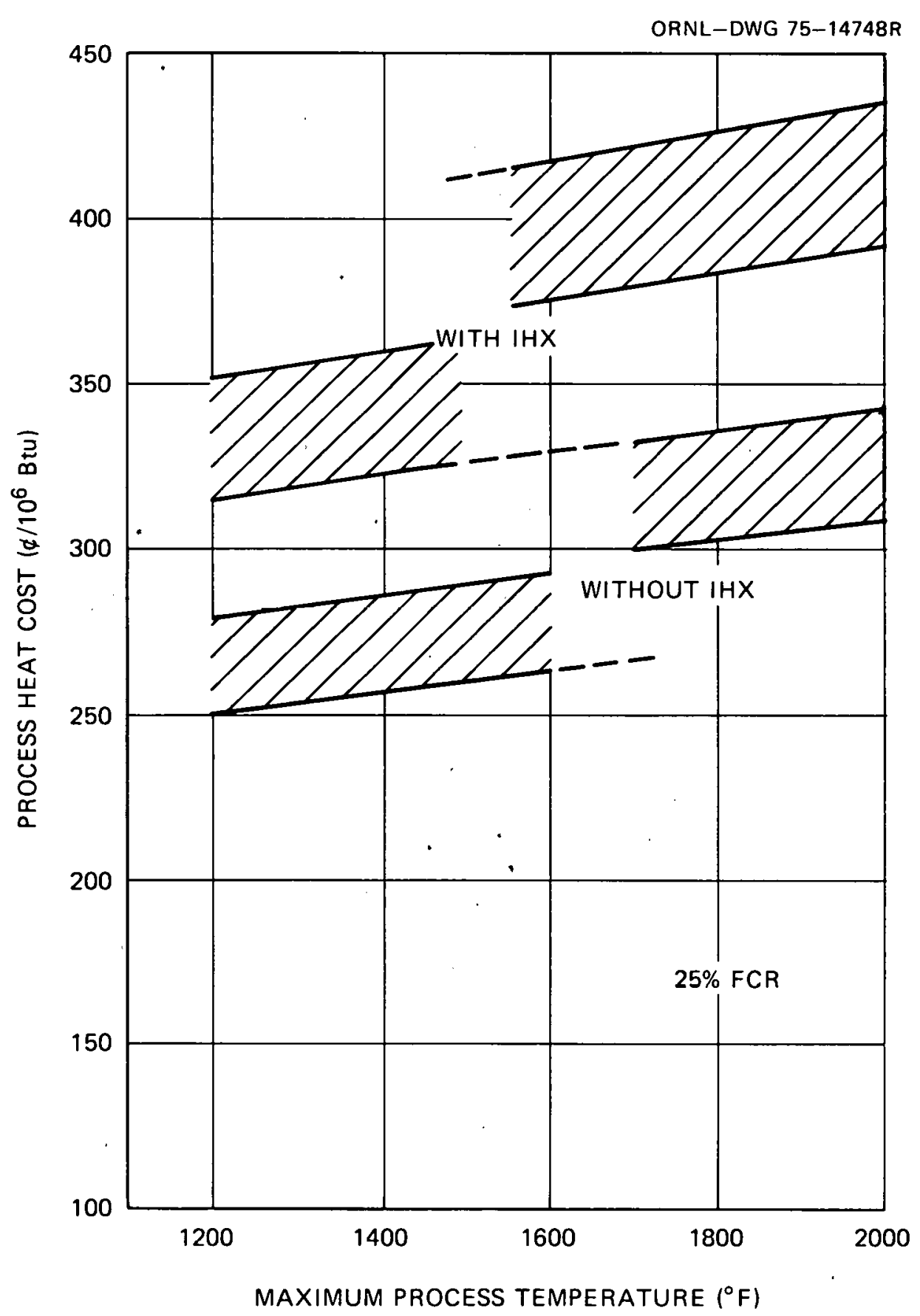

Fig. 1. Process heat cost from a VHTR vs maximum process temperature, industrial financing. 


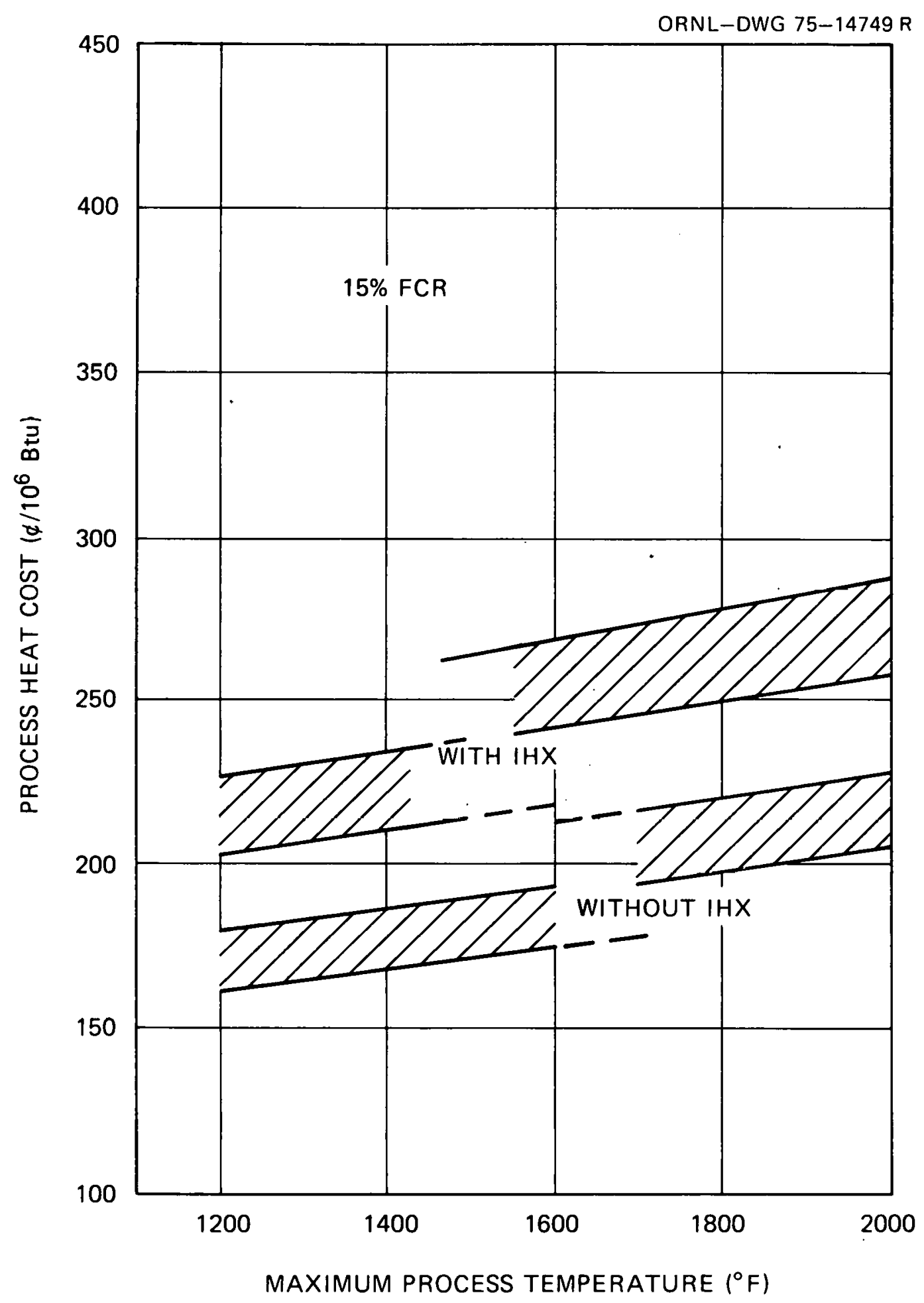

Fig. 2. Process heat cost from a VHTR vs maximum process temperature, utility financing. 


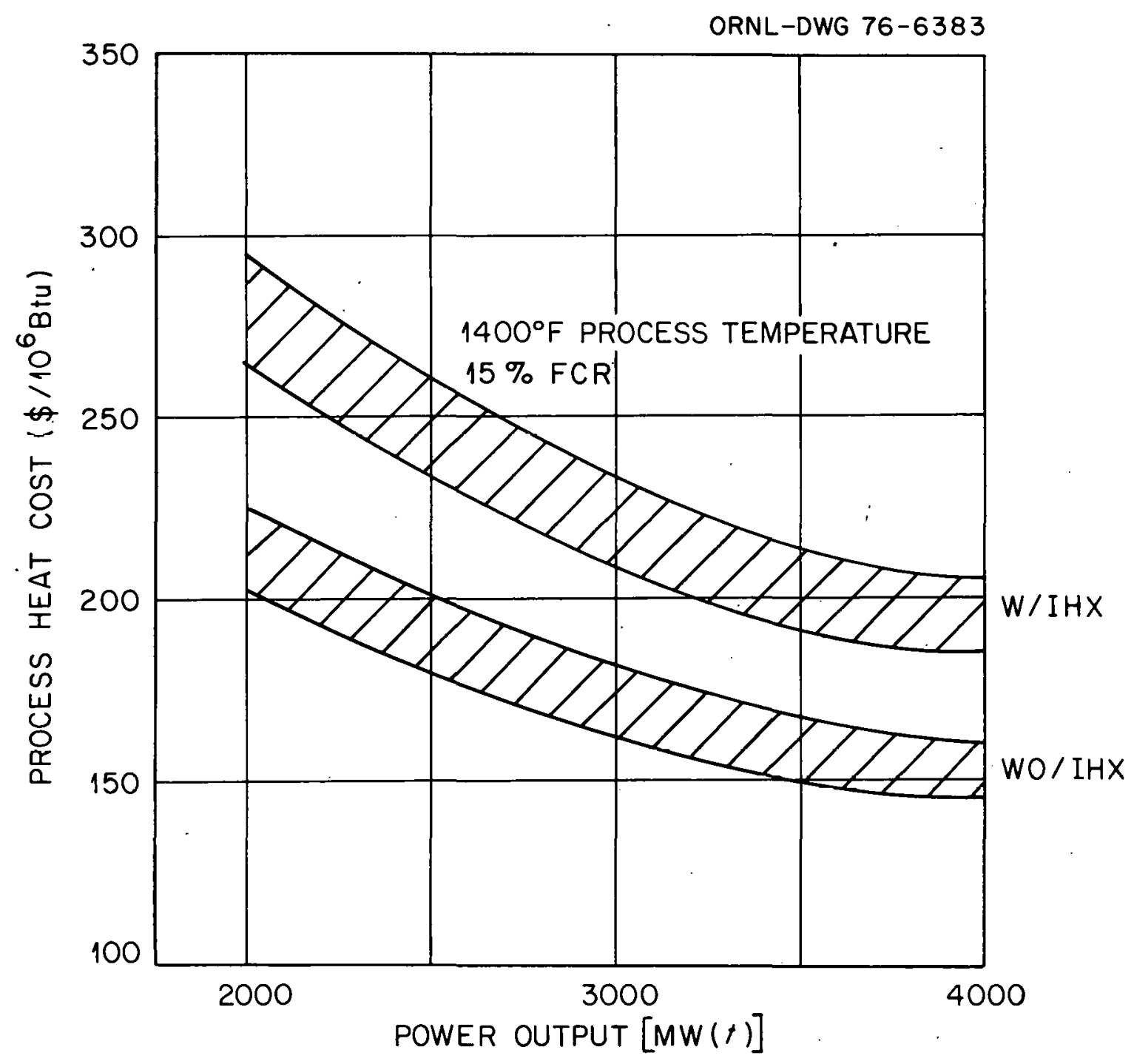

Fig. 3. Effect of size on process energy cost. 


\section{EVALUATION OF VHTR TECHNOLOGY}

This section reviews the three VHTR concepts prepared by General Atomic (GA), ${ }^{1}$ General Electric (GE),${ }^{2}$ and Westinghouse (WANL) ${ }^{3}$ and evaluates the concepts and technology available for producing process stream temperatures of $1200,1400,1600,1800$, and $2000^{\circ} \mathrm{F}$. The current technology limitations to the process temperature that can be obtained from VHTR systems are materials and safety. The basic limitation is the temperature at which the fuel and structural materials can operate, whereas the temperature required of the materials depends on whether an intermediate heat exchanger is required between the reactor coolant (helium) and the process fluid. Preliminary indications are that structural materials limits will dictate practical operating temperatures.

In the following evaluation, the relative merits of the different systems are reviewed in terms of the concepts and components and special problem areas concerning steam ingress, fission product behavior, and materials.

\subsection{Concepts and Components}

In comparing the different concepts, the systems are first considered on the basis of the temperature that can be obtained from the reactor core (which depends on fuel temperature limitations and the core design) and, second, on the manner in which the concepts accommodate and utilize the high-temperature helium.

Preliminary surveys of the requirements for high-temperature process heat indicate that the largest demand would be for steam-hydrocarbon reforming and that process temperatures in the order of $1500^{\circ} \mathrm{F}$ are both typical and satisfactory for this process. There are, of course, many uses for lower-temperature heat which are within the capacity of current technology.

The processes involved will have an important impact on the safety of the reactor system if an attempt is being made to avoid the use of a heat exchanger between the reactor coolant and the process stream. Most hightemperature processes of interest involve hydrogen and/or hydrocarbons, which, without an intermediate heat exchanger (IHX), would bring a combustible mixture into the containment building. Also, the elimination of the IHX would introduce additional problems such as hydrogen diffusion into the primary coolant and tritium diffusion into the process stream; also, in the case of a failure of the primary heat exchanger, the primary coolant could be mixed with the process stream. This latter accident could cause damage to the reactor core and other primary system components.

The GA design was the only one not to use an IHX; however, the need for an IHX had not been ruled out. General Electric included an IHX, with implications of some hope that additional studies would show that it could be eliminated. Westinghouse made a rather strong case for the necessity of the IHX. Because there does not appear to be any basic design feature or innovation that would allow only one concept to use the direct system, 
it is judged that this difference is one of philosophy. For comparison purposes, all systems should be compared on the basis of an equal degree of optimism or conservatism.

Because of the present conceptual nature of the studies and the potential difficulties that may be encountered with the direct reactor-coolant to process-stream system, the following system discussions are based on the premise that an IHX will be utilized.

The reactor coolant temperature required for a given process temperature depends on the design of the IHX, the design of the process heat exchanger ( $\mathrm{PHX}$, and the intermediate loop and process stream operating conditions. The GE reference system used a rather optimistic $142^{\circ} \mathrm{F}$ difference between the reactor coolant and the process stream for the reference case $\left(1600^{\circ} \mathrm{F}\right.$ process temperature). This was probably due to a desire to combine the maximum temperature at which the AVR pebble-bed reactor has been operated $\left(1742^{\circ} \mathrm{F}\right)$ with the $1600^{\circ} \mathrm{F}$ process temperature. A $250^{\circ} \mathrm{F}$ temperature difference was used by WANL. In the GA system, without an intermediate loop, a $200^{\circ} \mathrm{F}$ temperature difference was used. A realistic value for the temperature difference appears to be in the range of 200 to $300^{\circ} \mathrm{F}$ with an IHX. Thus, for the reference $1600^{\circ} \mathrm{F}$ process temperature, a reactor outlet temperature of 1800 to $1900^{\circ} \mathrm{F}$ is desirable.

\subsubsection{Reactor core}

All three reactor core concepts are based on coated fuel particles, either all TRISO or a combination of TRISO-coated fissile particles and BISOcoated fertile particles, with graphite for the moderator and reflector. Both the GA and WANL systems use prismatic fuel blocks, whereas the GE system uses the pebble-bed concept.

The GA approach to the fuel and core design was to tailor the design details to match the required outlet temperature rather than to use a single design for all conditions. The basic core structure and size are the same for the 493-column core currently used in the $3000 \mathrm{MW}(t)$ commercial plants. A summary of the core designs and operating conditions for core outlet temperatures of 1400 to $2200^{\circ} \mathrm{F}$ is shown in Table 11 . The 132 fuel-holes-per-block design used for the $1400^{\circ} \mathrm{F}$ case is the same as used for the commercial HTGR designs, whereas the 210 fuel holes per block used for higher temperatures is the same hole pattern now being used in the Ft. St. Vrain Nuclear Generating Station. In addition to changes in the block design, for a temperature of $1800^{\circ} \mathrm{F}$, all fuel particles have TRISO coatings, and for 2000 and $2200^{\circ} \mathrm{F}$, an advanced fuel material is specified. Also, for reactor coolant temperatures of $1800^{\circ} \mathrm{F}$ and above, the carbon-to-thorium ratio is reduced, and the fuel cycle is shortened from 4 to 3 years. The core power density in all cases is $8.4 \mathrm{~W} / \mathrm{cm}^{3}$, and the system pressure is $710 \mathrm{psig}$. 
Table 11. Process heat reactor study: Summary of fuel design conditions ${ }^{a}$ (from ref. 1)

\begin{tabular}{|c|c|c|c|c|c|}
\hline \multirow[b]{2}{*}{ Item } & \multicolumn{5}{|c|}{ Process temperature } \\
\hline & $1200^{\circ} \mathrm{F}$ & $1400^{\circ} \mathrm{F}$ & $1600^{\circ} \mathrm{F}$ & $1800^{\circ} \mathrm{F}$ & $2000^{\circ} \mathrm{F}$ \\
\hline Number of fuel holes in element & 132 & 210 & 210 & 210 & 210 \\
\hline Fuel cycle, year & 4 & 4 & 3 & 3 & 3 \\
\hline Fuel particle, fissile/fertile & TRISO/BISO & TRISO/BISO & TRISO/TRISO & Advanced $^{a}$ & Advanced $^{a}$ \\
\hline Maximum fuel temperature, ${ }^{b}{ }^{\circ} \mathrm{F}$ & 2513 & 2475 & 2562 & 2792 & 3010 \\
\hline Core helium inlet temperature, ${ }^{\circ} \mathrm{F}$ & 700 & 770 & 932 & 1050 & 1200 \\
\hline Core helium outlet temperature, ${ }^{\circ} \mathrm{F}$ & 1400 & 1600 & 1800 & 2000 & 2200 \\
\hline Core $\Delta P$, psi & 13.5 & 16.6 & 14.3 & 13.2 & 13.2 \\
\hline Refueling type & Segmenta1 & Segmental & Segmental & Segmental & Segmental \\
\hline Hot channel temperature, ${ }^{\circ} \mathrm{F}$ & 1751 & 2023 & 2170 & 2405 & 2627 \\
\hline Flow, $10^{6} \mathrm{lt} / \mathrm{hr}$ & 11.8 & 9.9 & 9.5 & 8.7 & 8.24 \\
\hline
\end{tabular}

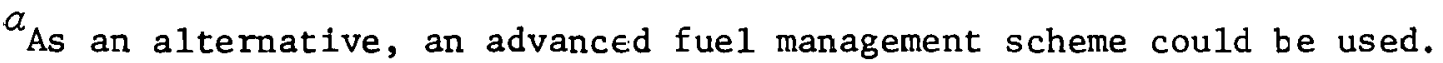

${ }^{b}$ Commercial HTGR value is $2560^{\circ} \mathrm{F}$.

Source: High-Temperature Nuclear Heat Source Study, Report GA-A13158, General Atomic Company, December 1974. 
A comparison of the VHTR core operating conditions (for the $1800^{\circ} \mathrm{F}$ mixed mean outlet temperature) to those of the Ft. St. Vrain and the Fulton plants is shown below.

$\begin{array}{lrcr} & \text { VHTR } & \text { Ft. St. Vrain } & \text { Fulton } \\ \text { Core inlet temperature, }{ }^{\circ} \mathrm{F} & 932 & 932 & 606 \\ \text { Core exit temperature, } a{ }^{\circ} \mathrm{F} & 1864 & 1445 & 1391 \\ \text { Maximum fuel temperature, }{ }^{\circ} \mathrm{F} & 2562 & 2300 & 2570 \\ \text { Average fuel temperature, }{ }^{\circ} \mathrm{F} & 1886 & 1500 & 1634\end{array}$

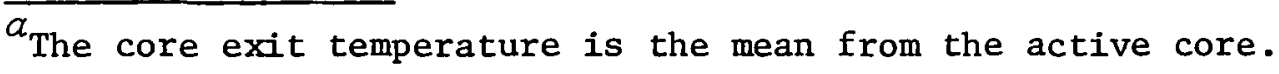

Although the peak fuel temperature for the VHTR is no greater than for the Fulton Generating Station, the higher gas temperature will lead to a higher average fuel temperature. The use of all TRISO, rather than the TRISO-BISO combination currently used in the large commercial stations, should compensate for the higher temperature. Thus the fission product release rates from the elements for the reference case should be comparable to those of the commercial plants.

The WANL fuel and moderator concept is similar to the GA system in that the fuel is supported within hexagonal graphite blocks. However, the dimensions across the blocks are about three times those of the GA design, and the active core contains only 61 column with eight fueled blocks per column. The principle difference in the two designs is that the WANL fuel rods (both fissile and fertile) are in the form of hollow tubes and are directly cooled on the inside diameter. In comparison with the GA design, this direct cooling of the fuel rods will reduce the temperature difference between the fuel particles and the coolant by several hundred Fahrenheit degrees.

For the WANL core, the average fissile and fertile fuel element temperatures for an $1850^{\circ} \mathrm{F}$ mixed-core outlet temperature were 2050 and $1925^{\circ} \mathrm{F}$ respectively. In order to minimize the radial power shape, ten different loadings in 14 radial zones were used. The resulting peak nominal temperature was reported to be $2169^{\circ} \mathrm{F}$. No detailed hot-channel analysis was made; however, the margin between the nominal and the peak permissible temperatures should be more than adequate to compensate for these factors. Although no fuel temperatures were reported for higher core outlet temperatures, the directly cooled fuel elements and the low radial power shape would probably permit outlet temperatures greater than $2000^{\circ} \mathrm{F}$ with currently available fuel technology.

Other WANL core parameters for the $3000 \mathrm{MW}(\mathrm{t})$ and $1850^{\circ} \mathrm{F}$ mixed-mean outlet temperatures were as follows: 


$\begin{array}{ll}\text { Core power density, } \mathrm{W} / \mathrm{cm}^{3} & 10 \\ \text { Pressure, psia } & 1000 \\ \text { Core pressure drop, psi } & 5 \\ \text { Core inlet temperature, }{ }^{\circ} \mathrm{F} & 810 \\ \text { Fissile elements } & \\ \text { Type fuel coating } & \text { TRISO } \\ \text { Tube OD, in. } & 1.162 \\ \text { Tube ID, in. } & 0.882 \\ \text { Fertile elements } & \\ \text { Type fuel coating } & \text { BISO } \\ \text { Tube OD, in. } & 1.000 \\ \text { Tube ID, in. } & 0.507\end{array}$

Although the WANL fuel element concept has considerable appeal from the viewpoint of low fuel-to-coolant temperature differences, there is some concern regarding its structural integrity. Irradiation experience has shown that severe debonding of the coated particle from the graphite matrix can occur and that the fuel rods will undergo shrinkage during irradiation. Shrinkage of the rods will lead to difficulties in ensuring an adequate bond between the rods and the moderator block during their lifetimes. Loose rods would be subjected to coolant-induced vibrations, which could accelerate the debonding problems. In our judgment, it will be necessary to test this element under the same conditions it would be exposed to during actual operation. This could lead to a very long and expensive development program.

The GE core design uses a pebble-bed concept similar to the German AVR, which has been operated at temperatures up to $950^{\circ} \mathrm{C}\left(1742^{\circ} \mathrm{F}\right)$. The core consists of a cylinder $41 \mathrm{ft}$ in diameter by $16.4 \mathrm{ft}$ in height and contains $3.23 \times 10^{6}$ fueled graphite balls. Each ball is $6 \mathrm{~cm}$ in diameter and consists of an inner fuel region loaded with low-enrichment uranium and an outer $0.5-\mathrm{cm}$-thick fuel-free graphite shell. The fuel particles are $\mathrm{UO}_{2}$ with either TRISO or BISO coatings for core outlet temperatures up to $950^{\circ} \mathrm{C}\left(1742^{\circ} \mathrm{F}\right)$ and TRISO coating for higher temperatures. There are alternate designs of the fueled balls that can reduce the fuel temperatures. For example, a zoned configuration in which the fuel is located in a $1-\mathrm{cm}-$ thick annular shell with an unfueled center sphere and dil unfueled outer shell w11l reduce the temperature gradient through the sphere by $56 \%$ in comparison to the reference design.

The GE core couples a two-zone core fueling system to the once-throughthen-out (OTTO) fuel cycle to minimize fuel element temperatures. With the OTTO fuel cycle, the fuel makes a single downward pass through the core (parallel to the coolant flow); the decreasing power output coupled to the increasing gas temperature gives a fuel temperature that is very nearly flat through the latter one-half to three-fourths of its life. The fuel temperature profile shown by $\mathrm{GE}$ indicates a peak temperature about 100 to $150^{\circ} \mathrm{F}$ greater than the core exit temperature for the zoned fuel ball design and about $250^{\circ} \mathrm{F}$ greater for the reference ball design. 
Other GE core parameters for the $3000 \mathrm{MW}(t)$ and $1742^{\circ} \mathrm{F}$ mixed-mean core outlet temperatures were as follows:

$\begin{array}{ll}\text { Core power density, } \mathrm{W} / \mathrm{cm}^{3} & 5 \\ \text { Pressure, psia } & 600 \\ \text { Core pressure drop, psi } & 5.5 \\ \text { Core inlet temperature, }{ }^{\circ} \mathrm{F} & 482\end{array}$

With the design options available and with current fuel technology, the pebble-bed core concept with the OTTO cycle should be able to produce core exit coolant temperatures greater than $2000^{\circ} \mathrm{F}$.

In summary, with current technology, all the core concepts are capable of producing coolant temperatures $\left(\sim 1800^{\circ} \mathrm{F}\right)$ sufficient to meet the reference $1600^{\circ} \mathrm{F}$ process temperature. The GE and WANL designs have a smaller temperature difference between the peak fuel temperature and the core outlet gas temperatures than does the GA design; they are capable of producing reactor coolant temperatures greater than $2000^{\circ} \mathrm{F}$; and they are possibly sufficient to meet the requirements for a $2000^{\circ} \mathrm{F}$ process temperature. The GA design will require the development of a higher-temperature fuel particle for core coolant temperatures much above $1800^{\circ} \mathrm{F}$.

The GA design is the most developed of the proposed systems. Although the AVR has proved the technical feasibility of the pebble-bed concept, the OTTO cycle is new and untried but does not involve new technology. It should also be noted that the GE core has a lower power density relative to the other two and thus requires a larger core and reactor vessel. There are rather serious questions as to the structural integrity of the WANL fuel rods for long-time, high-burnup operation.

\subsubsection{Process and power generation systems}

Both the GE and GA systems use the full high-temperature reactor outlet flow for process heat and the lower temperatures available from the IHX or PHX for steam generation, for power, or for other processes. The WANL system splits the high-temperature reactor outlet, with part going to the high-temperature process stream and part going to gas turbines for power production. The advantages of the WANL approach are dependent upon very large needs for low-temperature heat.

The GE concept uses a 55-1oop system in which the primary coolant first passes through the IHX, where $45 \%$ of the reactor heat is removed; the primary coolant then passes through a steam generator that produces highpressure $1000^{\circ} \mathrm{F}$ steam for a steam power system. The heat transferred to the IHX loop passes through a PHX, where $66 \%$ of its energy is given to the process stream, and then through a steam reheater that reheats steam from the high-pressure power turbine. Thus the total amount of energy given to the process system is $900 \mathrm{MW}(t)$, with the remaining $2100 \mathrm{MW}(t)$ going to the steam power generation system. The electrical power available for local use or to the grid was estimated to be 600 to $700 \mathrm{MW}(\mathrm{e})$ (20 to $23 \%$ of the reactor thermal output). 
The GA concept did not include an IHX. In this system, $52 \%$ of the reactor output went directly to the PHXs and $48 \%$ to steam generators located downstream from the PHXs. The output of the steam generators was used to drive the primary system helium circulators and other power and process needs. The GA concept, which includes an IHX, would give a system similar to that of $\mathrm{GE}$, with a somewhat different split in the energy utilization.

The WANL concept uses ten primary loops. Five of the loops supply about $52 \%$ of the reactor output to higher-temperature IHXs, and the other five loops supply the remaining $48 \%$ of the reactor output to gas turbines and low-temperature IHXs. The power output of the turbomachinery loops is $262 \mathrm{MW}(\mathrm{e})(8.7 \%$ of the reactor thermal output), with 39 to $40 \%$ of the reactor output given directly to the low-temperature IHXs. The reason the high percentage of reactor output goes to the process system with only about one-half of the reactor flow is that the temperature drop across the IHXs and PHXs is about $1000^{\circ} \mathrm{F}$, or twice that of the GA and GE systems.

The use of gas turbines in the WANL concept will introduce control problems for both normal operations and for upset transients. There are three basic methods of controlling closed-cycle gas turbines - by systems inventory or pressure, by turbine inlet temperature, or by bypass flow. Neither inventory nor turbine inlet temperature control appears applicable to the WANL concept. A control system has been shown with in-line valves for both speed and overall power control with a parenthetical statement that bypass valves may be used. The use of in-line valves ${ }^{4}$ is questionable. The turbocompressor is a single shaft machine that results in a constant-speed compressor. An accidental closure of the valve will send the compressor into a surge and may lead to extensive damage to the equipment. A bypass system that bypasses flow from a high-pressure to a low-pressure part of the loop should be satisfactory. This control mode can give a rapid response to load but results in a very poor partload efficiency. For some types of transients, a bypass system may be required for safety reasons. The plant control system must also provide turbine overspeed protection for a loss-of-electrical load. This type of protection will probably require rather large, fast-acting valves to bypass flow arouid the Lurbline.

The bypass valve operation, for either control or overspeed protection, will cause both pressure and temperature transients throughout the system. The magnitude of, or problems created by, these transients will depend on the relative high- and low-pressure inventories in the system, the rate of bypass flow, and the location of the high- and low-pressure bypass points. Such information is not available from the preliminary design.

The use of gas turbines also adds to the safety problems of the plant. The WANL units have a pressure ratio of about 2.5 , which means that some areas of the system must operate with a differential pressure of about 600 psia. With a pressure differential this large, a failure of the turbocompressor or ducting would lead to a very rapid shift of system 
inventory with large rates of pressure change. It is also possible that such a failure would subject parts of the system to high-energy shock waves.

The turbomachinery cavity and mounting system must provide protection for equipment seizure (and the resulting high torque) and missile protection in the event of failure of either the turbocompressor or the generator.

The monitoring, inspection, and maintenance of the turbomachinery may be a severe problem. Calculations made by $\mathrm{GA}^{5}$ (for a different project) for the radiation field around the power turbine of a split-shaft turbocompressor for a high-temperature $\left(1500^{\circ} \mathrm{F}\right)$ gas-cooled reactor system estimated an intensity of $10.5 \mathrm{rads} / \mathrm{hr}$ at a distance of $60 \mathrm{in}$. This level included the activity on the casing, rotor, and stator of the unit, ten days after a four-year operating period and excluded bromine and iodine. Thus conventional inspections and maintenance procedures cannot be used. It is probable that rather sophisticated condition monitoring equipment will have to be developed to detect impending operating problems in the rotating equipment.

The feasibility of equipment maintenance or repair may depend on the degree to which the equipment can be decontaminated. The current state of technology concerning the behavior of the fission products precludes any firm predictions of decontamination factors. At best, the fission products will probably be sufficiently tenacious to require some removal of material from the turbomachinery. At worst, direct-contact maintenance may not be possible.

The inclusion of gas turbines will also add appreciably to the cost and difficulty of the development program. One obvious problem will be the testing of a full-scale power conversion system at operating temperature. This will probably require the development of a fossil-fired heater capable of delivering $1850^{\circ} \mathrm{F}$. helium to the turbine. Thus the test facility may have a materials problem more severe than the heat exchangers for the reactor system.

\subsubsection{Reactor vesse1s}

The GA and GE concepts use large conventional prestressed concrete reactor vessels (PCRV) that are typical of those currently in use for gas-cooled reactors. These units are within current technology, and any development required would be a scale model test to prove the final design.

The WANL concept specified a prestressed cast iron vessel (PCIV). The recommended design is that of gray cast iron sections (60 to 65 tons each) mechanically assembled around a welded steel liner. The vessel is prestressed circumferentially and axially in the same manner as the PCRV, with which the PCIV is compared in this study. The primary advantages cited for choosing cast iron over concrete are that cast iron has a compressive strength 20 times that of concrete, whereas its density and 
Young's Modulus are 3 times that of concrete. It is also stated that the use of cast iron will result in a superior structure with reduced weight and size and reduced sensitivity to overtemperature incidents. The design is based on the work of a German firm, Siempelkamp. ${ }^{6}$

No details of the cast iron section configurations are presented. The sections are described as webbed, egg-crate style structures of 60 to 65 tons, with web thicknesses of 1 and 4 in. The referenced paper by Siempelkamp ${ }^{6}$ recommends 40 tons as the limiting weight of a section. The WANL study states ${ }^{7}$ that a 4-year research and development program would be required to develop the process for producing and testing the intricate $60-$ to $65-$ ton castings. Siempelkamp, 6 on the other hand, states that a simple manufacturing of units in cell structure can now be assured. It is felt that a great deal of study is needed concerning both of those statements, especially with regard to the "simple" process of cel1structure casting. The casting problem should be critiqued by a producer of heavy section castings. With further regard to the cast iron material, it is stated that only Class 40 gray iron will be used. (Class 40 is a very general specification.) No mention is made of special requirements such as chemical composition, heat treatment, methods of testing, and acceptance criteria. It is interesting that the American Society for Testing and Materials (ASTM) specification A278-64 ${ }^{8}$ allows castings with continuous sections greater than 2 in. to satisfy a criteria of only $80 \%$ of the rated tensile strength. The material specifications would need to be more explicit in a design situation.

With regard to shear keys, it is stated $^{9}$ that the blocks are provided with shear keys for location and transfer of structural loads. However, it states that there are no shear keys between the wall elements. ${ }^{10}$ In addition, the material for the shear keys is not specified.

Concerning the irradiation testing, WANL briefly mentioned that the influence of irradiation on both the liner, insulation, insulation retainer plates, grout, and vessel cast iron is a subject of concern. Il If the carbon steel liner (ASTM A537) is subject to low-temperature irradiation, it will embrittle rather severely. (The 1-5/8-in. thickness in the core cavity is over twice that of current HTGR PCRV designs.) The effects on the other materials is not known, but, depending on the fluence levels (which were not mentioned), they could likewise experience severe radiation damage. In addition, no details are provided concerning the thermal and residual stress effects on the core cavity liner due to the welding and bolting of the insulation retainer plates. It is assumed that the grout transfers the compressive prestress to the liner, but localized tensile loading seems probable. Thus a detailed analysis of possible load-bearing responsibilities for the liner should be made. A fracture toughness characterization may be required in that regard. The operating temperatures of the liner, cast iron, and insulations are not specified, nor is there an analysis of the ramifications of a loss of primary coolant and/or PCIV cooling water. 
Westinghouse states that the cost of a concrete vessel would be approximately $30 \%$ more than that of the cast iron vessel, not including indirect costs.12 No figures are provided to substantiate that conclusion, and a definitive cost analysis would certainly be required.

In summary, the assessment of the PCIV concept is inadequate. It is difficult to constructively critique the pressure vessel portions of this technology assessment. Although a research and development program for the PCIV is provided, 13 much more detailed design information would be required to enable a more precise definition of the PCIV feasibility and areas requiring long-term research expenditures. It is felt that the concept of the PCIV offers some advantages for power reactors that are worthy of further study.

\subsubsection{Ducting and insulation}

An insulation system is required to protect the pressure vessel from the hot coolant gas and to minimize the heat losses from the primary coolant, and thus, the heat load on the pressure vessel cooling system. There are two basic approaches to the problem. The first is to use a hightemperature insulation attached to the inside of the ducts and cavities which is exposed to the maximum coolant temperatures. The second method, which reduces the insulation requirements, is to use concentric ducting with the hot helium in the inner duct and the cooler return helium in the outer annulus.

Attaching the insulation to the inner surface of the reactor vessel liner is the method currently used with gas-cooled reactors in the United States. The ducting insulation consists of a blanket of alumina-silica or a combination of alumina-silica and pure silica fibers held to the liner by metal cover plates and is limited to a continuous average operating temperature of $1500^{\circ} \mathrm{F}$ and local hot spots or streaks of about $1700^{\circ} \mathrm{F}$. Additional insulation in the form of silica blocks capable of withstanding higher localized temperature is used on the bottom of the reactor cavity below the core. Thus the currently used insulation materials and techniques are limited to a reactor outlet temperature of about $1500^{\circ} \mathrm{F}$ or a process temperature of about $1300^{\circ} \mathrm{F}$.

In addition to the temperature and thermal conductivity requirements, the insulation must be capable of withstanding a system depressurization accident without damage to the insulation which would interfere with the auxiliary cooling system; that is, the insulation must not be displaced in such a manner as to block flow passages essential to the removal of the decay heat following all postulated accidents.

The problem associated with the insulation of the ducting and cavities is primarily one of developing an adequate mechanical design using currently available insulating materials. The development program will require tests to prove the adequacy of the design in regard to heat losses in a flowing system, noise and vibration effects, and system depressurization accidents. 


\subsubsection{Heat exchangers}

The high-temperature IHX and PHX are the major items affecting the nearterm feasibility of the VHTR and will be the key item in the development of the concept. For process temperatures in the range of $1400^{\circ} \mathrm{F}$, the temperature requirements for the IHX are in the range of 1700 to $1800^{\circ} \mathrm{F}$, which is borderline for the available superalloys. Maximum PHX temperatures would be in the order of 1550 to $1600^{\circ} \mathrm{F}$ for the same conditions. Although there are a number of candidate materials for this temperature range $\left(1500\right.$ to $\left.1800^{\circ} \mathrm{F}\right)$, a major development program will be required to prove their compatibility with the primary coolant and to obtain sufficient data to qualify the materials to some form of ASME (American Society of Mechanical Engineers), ERDA, or other codes. These problems are discussed in Sect. 2.1.2.

The mechanical design problems will depend on the material properties and the operating conditions imposed on the units. The requirements for the GE and GA concepts should be similar. However, the WANL system may be subjected to greater pressure differential and transient because of control or safety actions required for the turbomachinery.

The WANL concept also has a lower-temperature heat exchanger that serves as the compressor precooler. Under normal operation (for the $1600^{\circ} \mathrm{F}$ process temperature case), the helium conditions to the precooler are $1200^{\circ} \mathrm{F}$ and 396 psia. This unit could be subjected to severe pressure and temperature transients from control or safety requirements.

The steam generators for the GA and GE systems use operating conditions no more severe than do units for commercial HTGR steam plants.

\subsubsection{Valves}

The current U.S. GCRs use isolation valves for the containment system and the main steam lines, split butterfly type valves for the core auxiliary cooling system, and shutoff valves to prevent flow reversal through the primary coolant loops. These valves or adaptations should be adequate for the VHTR. The VHTR will also require isolation valves if an intermediate helium loop is used. Several concepts for these valves have been investigated and appear to be satisfactory. However, this could be an area where significant development is required.

The WANL system using gas turbines will require additional primary system valves for control and overspeed protection of the turbomachinery. Large, quick-opening valves will probably be required to protect the turbine from excess speed in the event of a loss-of-electrical load on the unit. Smaller valves for speed control will probably also be required. The operating requirements for these valves will be more severe than those for the intermediate loop isolation valves and will require an extensive development and proof-testing program. 


\subsubsection{Safety}

With the inclusion of the IHX, the safety related problems of the GE and GA concepts for the VHTR are similar to those of the current U.S. GCRs for steam plants. There will be some additional requirements for the VHTR such as isolation valves for the intermediate loop. Also, the margin of safety, in regard to temperature, between the normal operating conditions and those that may cause failure of safety related components will be reduced. However, the basic problems and the design approaches are quite similar. If the IHX is not used, then safety questions related to process fluids must be carefully investigated.

The WANL concept, because of the use of gas turbines, will have a number of safety related problems in addition to those of the GE and GA designs. A list of those problems associated with the turbomachinery which will require further evaluation and/or specific safety design features are: the effect of transients induced by a failure of a component or duct separating the high- and low-pressure parts of the system; the effects of a loss-of-electrical load on turbomachinery speed and the effects of transients induced by control actions to limit the turbomachinery speed for the loss of load; the effects of a failure of the turbonachinery components such as blades, rotors, or generator or a seizure of the machinery; and whether a depressurization incident in the low-pressure part of the primary system would drive the compressor into surge. Also, the location of the generators within the pressure vessel and the containment system requires that the power output of the plant penetrate both of these structures; special care will be required to ensure that any electrical short in these penetrations does not violate the containment system. The magnitude of these problems is not known; however, they will add to the complexity of the safety analysis and the plant protection system.

\subsection{Materials (alloys)}

\subsubsection{Status of technology}

This section will attempt to outline the state of the art relative to alloys of potential use for various components of VHTR process heat systems. The reference process heat temperature will be assumed as $1600^{\circ} \mathrm{F}$, and major emphasis will be given to alloys for the higher temperature components. Discussion of nonmetallic structural materials is presented in Sect. 2.3.

\subsubsection{Alloy classes}

Alloys used to fabricate primary system components for commerical GCR plants range, in sophistication and cost, from low-carbon steels to nickel-base superalloys. The materials employed are commercially available, are accepted by the ASME Boiler and Pressure Vessel Code, and have 
been and are continuing to be evaluated extensively with regard to environmental stability and compatibility. Some of these alloys (e.g., Alloy 800 , Hastelloy $X$, and $2-1 / 4$ chromium ( $\mathrm{Cr}$ ) $-1 \%$ molybdenum (Mo) steel) are also being considered for use in VHTR process heat systems.

Although much of the materials technology of conventional GCRs will be applicable to various components (e.g., steam generators and helium circulators) of VHTR systems, some of the components in the VHTR are unique to. the concept with regard to purpose, operating conditions, or both. Depending upon the exact VHTR concept under consideration, these unique applications are the intermediate and process heat exchangers (IHX and PHX respectively), hot ducts, thermal barrier cover materials, hot valves, and turbomachinery. The materials currently being considered for these applications are, in general, commercially available but have not been studied and evaluated to the extent of those employed in the present generation of GCR plants.

The general classes of alloys available for VHTR process heat system construction are listed below in qualitatively increasing order of temperature capability. Comments relative to the applicability of specific alloys for specific applications are deferred until later in this chapter.

\subsection{Carbon and low-alloy steels}

This large class of relatively low-cost materials includes materials normally employed below $1000^{\circ} \mathrm{F}$. Examples are AISI 1010/1020 steels and 2-1/4 $\mathrm{Cr}-1$ Mo steel.

\subsection{High-alloy ferritic steels}

Some high-alloy ferritic steels (e.g., of the $12 \% \mathrm{Cr}-1 \%$ Mo family) offer strength improvements over the low-alloy materials. It is unlikely, however, that they could be used at $>1200^{\circ} \mathrm{F}$. Materials of this class are not currently employed in commercial steam-cycle GCR plants but are being considered for possible future use in the steam generator.

\subsection{Ferritic stainless steels}

There are a wide variety of 400 Series ferritic stainless steels available commercially. These steels, containing from 11 to $27 \%$ chromium, are used for a number of applications requiring chemical and air corrosion resistance but generally are not attractive in terms of hightemperature strength. 


\subsection{Austenitic stainless steels}

The 300 Series austenitic stainless steels (with both high nickel and chromium contents) have potential for use up to about $1500^{\circ} \mathrm{F}$. Two of these materials, Types 304 and 316, are ASME approved for high-temperature nuclear service.

\subsection{Iron-nickel ( $\mathrm{Fe}-\mathrm{Ni}$ )-base alloys}

The iron-nickel-base alloys (e.g., the 800 and 900 series Incoloys) also offer potential for application at temperatures to $1500^{\circ} \mathrm{F}$. Most of these materials would require considerable study before their use in VHTR systems. However, one of the alloys, Alloy 800 (Incoloy 800), is currently ASME Code approved for nuclear use.

\subsection{Nickel (Ni)-base alloys}

A large number of nickel-base superalloys capable of high-temperature service are also available. These alloys generally have additions of 10 to $25 \%$ chromium, up to $12.5 \%$ cobalt, and lesser amounts of various combinations of tungsten, niobium (columbium), molybdenum, titanium, and aluminum. Some of the highest-strength alloys (i.e., $\gamma^{\prime}$ strengthened) may not be viable candidates for use because of difficulties with fabricability and microstructural stability.

\subsection{Cobalt (Co)-base alloys}

Commercial cobalt-base alloys, although very strong at elevated temperatures, may be unacceptable in the primary system of the VH'l'R because of possible radioactive cobalt contamination. The problem of radioactive cobolt contamination needs to be better quantified.

\subsection{Refractory metal alloys}

The refractory metals and their alloys are not well developed commercially but have high strengths at temperatures in the 1700 to $2300^{\circ} \mathrm{F}$ range. However, as a class, they are extremely susceptible to interstitial embrittlement. At present, only molybdenum and its alloys may be considered as serious candidates for service in VHTR helium. Use in process gases is almost assuredly out of the question.

\subsubsection{Requirements for nuclear service}

Selection and application of materials for use in nuclear systems requires a large amount of information and data as well as compliance with the rules and codes of the ASME and Regulatory/Licensing bodies. Section III of the ASME Boiler and Pressure Vessel Code contains rules for construction 
of "components which are designed to provide a pressure-containing barrier or to act as a pressure-retaining member in the nuclear power system or to support the reactor core."14 These rules, however, "do not cover deterioration which may occur in service as a result of radiation effects, corrosion, erosion, or instability of the material."14 When Class 1 nuclear components are to be used at elevated temperatures (i.e., above $700^{\circ} \mathrm{F}$ for ferritic alloys and $800^{\circ} \mathrm{F}$ for austenitic alloys), the rules of Code Case 1592 must be applied. The rules and allowable stresses contained in this Code Case reflect both time-independent (yield and ultimate tensile strengths) and time-dependent (creep and stress rupture) materials properties and structural behavior.

If the material selected for use in a VHTR high-temperature component is not qualified under Code Case 1592 (assuming elevated temperature use as defined in the paragraph above and a Class 1 application), qualification of the material must be undertaken since only alloys having ASME Code approval may be used in such construction. Since only four materials 304 and 316 stainless steels, Alloy $800 \mathrm{H}$, and 2-1/4 $\mathrm{Cr}-1$ Mo ferritic steel - are included in Code Case 1592, it is 1ikely that most of the alloys finally selected for VHTR Class 1 applications will fall into the "unqualified" category. Qualification of these materials to ASME, Regulatory, or other rules will require the acquisition, compilation, and analytical treatment of large amounts of data on tensile, creep, and fatigue behavior. Qualification of materials for Class 2 and 3 applications will require a smaller, but still significant, effort. It will also be necessary to account for the effects of chemical and material instabilities (e.g., gas-metal reactions and thermal aging and possible interactions) on mechanical properties and behavior. Such information is essential to ensuring the integrity and continued functioning of components over the desired service life.

Currently accepted practice permits design for long service life based on relatively short-time property information (e.g., permits extrapolation of creep data from tests of less than $50,000 \mathrm{hr}$ to several hundred thousand hours). This, considering the safety margins incorporated into allowable stresses, is acceptable if the materials are metallurgically stable (i.e., do not transform on aging to produce a material of different character in terms of strength and/or ductility) under the time-temperatureenvironment conditions experienced in service. Short-time instabilities are probably sufficiently accounted for in the typical range of data acquisition, but possible longer term changes, which might occur from sequential transformations and/or transformations reflecting interaction with the environment, are generally poorly known and characterized. Questions of long-time thermal stability and environmental compatibility with both the VHTR helium coolant and process gas must be addressed in the selection and qualification of VHTR system materials.

\subsubsection{Reactions with VHTR environments}

At least three extremely different gaseous environments may be associated with an operating VHTR system. In the first of these - the primary 
coolant helium - the levels and ratios of the major impurity gases expected to be present (i.e., $\mathrm{H}_{2}, \mathrm{H}_{2} \mathrm{O}, \mathrm{CO}, \mathrm{CH}_{4}, \mathrm{CO}_{2}$, and $\mathrm{N}_{2}$ ) may result in conditions that are oxidizing or reducing and also carburizing or decarburizing with respect to individual elements within the alloys employed in system components. Helium in the intermediate loop will likely contain similar impurities but at different concentrations. If steam generators and/or auxiliary cooling systems are incorporated into a VHTR, it will also be necessary to consider reactions with steam, steam-water mixtures, and appropriate contaminants (from condenser leakage, water chemistry control, etc.). Finally, depending upon the exact process under consideration (i.e., the purpose or use for the process heat), reactions between structural alloys and quite severe environments in terms of the desired lifetime and reliability of VHTR components - will be expected. In this case, diffusion of process gas species into the helium stream will also be of concern.

A generalized description of the characteristics of gas-metal reactions and their effects is given in paragraphs immediately below. Although the description was developed with reference to impure helium, much of the information presented is applicable to, or can be extrapolated to, steam and process gas environments.

\subsection{Impurity concentrations}

At lower temperatures of exposure in environments of moderate to high oxidizing potential, oxidation resistant alloys should form thin surface films of oxide. If the oxide film is adherent and impervious to the gas, reaction rate should be almost independent of the concentration of oxidizing species. However, the composition of the oxide film and hence its ability to adhere to the metal surface may change with exposure time and could result in local and/or intermittent accelerations in reaction rate or breakaway. In cases where the oxidizing potential is low and temperatures are relatively high, oxide films may be absent or may cover only a fraction of the alloy surface because of limited availability of reactive gases. Under these conditions, reaction rate should increase with increased concentration of reactive species.

\subsection{Temperature}

Reaction rates generally increase exponentially with temperature as long as the supply of the reactive species is sufficient. If the supply is limited, rates significantly below those predicted by the Arrhenius Law will be observed, and the effective reaction rate may remain constant over a wide range of temperatures above some minimum temperature. Limited availability of reactive species can also result in selective reactions. For example, an environment with very low oxygen potential can result in selective oxidation of those alloying elements that form the most stable oxides. These conditions favor the internal oxidation of alloying elements such as titanium, aluminum, and chromium. 


\subsection{Carburization and decarburization}

At relatively low temperatures, there should be little tendency for either carburization or decarburization because of the low diffusivity of carbon. When surface oxides are produced in the presence of a carburizing gas at such temperatures, free carbon can be deposited in the oxide film without affecting the carbon content of the substrate alloy. Carburization of common "oxidation resistant" alloys generally occurs only at very high temperatures. Again, however, this depends on the gas species in the environment and their chemical potentials. Reactions other than oxidation and carburization/decarburization will likely be important with respect to process gases (e.g., reactions involving sulphides).

\subsection{Alloy composition}

To illustrate the principles of the reactions described above, the behavior of certain classes of alloys [at their normal-use temperatures in helium containing $\mu$ atm (microatmospheres) of the impurities expected in GCR primary coolant] is mentioned below. Relatively simple carbon steels are expected to decarburize and to form no oxide. Low-alloy ferritic chromium steels could be both decarburized and oxidized (i.e., the matrix carbon is expected to decrease, and chromium oxide may be present as a grain-boundary phase near the surface). Higher temperature alloys such as austenitic stainless steels and nickel-base materials with high chromium contents will form chromium-rich oxide films. Chromium depletion at the alloy surface may be accompanied by carburization of the substrate, especially above $1500^{\circ} \mathrm{F}$. The higher service temperatures may also result in internal oxidation of titanium, aluminum, and chromium. As opposed to the helium environment referenced above, exposure of similar materials to steam (e.g., in a steam generator) should always provide a highly oxidizing atmosphere. However, in this instance, phenomena such as localized (pitting) corrosion and stress-corrosion cracking must be considered. Process gas environments should, in general, be quite reactive. Oxidation and carburization will certainly be important as may reactions involving other gaseous elements and compounds.

\subsection{Gas-metal reaction effects}

The high-temperature mechanical behavior (e.g., creep, fatigue, and crackgrowth properties) of structural alloys can be affected by reactions with gaseous environments. It is not, in general, possible to satisfactorily predict the effect.s of environment on mechanical properties because alloys can be strengthened as well as weakened by such reactions. Also, it has been observed that the elevated temperature creep strength of some alloys is less during their interaction with gases than when the same alloys are doped with identical impurities prior to creep testing. Alloys exhibiting this characteristic can also undergo accelerated transient creep rates for short periods. In general, such alloys do not form a surface film, and 
this phenomenon is thought to be related to the reaction and solution of the impurity gases and the precipitation of a grain boundary phase at the solubility limit. Gas-metal reactions resulting in the formation of a continuous surface film are usually strengthening, provided that applied stresses are lower than those required to crack the film.

Studies performed in Europe and Japan on the effects of HTGR helium environments have suggested that the working stresses for creep and rupture of some alloys may be reduced up to $25 \%$ in simulated HTGR helium. Although most studies have shown somewhat smaller effects, all have indicated that this environment (as opposed to air) can cause both surface degradation and reduction of mechanical properties. Quantitative differences in results are believed to accrue primarily from differences in environment (i.e., differences in impurity concentrations and/or ratios of impurity gases). Another contributing factor may be test-section geometry (i.e., since gas-metal reactions occur mainly at the gas-metal interfaces, the extent of a mechanical property change in a given time should be dependent on the metal surface-to-volume ratio).

\subsubsection{Other considerations}

Some fraction of the gaseous and volatile fission products that will exit the core of a VHTR system will condense or be impacted on the surfaces of components in the primary coolant circuit. It is important, then, to determine whether these products are compatible with the materials of construction (i.e., whether reactions between fission products and structural alloys degrade the properties of the alloys in such a fashion and to such extent that component reliability and integrity are compromised).

Questions of wear, galling, and fretting could be a problem in VHTR components. This is particularly true in connection with the VHTR primary coolant environment. Its low oxidizing potential may prevent the formation of "lubricating" protective oxide films and may require that preoxidation or other surface treatments be employed. Erosion, especially in conjunction with process gases, may require application of hard-facing materials.

The development of welding procedures and the testing of weldments under appropriate conditions will likely be important considerations in the construction and performance of VHTR system components and should be addressed as early as possible in system design. Additionally, questions of weldability and general formability may be influencial in the selection of candidate alloys.

\subsubsection{Alloys for the reference system}

The studies/assessments on VHTR systems for process heat prepared by WANL, GE, and GA gives, in varying degrees of detail, suggestions for materials to be used in various parts of the system. In this section 
we will examine these suggestions for the reference plant, especially as they relate to the highest service temperatures, and comment, where possible, on whether these alloys or alternates offer a good chance of successful design and operation of the component.

\subsubsection{Ducting}

The reference VHTR for a $1600^{\circ} \mathrm{F}$ process heat source will require a reactor exit helium temperature in the neighborhood of $1800^{\circ} \mathrm{F}$. Portions of the hot ducting will be exposed to this temperature and, because of temperature streaking in the exit gas, to higher temperatures for the design life of the plant. The WANL assessment does not give recommendations specific to hot ducting but, by implication with respect to the IHX, suggests the use of Inconel 617, refractory metals, or ceramics. General Atomic Company favors the use of molybdenum-TZM, carbon-fiber reinforced composites, or ceramics (e.g., $\mathrm{SiC}, \mathrm{Si}_{3} \mathrm{~N}_{4}$, and $\mathrm{Al}_{2} \mathrm{O}_{3}$ ). The GE study recommends that materials for high-temperature (i.e., >1500 $\mathrm{F}$ ) applications, including ducting, heat exchangers, and hot valves, should be selected from one of the following classes: advanced nickel-base alloys (e.g., Inconel 617 or modification), refractory metals, thorium oxide dispersion strengthened (ODS-TD) nickel, and nonmetallics.

It seems unlikely that any one of the materials mentioned above could be selected for use in the near term in the reference VHTR system with confidence in its ultimate success. The metallic materials and their potential in terms of service temperature will be discussed in Sect. 2.2.3.

\subsubsection{Intermcdiate heat exchanger (IHX)}

The temperatures in the helium/helium IHX will approach those of the reactor exit gas stream (i.e., $\sim 1800^{\circ} \mathrm{F}$ ), but gas temperature streaking should be a lesser problem. Both GE and WANL suggest the use of Inconel 617 or modifications but realize that (1) there is little information regarding its compatibility with GCR helium, (2) it is not an ASME Codeapproved material, and (3) fabricability and weldability of large components of Inconel 617 have not been demonstrated. Several commercially available materials (e.g., 300 Series stainless steels and Alloy 800) may be suitable for use in the cooler $\left(<1500^{\circ} \mathrm{F}\right)$ portions of the IHX.

\subsubsection{Helium circulator}

Temperatures in the circulator of the reference GE VHTR are relatively low $\left(482^{\circ} \mathrm{F}\right.$ inlet); and therefore, gas-metal reaction effects should be minimal, if not totally absent. Ferritic stainless steels (400 Series) similar to materials used by GA in HTGR circulator design with $640^{\circ} \mathrm{F}$ inlet to the compressor - are proposed by GE for this application. Both WANL and GA list significantly higher design temperatures ( $>800$ and $900^{\circ} \mathrm{F}$ respectively) for their reference VHTR plant circulators. This 
could require that a choice of materials other than the 400 Series stainless steels be made but should not preclude the successful design and operation of circulators as a result of materials limitations.

\subsubsection{Auxiliary heat exchangers}

The helium/water heat exchangers, which are part of the auxiliary cooling system of the reference VHTR, will be designed to operate (per the GE proposal) at about $900^{\circ} \mathrm{F}$. Design alternatives might raise this temperature to $1200^{\circ} \mathrm{F}$. In either case, commercial alloys of suitable properties and compatibility with GCR helium should be available to permit satisfactory design, construction, and operation of this heat exchanger. Tubes of 2-1/4 Cr-1 Mo steel could be used for the lower temperature, while Alloy 800 is a candidate for tubes at the higher temperature. Hastelloy $\mathrm{X}$ may be a viable shroud and tube support material.

\section{2 .2 .5 Steam generator}

Both the GE and GA $1600^{\circ} \mathrm{F}$ process heat VHTR designs incorporate steam generators. General Atomic Company states that the "general features of the steam generator for the $1600^{\circ} \mathrm{F}$ plant are basically similar to those of the steam generators of the ...HRGR."l This implies the use of 2-1/4 Cr-1 Mo steel in the economizer-evaporator section and Alloy $800 \mathrm{H}$ in the superheater. The GE steam generator has an inlet helium temperature just under $1200^{\circ} \mathrm{F}$ and a design similar to that in the GA HTGR. Alloy 800 and $2-1 / 4 \mathrm{Cr}-1$ Mo are suggested as the major materials in their reference plant steam generator design; design uprates would be effected by use of higher temperature materials such as Inconel 625, Inconel 617, Hastelloy $\mathrm{X}$, and Hastelloy S. Although the materials selected for the reference design are probably satisfactory, the applicability of the materials for the uprated design has not been demonstrated.

\subsubsection{Reheat steam generator}

The GE VHTR reference design employs a reheat steam generator in the intermediate helium loop between the PHX and the intermediate loop circulator. Maximum helium and steam temperatures of 1100 and $1000^{\circ} \mathrm{F}$, respectively, are expected. As with the steam generator, Alloy 800 and 2-1/4 $\mathrm{Cr}-1$ Mo steel are suggested as the major materials. The use of these alloys should be satisfactory.

\subsubsection{Hot valves}

General Electric suggests that candidate alloys for hot valves operating at $1500^{\circ} \mathrm{F}$ in helium should include Alloy 800, Inconel 617, Inconel 625, Inconel $X$, and Hastelloy $X$. Faces and seats would be plasma sprayed with materials such as CrC. Valves for use at higher temperatures may present formidable problems. 


\section{2 .2 .8 Seals}

Many seals, operating at a variety of temperatures, will be required to control leakage of helium (e.g., in connections between heat exchangers and hot ducts). General Electric designs for $1800^{\circ} \mathrm{F}$ operation would use Inconel $617 ; 1600^{\circ} \mathrm{F}$ designs would employ Hastelloy $\mathrm{X}$. The compatibility of these materials with the primary coolant environment at these temperatures is questionable at this time.

\subsubsection{Gas turbine}

The WANL VHTR reference design includes gas turbines for electric power generation as opposed to the steam generators of the GE and GA designs. The turbine inlet temperature is nominally $1850^{\circ} \mathrm{F}$, precluding the use of currently available nickel-base blading alloys, unless a very high degree of blade cooling (probably $>300^{\circ} \mathrm{F}$ ) is employed. Westinghouse suggests that it may be more feasible to consider materials such as SU-31 [a niobium (columbium)-base alloy], molybdenum-base alloys such as TZM, and ceramic materials (e.g., $\mathrm{Si}_{3} \mathrm{~N}_{4}$ and $\mathrm{SiC}$ ). With respect to the above, it is agreed that nickel-base alloys will not be satisfactory. (The temperature $1500^{\circ} \mathrm{F}$ should be considered a practical upper limit at present.) Further, niobium (columbium)-base materials will probably be incompatible with the helium environment. Use of molybdenum-base alloys or ceramics for immediate design would be premature at the present.

\subsubsection{Reformer process heat exchanger (PHX)}

The GA VHTR assessment concentrates on steam-methane reforming as the standard or reference process heat system. They conclude that a process heat temperature of $1600^{\circ} \mathrm{F}$ (helium temperature of $1800^{\circ} \mathrm{F}$ ) requires the development of a ceramic PHX. Lower temperature systems, however, could consider the use of alloys such as HK-40, Hastelloy X, Alloy 800, and MA 753 .

It can be seen from the preceding paragraphs that, in general, alloys are available for construction of VHTR reference system components that will operate at temperatures below $\sim 1500^{\circ} \mathrm{F}$ (e.g., steam generators and circulators). However, materials for components such as ducting, hot valves, and heat exchangers, which will be required to operate at temperatures up to $1800^{\circ} \mathrm{F}$, are not currently state of the art. Alloys with potential for these applications are discussed in the next section.

\subsubsection{Advanced materials}

This section will discuss briefly the potential for the use of various metallic materlals at temperatures in excess of $1500^{\circ} \mathrm{F}$ in the process heat VHTR. It is recognized that ceramics and fiber-strengthened compacts are also candidates for these applications but that their development to commerctal use is perhaps somewhat further in the future. 
It is possible that modifications to existing nickel-base alloys (e.g., Inconel 617) or the development of new nickel-base alloys may extend the range of their use for the VHTR system to temperatures approaching $1800^{\circ} \mathrm{F}$. A restriction on the development of such alloys may be the elimination (or minimization) of alloying elements that could cause radioactive contamination problems (e.g., cobalt and tantalum). Additionally, some alloying elements that oxidize selectively in GCR helium (e.g., titanium and aluminum) may also require minimization. Efforts directed at alloying element substitutions or at new alloy developments will likely benefit from the strengthening potential of elements such as molybdenum, tungsten, and niobium (columbium). Improvements in the properties of cast nickelbase components (e.g., cast nickel-base alloy turbine blades) may be possible by control of grain size and microporosity. This might be effected by improved casting techniques and subsequent processing treatments such as hot isostatic pressing.

A new class of solid-solution-strengthened nickel alloys that could be promising are the long-range-ordered alloys based on the $A_{3} B$ structure. These alloys offer good potential for high-temperature creep resistance, contain no precipitated phases or segregation that might aggravate selective gas-metal reactions, and do not overage or decarburize.

Oxide-dispersion-strengthened (ODS) nickel alloys offer the potential for use at temperatures in excess of $1800^{\circ} \mathrm{F}$. These alloys (e.g., TDNi and MA-753) receive their strengthening from careful control of oxide thoria and yttria respectively - particle size, and interparticle spacing. Anisotropy of properties could be a problem with these materials as well as questions related to environmental compatibility.

Molybdenum-base alloys may be very good choices for use at temperatures in the 1700 to $2200^{\circ} \mathrm{F}$ range. However, considerable development will be required for these materials. The only current commercial alloy, TZM, is a carbide-strengthened material ( $50 \%$ titanium, $8 \%$ zirconium, $3 \%$ carbon, and balance molybdenum) which could suffer some degeneration through selective oxidation of titanium and zirconium. However, preliminary testing of TZM in a simulated GCR environment in Europe has shown exce1lent compatibility. Development of satisfactory solid-solution-strengthened molybdenum alloys is also a possibility worth investigating. Finally, the properties and behavior of molybdenum are very sensitive to structure, and studies of the effects of processing history will be required.

In instances where the service temperature of VHTR candidate alloys is limited by environmental compatibility problems, it may be possible to consider protection by the application of coatings. However, to be effective, these coatings must not only be impervious but also must not degrade the substrate alloy under service conditions. Potential problems with this method of increasing temperature capabilities are lack of long-term reliability and proven methods of assuring high quality of the coatings. 


\subsubsection{Research and development needs}

In earlier discussions on the status of technology of alloys for application to VHTR systems, some general materials requirements for nuclear service were mentioned, and factors that may influence materials performance (e.g., gas-metal reactives) were indicated. This section attempts to outline in very brief form the scope of programs that should be required to screen, select, and qualify alloys for service in the components of the VHTR process heat system.

\subsubsection{Recommended R\&D program}

\subsection{Screening}

The first step in the R\&D program should be the screening of candidate alloys for the $1600^{\circ} \mathrm{F}$ VHTR process heat plant $\left(1800^{\circ} \mathrm{F}\right.$ reactor exit temperature). The first phase of screening can be accomplished by the compilation and examination of available mechanical property data. (Some of this obviously has been done in connection with preparation of the WANL, GE, and GA VHTR proposals.) Such data - in addition to conventional information on tensile properties, fracture toughness, etc. - may include environmental compatibility and creep information from the Dragon Project, other European programs, and Japan.

In addition to "literature" screening, tests should be conducted to evaluate the compatibility of the candidate materials with the anticipated VHTR helium environment. Specimens should be tested in at least three environments (i.e., helium with two levels of impurities and air) at no less than two temperatures appropriate to their anticipated service. It would be desirable to conduct this phase of screening under stress (e.g., as in the high-capacity, low-sensitivity creep rings operated by the Dragon Project). Facilities for these tests do not currently exist in this country. The compatibility of PHX alloys in the process gases must also be evaluated.

\subsection{Materials selection}

At least two candidate alloys for each intended application should be selected for further evaluation. However, as indicated earlier, it may not be possible to find commercial alloys for components that are to operate at temperatures in the 1500 to $1800^{\circ} \mathrm{F}$ range. In fact, it may be necessary to go directly to advanced-alloy development programs to obtain suitable candidates for these uses. Where candidate materials are currently available, or when they are made available, evaluations should include the test types and areas listed below.

1. Creep-rupture tests should be made on all alloys that will operate at temperatures exceeding $700^{\circ} \mathrm{F}$. Two temperatures 
spanning the expected service range should be employed. Tests should be run in helium environment ${ }^{a}$ and in air.

2. High-sensitivity, long-time creep experiments should be performed with temperatures and environments as above.

3. Fracture toughness measurements on alloys should be made. The tests can be performed in air on both unaged materials and materials aged in the helium environment.

4. Tensile properties and their notch sensitivity for all alloys should be determined. Tests should be run in air on aged and unaged materials.

5. Static and cyclic flaw growth measurements should be made on alloys for fixed and moving parts respectively. Tests should be run in air and helium at two temperatures.

6. High-cycle fatigue on alloys, where appropriate to their use, should be determined.

7. Low-cycle fatigue in air and helium on all alloys for application at $1000^{\circ} \mathrm{F}$ and higher should be determined.

8. Compatibility (i.e., gas-metal reaction) information can be obtained as a by-product of many of the tests listed above.

9. Tests to evaluate the compatibility of fission products with materials should be conducted where appropriate.

10. Fretting and wear should be evaluated for alloys of components where such are important.

11. Welding characteristics and properties of weldments must be considered where appropriate.

12. Physical property measurements (e.g., thermal conductivity) will be necessary for some materials.

Environmental facilities will be required for most of the test areas listed above. In every instance, facilities for these tests are either inadequate or do not exist.

\subsection{Materials qualification}

The testing described above should provide an adequate basis for the selection of alloys and possibly alternates for construction of many of

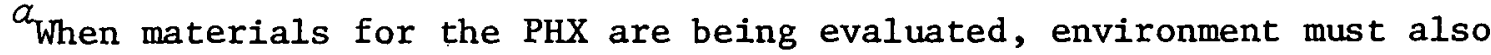
include process gases. This applies for all evaluations. 
the components of the VHTR. However, there is some doubt that alloys suitable for $1800^{\circ} \mathrm{F}$ application will be tound in this first round of testing on commercial materials. As mentioned earlier in this report, materials for nuclear service are required to conform fully with the rigid codes and standards of the ASME Code and, in addition, will be closely scrutinized by the Nuclear Regulatory Commission (NRC) Licensing body. Qualification of materials for nuclear service will be a substantial task. For example, to qualify materials for Class 1 nuclear components at elevated temperatures will require the determination and specification of time-independent allowable stresses (based on minimum yield and ultimate tensile strengths), time-dependent allowable stresses (based on various creep properties), fatigue properties, isochronous stress-strain curves, elastic moduli, and various physical properties. These same data, however, are needed for component design.

Most of the experimental effort in materials qualification will be centered about high-sensitivity creep, low-cycle fatigue, and creepfatigue interactions. Facilities developed for conduct of "materials selection" programs should be adequate for these experiments. It should be anticipated also that some continuation of work in all of the test areas described in the previous section will be required.

\subsection{Gas-metal reaction studies}

During the course of the screening, selection, and qualification programs, there will be a good deal of information obtained relative to gas-metal reactions and their effects. However, other studies aimed more directly at understanding the effects of gaseous impurities on materials behavior are desirable. Both GCR helium and process gas environments must be considered. Such studies would address the effect of (1) gaseous impurity species; (2) impurity levels and ratios; (3) time, temperature, and stress level and type; (4) gas flow conditions and pressure; and (5) alloy base, alloying additions, and tramp elements.

Information obtained in such a study would be highly beneficial in providing the knowledge and confidence needed for extrapolation of mechanical property data to long times and to environments of different impurity levels.

\subsection{Advanced alloys}

The development of alloys for use at temperatures above $1500^{\circ} \mathrm{F}$ (Sect. 2.2 .3 ) in the VHTR system will require all of the steps discussed above in addition to the development itself. Fabrication and materials processing considerations will also entail considerable efforts. 


\subsection{Program costs}

Detailed estimates of the cost to complete the programs described above have not been made. However, it is likely that such programs would require no less than 6 to 8 years at an annual rate of $\$ 2,000,000$. Equipment costs will add at least another $\$ 1,500,000$ for a total program cost of approximately $\$ 1,400,000$ to $\$ 1,800,000$.

\subsubsection{WANL R\&D program}

The R\&D program proposed by WANL to bring the VHTR to first large-scale demonstration includes a number of tasks devoted to materials. Tasks on the high-temperature properties of turbine blade and PHX alloys are proposed, as well as more general studies on mechanical properties in simulated GCR helium, development of superalloys and refractory metals, and fabrication. However, neither the costs nor the tasks themselves are given in sufficient detail to allow critique of the experimental programs on materials.

\subsubsection{General Electric R\&D program}

The materials R\&D program described by GE includes (1) properties of commercial alloys, (2) environmental behavior, (3) coating/cladding studies, (4) insulation systems, (5) Code approvals, (6) component certification, (7) advanced materials development, and (8) advanced materials scale-up.

All but the final task are to be completed by the end of FY 1980 (assuming a start in FY 1975) at a total cost of just over $\$ 8,300,000$. Costs to develop materials for use in the 1500 to $1800^{\circ} \mathrm{F}$ range (tasks 1 through 6 listed above) would be completed in this time period for slightly less than $\$ 7,000,000$. The description of R\&D subtasks provided by GE would seem to indicate that almost all essential areas of materials research in connection with the VHTR are addressed. However, their program with the exception of tasks 7 and 8 on advanced materials - is entirely concerned with temperatures between 1500 to $1800^{\circ} \mathrm{F}$. Considerable mechanical properties, environmental and Code qualification work will also be required for alloys operating at temperatures $<1500^{\circ} \mathrm{F}$. Additionally, two environmental considerations (i.e., the possible effects of fission products and process gases on materials properties and behavior) are not mentioned in the GE program.

\subsubsection{General Atomic R\&D program}

The GA program of R\&D on alloys for VHTR reformer plants is presented as a seven-year effort at a total cost of less than $\$ 1,400,000$. Code qualification efforts are judged as requiring another $\$ 3,000,000$. The total of $\$ 4,400,000$ seems low in terms of estimated costs for the 
"recommended" and GE programs. However, it is extremely difficult to make direct comparisons because of differences in emphasis and level of effort included within each proposal. The temperature range of interest in the GA proposal is 1400 to $2200^{\circ} \mathrm{F}$, with major interest between 1600 and $2000^{\circ} \mathrm{F}$. This, of course, omits possible important consideration of materials behavior at lower temperatures. It is assumed that the proposal also covers only commercial alloys since no mention is made of advanced materials development. Finally, the detailed testing tasks presented seem to cover quite well the necessary considerations of environmental effects and mechanical properties.

\subsubsection{Structural design technology for high-temperature applications}

Structural design technology embraces four main ingredients. These include (1) information on material responses to applied loads, (2) mathematical descriptions of materials behavior or constitutive equations, (3) structural analysis methods and associated computer programs, and (4) design rules and criteria.

Design rules and criteria are contained in the ASME Boiler and Pressure Vesse1 Code, for example. The ASME code is designed mainly to guard against failure; functional limits are imposed by the system or component designer or owner. The remaining ingredients can be considered as essential to providing information and methods for use in determining compliance with functional limits and failure criteria. Each ingredient must be addressed in establishing suitable design technology for VHTR processing components and systems.

\subsubsection{Design criteria and mechanical properties data}

As stated under the section on materials (Sect. 2.2), Code Case 1592 extends the coverage of Section III of the ASME Boiler and Pressure Vessel Code to the use of materials in the creep range. Stress limits and revised design rules are provided for this range. Four alloys types 304 and 316 stainless steels, 2-1/4 Cr-1 Mo steel, and Incoloy $800 \mathrm{H}$ - are currently approved for use. Allowable stress intensities are given for temperatures to $1500^{\circ} \mathrm{F}$ for the stainless steels, $1400^{\circ} \mathrm{F}$ for Incology $800 \mathrm{H}$, and $1200^{\circ} \mathrm{F}$ for $2-1 / 4 \mathrm{Cr}-1$ Mo steel.

Since proposed VHTR processing systems will have temperatures that may range from 1600 to $2200^{\circ} \mathrm{F}$, modification and extension of the design rules and criteria of the ASME code will be required in addition to qualification of new materials and extension of the applicable temperature ranges. As presently formulated, the Code is addressed to systems that operate at homologous temperatures of around 0.5 or less. For higher homologous temperatures, the rules and criteria must be reexamined and reworked as necessary. 
Present rules also apply only to relatively ductile alloys. Hence the introduction of refractory metals will require changes in philosophy and treatment. Additionally, the use of ceramics as structural materials will require restructuring of the design philosophy and extensive design rule and criteria development. However, experience and existing knowledge concerning the use of graphite as a structural material will provide valuable guidance in addressing ceramics and other relatively brittle materials.

Since high temperatures can increase the importance of environmental effects, these must be given added emphasis in the consideration of mechanical properties and design criteria. The need for investigating influences of reactor system environments was discussed in the materials section. The process system portions of combined nuclear and process systems must be given special attention because of potentially more hostile environments and expected operating time spans, which are long in comparison to current process system and component lifetimes.

Code approval or qualification of a material requires the acquisition of substantial amounts of data. In addition, mathematical modeling of materials behavior for structural analysis purposes requires a significant experimental data base beyond that needed for Code approval or qualification. This will be discussed subsequently.

To make use of present criteria, inelastic structural analyses are required. The extents and details of these analyses are determined through the use of simplified analysis methods and screening rules: These methods and rules contribute heavily to the tractability of design assessments and to reducing the amount of effort needed as well as lessening the overall costs for examinations of structural adequacy under inelastic behavior conditions. Therefore, the extension of existing and the development of new simplified analysis methods and screening rules will be an important part of the overactivity of extending design rules.

\subsubsection{Structural analysis tools}

Detailed inelastic analysis capability depends on adequate mathematical modeling of material behavior under applied load, deformation, temperature, and other environmental conditions, and on the availability of appropriate structural analysis methods and computer programs. Computer programs. for treating inelastic behavior responses of complex geometries, subjected to time-varying load and temperature conditions, are currently available and in use. The programs are predominantly based on finite element methods of analysis, with some programs being based on finite difference methods. Such programs have been used extensively in the design of Liquid Metal Fast Breeder Reactor (LMFBR) and High-Temperature Gas-Cooled Reactor (HTGR) systems and components. 
Since current inelastic analysis procedures are relatively difficult and expensive to use, additional work is needed to improve computational capability and efficiency. The goal would be to make significant advances in the development and technically-sound, user-oriented, efficient programs to handle static and dynamic analyses under inelastic material behavior conditions, as well as to handle structural instability (buckling). The programs, in all cases, must be structured to accommodate changes in mathematical descriptions of material behavior with only minor modifications. To be complete, these programs should include structural evaluation packages to provide design assessments on the basis of criteria appropriate to the application.

Key ingredients for any structural analysis package are proper mathematical descriptions of material responses to applied loading and temperature histories. The material responses to be described include both deformation and failure behaviors. Inelastic deformations of metals and alloys are presently treated by separating the total deformation into time-independent (elastic-plastic) and time-dependent (creep) components. In the subcreep temperature range, elastic-plastic behavior is dominant, with time-dependent deformation effects being essentially negligible in the main. As the operating temperatures are increased, time-dependent behavior must be taken into account and the so-called creep effects included in the descriptions. At high temperatures (homologous temperatures above 0.5 ) the characteristics of the deformations essentially preclude the separation into time-independent and time-dependent components and the task of treating the behavior becomes much more difficult. Thus design for process temperatures around $1400^{\circ} \mathrm{F}$ will require significant constitutive equation development along with attendant in-depth studies of material behaviors. Above $1400^{\circ} \mathrm{F}$, major theory and constitutive equation development work will be required.

The use of refractories and ceramics is expected to entail philosophy and treatment substantially different than those employed for ductile metals and alloys. Major factors contributing to differences of treatment are high strengths and low ductilities exhibited by refractories and ceramics.

Deformation and failure are closely linked. Therefore, failure descriptions will make use of developments in the constitutive equation area. Creep rupture, crack growth, brittle and ductile fracture, and timedependent and time-independent fatigue are to be addressed. Time-dependent fatigue is associated with combinations of cyclic loading and creep effects, commonly called "creep-fatigue" behavior. Important to failure considerations is the amount of usable operating life expended during a sequence of loading and temperature events, that is, the "damage" incurred. Associated with this is identification of means for determining damage through calculation and ways for combining damage measures for realistic predictions of subsequent responses. Both aspects must be addressed.

The constitutive equations and failure descriptions can be expected to introduce needs for mechanical properties data in addition to those now commonly obtained for structural materials and those needed to qualify 
a material in accordance with the ASME Code. These data will be necessary in order to make use of the mathematical models derived; the details will depend upon the mathematical developments.

Certification of the structural analysis methods and computer programs derived will be required. Each computer code is to be verified to assure that the programming is correct and that the code performs as prescribed. The computer codes must then be qualfied by comparing calculated results with experimental data for structures or with results from computations using other programs that have been certified. During this phase, the constitutive equations and the structural analyses techniques and methods are to be examined. In a broad sense, qualification is a part of an iterative process. The qualification studies are to cover a sufficiently wide variety of conditions and geometries to allow examination of major features of a given program.

Structural tests, which have either been completed or are in process, will supply a large part of the information necessary to examine primary features of structural analysis tools. Computed results are also available for comparison. Therefore, additional structural tests to be performed are expected to be addressed to extending the data base to cover materials to be used in VHTR processing systems and to derive data at temperatures corresponding to actual operating temperatures.

\subsubsection{Summary of design technology needs}

To summarize, there are needs for work in each of the four areas listed at the outset. This work can be outlined in task form as follows:

Task 1. Materials behavior studies. Deformation and failure behaviors of materials are to be addressed in support of constitutive equation and failure-prediction method development.

Task 2. Mathematical analogs for describing materials behavior. In this case, constitutive equations and failure descriptions must be modified and extended in some cases and newly derived in others to cover both the materials to be used and the temperatures of interest.

Task 3. Structural analysis methods. Structural analysis methods and computer programs are available for treating high-temperature inelastic behaviors. Appropriate materials behavior descriptions must be incorporated and the computer programs refined to achieve efficiency in computation and ease of use and also modified to include processing capabilities for making design evaluations in accordance with applicable criteria.

Certification of the computer programs, including the materials behavior descriptions developed, is required. This is necessary to ensure that the constitutive equations properly model the responses and that the program, as a whole, gives results with acceptable accuracy. Structural tests will be necessary to provide data for the certification examinations. 
Task 4. Design criteria. Design rules and criteria have been discussed at some length. These rules and criteria must be extended to cover the ductile metals and alloys to be used in VHTR processing systems; the temperature range addressed in present design codes must be increased. Environmental effects must be brought into the criteria in a more prominent and definitive way.

The use of refractories and ceramics as structural materials will require modification of current design philosophy and changes in or replacements for rules and criteria. A significant body of information exists on the use of low ductility materials, and extensive use is to be made of this information.

Under this task, simplified design methods and screening rules are to be developed. These are necessary to make design evaluations tractable and to reduce the number of detailed inelastic analyses to be carried out. The development of these methods and rules requires certified inelastic analysis capabilities and detailed knowledge of behaviors of engineering components in particular situations.

\subsubsection{Estimated costs}

Cost projections for design technology development commensurate with VHTR processing system needs (process temperatures of 1400 to $1500^{\circ} \mathrm{F}$ ) are given below.

Cost projection for design technology development

\begin{tabular}{cc} 
Task & $\begin{array}{c}\text { Projected costs } \\
\text { (thousands of dollars) }\end{array}$ \\
\hline $\begin{array}{c}\text { Materials behavior studies } \\
\text { Mathematical analogs for describing } \\
\text { materials behavior } \\
\begin{array}{c}\text { Structural analysis methods } \\
\text { Design criteria }\end{array}\end{array}$ & 4,300 \\
Total & 6,800 \\
\hline
\end{tabular}

\subsection{Materials (Ceramic)}

For the higher temperature range considered for the VHTR $\left(>1800^{\circ} \mathrm{F}\right.$ core outlet temperature), ceramic materials may be of interest. The materials development cost at this very high temperature range is likely to be substantially higher than the 1500 to $1800^{\circ} \mathrm{F}$ temperature range where the application of metallic alloys appears possible. 
There are two basic classes of application for ceramics which can be envisioned. First, are those applications involving the thermal insulation and wear-resistant characteristics of these materials. Second, are applications in "control components," involving structural or loadbearing characteristics such as tubes, ducts, etc.

Materials selected for evaluation as wear-resistant (plasma-sprayed $\left.\mathrm{Al}_{2} \mathrm{O}_{3}, \mathrm{ZrO}_{2}, \mathrm{CrC}\right)$ and galling- and sticking-resistant $\left(\mathrm{Al}_{2} \mathrm{O}_{3}, \mathrm{Cr}_{2} \mathrm{O}_{3}\right.$, $\mathrm{SiC}-\mathrm{Cr}_{2} \mathrm{O}_{3}$ cermets) materials are excellent choices as a starting point because many of their properties are known. However, long-term testing under load in a simulated process environment is required. The same holds true for insulating materials, such as $\mathrm{SiO}_{2}$-bearing materials, which may suffer in reducing environments due to loss of Sio.

Many types of insulating ceramics should be tested, including fibers, blocks, or coatings of $\mathrm{ZrO}_{2}$. There is some concern over the $\mathrm{SiO}_{2}$ or $\mathrm{SiO}_{2}$-containing materials since impurities in the helium may well cause the volatilization of $\mathrm{SiO}$ and its subsequent transport to other parts of the reactor. Yet $\mathrm{SiO}_{2}$ appears to be a material of primary interest in at least one of the studies. A circulating helium test loop, simulating the expected gaseous environment, should be used to screen candidate materials and to determine the effects of such environments on $\mathrm{SiO}_{2}-$ bearing insulation. This testing should include other materials as well, such as $\mathrm{ZrO}_{2}, \mathrm{MgO}$, and mullite. With the construction of such a loop, materials could be evaluated rapidly.

Many nonmetallic materials possessing outstanding thermal stability and resistance to harsh gaseous environments can be utilized in designs that minimize the tensile loads the components must bear. For example, Ford Motor Company, Westinghouse, and others are actively pursuing R\&D on compounds such as $\mathrm{SiC}$ and $\mathrm{Si}_{3} \mathrm{~N}_{4}$ for high-temperature $\left(2500^{\circ} \mathrm{F}\right.$ ) gas-turbine applications. Results presented at meetings in 1974 indicate that al1ceramic turbines of this type can be built with materials technology existing at present.

The reformer tubes and associated components are required to withstand not only the hot helium reactor coolant, for which application $\mathrm{SiC}$ and $\mathrm{Si}_{3} \mathrm{~N}_{4}$ appear excellent choices, but also the $\mathrm{H}_{2} \mathrm{O}$ and $\mathrm{CH}_{4}$ feed gases. Metallic alloys may be expected to be oxidized and/or carburized at operating temperatures above 1600 to $1800^{\circ} \mathrm{F}$, whereas $\mathrm{SiC}$ and $\mathrm{Si}_{3} \mathrm{~N}_{4}$ would not be significantly affected.

A program to develop these ceramics for this use requires satisfactory resolution of at least three major problems:

1. First, are the materials compatible with the hot-gas environment? It is anticipated that $\mathrm{SiC}, \mathrm{Si}_{3} \mathrm{~N}_{4}$, and the newer class of $\mathrm{Si}-\mathrm{Al}-\mathrm{O}-\mathrm{N}$ (SIALON) ceramics would be compatible. This judgment is based on experimental results reported in 1974 by Westinghouse, Ford, and others involved in the development of a high-temperature $\left(2500^{\circ} \mathrm{F}\right)$ all-ceramic gas turbine. 
2. Second, can these ceramics be fabricated into the required shapes? Fabrication of a 40-ft long single-piece tube would certainly require much further development of techniques now available, such as extrusion, reaction-sintering, and then perhaps chemical vapor deposition coating. (The task is formidable but not insurmountable).

3. Finally, can they be effectively joined to the metal components to provide a leak-tight fit? In this area a large developmental effort is required.

In summary, the proposals are not quite complete in regard to potentia1 application of ceramics as insulating materials. Many more materials should be evaluated than are suggested by these proposals. The application of ceramics in the area of "critical components" may be necessary in the higher-temperature range. The major questions are found in (1) the selection of compatible materials, (2) the ability to fabricate shapes, and (3) the ability to fabricate joints between ceramic and metallic components. Application of ceramic materials in this area would undoubtedly involve a long and expensive development program, the extent of which has not been defined.

\subsection{Fission Product Behavior Aspects}

Fission products enter the coolant circuit of an operating HTGR by one of three general mechanisms. The most direct of these mechanisms concerns volatile fission products that are born in surface contamination; these species enter the coolant circuit with virtually no attenuation. A second mechanism involves the release of fission products from coated fuel particles in which the effectiveness of the protective coatings has in some manner been compromised. Such a loss in coated-particle integrity may result in the fabrication process or to the combined influence of thermal and mechanical stresses on otherwise sound coatings or on coatings that have been weakened as a result of irradiation or chemical effects. The third mechanism for release involves transport through phyeically intact particle coatings. Obviously not all three generalized mechanisms are significant, in a practical sense, for all fission products of interest. For example, transport of krypton or xenon through intact coatings can be safely ignored as an influence on coolant circuit inventories of these fission products, yet it is precisely this mechanism that can dominate control of cesium inventories.

In a similar vein, the significance of the release of a particular fission product need not directly involve radiological considerations. For cxample, the stable fission product, barium nuclides, can appreciably influence effects of steam ingresses. Similarly, fission-product tellurium offers the potential for attack on metallic components, regardless of radiological factors. Additionally, rare earth fission products are known to attack SiC coatings of TRISO fuel particles and thus become significant in terms of providing a mechanism for fuel failure. 
Fission products enter the coolant circuit as volatile species and as species attached to otherwise inert debris. The relative magnitudes of these two types of distribution are, in general, unknown and probably vary widely from reactor system to reactor system. It is also significant to note that species attached to mobile debris provide a mechanism for dispersal of normally very stable chemical forms (which may possess high radiological toxicity). The manner by which the fission products enter the coolant circuit will likewise determine their distribution in, and their removal from, the circuit; this can be a major concern relative to maintenance.

Transport of fission products along the release pathway into the coolant circuit, and in large measure the distribution along the coolant circuit, is primarily a temperature-dependent process. Fuel failure mechanisms, on the other hand, exhibit a complex interrelationship between temperature, temperature gradient, irradiation history, chemical composition, and possibly, time.

The diverse manner in which the GA, GE, and WANL concepts have been presented makes system intercomparisons from the standpoint of fission product behavior a difficult task. Moreover, data pertinent to the intercomparisons are not always presented, and one is frequently required to accept statements at face value. Thus, although the primary coolant core exit temperature for a $1600^{\circ} \mathrm{F}$ process heat loop is calculated to be $1800^{\circ} \mathrm{F}$ for the GA design, $1742^{\circ} \mathrm{F}$ for the $\mathrm{GE}$ design, and $1850^{\circ} \mathrm{F}$ for the WANL design, such a clear indication of average (or maximum) fuel temperatures and thermal gradients from fuel to coolant are not, in general, presented; these factors significantly affect fission product release and transport. It is fairly evident from the proposals that the largest fuel-to-coolant temperature drops are encountered in the GA design, the next largest are probably those of the GE design, and the smallest those for the Westinghouse design. However, the order for fuel-to-coolant temperature drops is different from that of the coolant exit temperature, and it is not possible on the basis of the data presented to determine the extent to which the two factors compensate one another.

A second deficiency that is evident in all three proposals is a lack of concern for a fission-product surveillance program; this should be a major consideration in the design of a demonstration plant. In addition, it is noteworthy to indicate that gross failure of BISO particles can be readily detected by the attendant increases in fission gas inventory in the coolant. However, gross failure of SiC coatings in TRISO particles (which appears possible due to attack by rare earths), without corresponding failures of the pyrocarbon coatings, do not appear to be capable of detection unless (1) devices to monitor the resulting cesium releases that are installed in the coolant circuit, and (2) cesium plateout behavior is sufficiently well understood that one can position the cesium monitoring devices properly. Likewise, this aspect appears to have gone unappreciated in all three proposals as well. 
Some of the advantages and disadvantages for the designs as presented (generally that for the reference $1600^{\circ} \mathrm{F}$ ) and comments on some of the claims in the supporting discussions are given in the following sections.

\subsubsection{The General Atomic Company concept}

The General Atomic Company proposal extends current HTGR designs to include, for example, catalytic reformers (in pods in the PCRV) for the steam-methane process for hydrogen. Gas from a core of essentially current design emerges at $1800^{\circ} \mathrm{F}$, produces process temperatures of $1600^{\circ} \mathrm{F}$, and then passes into a steam generator of current design. The most advanced fuels of current design are necessary because maximum fuel temperatures of $2562^{\circ} \mathrm{F}\left(1406^{\circ} \mathrm{C}\right)$ are anticipated. The fissile TRISO fuel particles contain highly enriched uranium, such as $\mathrm{UC}_{2}$, which is formed from resin; the fertile material is $\mathrm{ThO}_{2}$ with a TRISO coating. The reformer is constructed of a super alloy or possibly SiC.

Some advantages of this design are:

1. The current technological base should permit development of designs up to $1600^{\circ} \mathrm{F}$ process temperature with the lowest cost and time.

2. The inventory of enriched uranium is minimized.

3. The design should permit a relatively dust-free primary coolant circuit.

4. Fuel rods are contained within graphite blocks; thus fuel particle release is essentially prevented.

5. Fission products leaving particles must permeate graphite before reaching the primary circuit, and graphite is an effective sink for metallic fission products.

Some possible disadvantages of the GA design include:

1. Maximum fuel temperatures and the temperature gradient in the fuel are higher than for other designs and may result in loss of integrity of some particles.

2. It is necessary to shut down to reload fuel.

3. Without axial fuel shuffling, the high burnup particles have relatively high-temperature gradients at high temperature, favoring particle breakage by various mechanisius.

4. Inclusion of the reformer in the PCRV provides an additional potential pathway for fission-product release. For example, fission products from the primary gas could enter the process material in the reformer. 
5. Servicing or replacing the reformer is a hot operation involving the primary circuit.

6. Permeation of hydrogen and tritium through reformer materials will put tritium in the product, and will increase the hydrogen removal service required of the primary system purification plant.

7. Operation at moderator temperatures over $300 \mathrm{~F}^{\circ}$ greater than in a conventional HTGR will result in a need for better detection of moisture inleakage, as from steam generators.

The extent and causes of failure of TRISO particles under design conditions are not clear. Migration values ${ }^{15}$ (presumably amoeba effect) may indicate that in certain regions the silicon carbide layer is reached in a few months. Rare earth fission products may then attack the SiC. In such cases, metallic elements such as cesium and strontium could permeate the pyrocarbon layer and escape from the particle. Because the pyrocarbon layer would retain noble gases and halogens, the easy detection of these elements in the gas would not be available to indicate loss of particle integrity. Other prompt means for detecting the occurrence of such internal failure of particles is needed.

The treatment of tritium generation, release, and permeation is insufficient or incorrect in several respects. Appreciable tritium is formed from boron that is used in fuel elements as a burnable poison and from boron in control rod material. Tritium is not well retained by boron carbide at temperatures higher than about $700^{\circ} \mathrm{C}$. The extent of retention of tritium from the ${ }^{6} \mathrm{Li}(n, \alpha) \mathrm{T}$ reaction in graphite is uncertain at design temperatures, and some fission-product tritium may permeate the coatings of TRISO particles and enter the coolant.

The permeation of hydrogen isotopes through metals has been shown by Strehlow and Savage 16 to follow the square-root law down to low partial pressures, rather than exhibiting linear behavior as stated. Control of tritium permeation is consequently more difficult, and metal oxidation does not guarantee permeation resistance. The presence of $\mathrm{l}_{\mathrm{H}_{2}}$ may be beneficial.

The effect of fuel temperatures appreciably greater than those for the commercial HTGR is offset essentially only by TRISO coating on the fertile particles and by shorter operating life. "As temperatures increase, the amount of metallic fission products released to the circuit increases rapidly."l The only sinks for these substances are plateout on system surfaces and the relatively insignificant removal in the purification plant. Thus, different primary circuit temperatures and materials will not alter the amount of plateout but only its location and possibly its ease of release. Thus, if a fixed fraction is assumed for liftoff or desorption of plateout, then surface release becomes proportional to the amount released from particles; this may vary significantly with temperature. 
The first major surface after the core is the reformer. This may well be in need of maintenance. Substantial plateout on the reformer would make maintenance more difficult.

\subsubsection{The General Electric Company concept}

The General Electric concept is based on the German AVR pebble-bed reactor, which has been operating with core outlet temperatures of $950^{\circ} \mathrm{C}$ $\left(1742^{\circ} \mathrm{F}\right)$. The core of a $3000 \mathrm{MW}(t)$ reactor will contain about $3 \times 10^{6}$ spherical fuel elements, consisting of TRISO coated particles with $\mathrm{UO}_{2}$ or $\mathrm{ThO}_{2}$ kernels in a $5-\mathrm{cm}$ center covered with $1 / 2-\mathrm{cm}$ graphite. The reference design uses only low-enriched uranium oxide fuel. During operation about 2400 balls per day are added one-by-one to the top of the core and are removed from the bottom of the core, resulting in a slow downward shuffling of the fuel. The favored design transfers heat to an IHX within the PCRV, and the gas then passes into a steam generator. The secondary helium coolant transfers heat from the IHX to a steammethane reformer outside the PCRV. High-temperature ducting and valving are provided.

Some advantages of the GE pebble-bed process heat reactor are:

1. The viability of operating with core outlet temperatures of $950^{\circ} \mathrm{C}$ $\left(1742^{\circ} \mathrm{F}\right)$, which is adequate to produce process temperatures of $1600^{\circ} \mathrm{F}$.

2. On-line refueling - no shutdown.

3. Downward fuel movement results in the separation of regions with the highest thermal gradient (top) from the regions with highest temperature and burnup. This reduces loss of particle integrity due to amoeba effect.

4. The use of an intermediate heat transfer circuit largely prevents transfer of fission products (including tritium) to the product or hydrogen from the reformer to the primary circuit. (It ie being assumed that the intermediate circuit has a purification system.)

5. Maximum fuel temperatures can be diminished by use of "she11" fuel in which a 3-cm-diam graphite sphere forms the center of the fuel, which is covered by a $1-\mathrm{cm}$ layer of matrix containing coated fuel particles (the layer being covered by $1 / 2-\mathrm{cm}$ of graphite). Higher gas temperatures appear possible for a particular maximum fuel temperature.

6. Blocking of fuel coolant channels in the core is not possible.

7. Incremental fuel loading permits minimum use of control rods. 
8. Servicing and maintenance of an external reformer should be comparable to a nonnuclear system and possibly could be done without reactor or electrical generation system shutdown.

9. The design appears applicable to the use of thorium or ${ }^{238} \mathrm{U}$ as the fertile material, with on-line changes in fuel being possible.

Some disadvantages of the pebble-bed reactor as presented by GE include:

1. Greater pressure drops per unit length occur across the fuel bed, resulting in a "pancaked" core shape.

2. Greater fuel loading is required.

3. Motion of fuel throughout operation increases the possibility of dust and also debris from broken fuel elements entering the coolant circuit. This could collect fission products, complicating generator maintenance and adding to liftoff hazard in a design basis decompression accident (DBDA). Furthermore, such debris could clog some coolant paths and cause hot spots.

4. The reference design burnup is only $13.4 \%$ fissions per initial metal atom using low-enriched uranium fuel.

The change to TRISO coated particles at $1600^{\circ} \mathrm{F}$ process temperature is needed and implied but ambiguous in the process description. We assume it will be done.

The quality of fuel required for this design, as fraction of particles initially faulted and as uranium contamination outside, is quite high. Little treatment of any interaction of fission products with primary circuit materials is presented. However, it is known that iodine may react with materials and may transport iron or other elements. Barium and iron can catalyze the steam graphite reaction. Cesium, silver, and strontium can diffuse into alloys. Tellurium can localize at grain boundaries and weaken some nickel-based alloys.

The use of $\mathrm{BF}_{3}$ for core shutdown could be ineffective if appreciable steam were present in the coolant at the time.

Unless a purification system is included as part of the intermediate heat transfer loop, the passage of tritium from the primary system to the product will be inhibited only by the added metal thickness. The dependence on hydrogen and tritium permeation on the square root of pressure (while removal depends directly on partial pressure) will, in any event, require consideration of transport.

The rare earth fission product attack on SiC coatings remains possible if amoeba or other effects permit the kernel to reach this coating. The gas-transfer mechanism cited for the amoeba effect may not be the dominant process. 
A good means of detecting the development of defective SiC coatings does not appear to be available.

The performance of the system appears to depend on the steady movement of all fuel, with the possibility of two or more radial fuel zones. No definition is available on the axial and radial trajectories of fuel or on the possibility that some elements move significantly less than others. Uneven heating and unpredicted fission-product release become possible.

\subsubsection{The Westinghouse Astronuclear Laboratory concept}

In the Westinghouse concept coolant gas passes upward through fuel tubes embedded in graphite blocks in a manner similar to the NERVA (and UHTREX) reactors. The fuel consists of $\mathrm{UO}_{2}$ and $\mathrm{ThO}_{2}$ kernels with TRISO coating, which are embedded in a graphite-resin matrix. Heat is transferred to an intermediate coolant system that circulates to a PHX outside the PCIV. The primary coolant drives a gas turbine to produce electrical power.

This proposal contains considerably less technical detail than the others, so that even the recognition of certain problems can only be conjectured, and no explicit solution is stated.

Some advantages of the WANL concept are:

1. Direct contact of coolant with the fuel matrix gives lowest fuel particle temperature for a given gas or process temperature.

2. The intermediate heat transfer loop reduces cross contamination between nuclear and chemical plants.

3. The process heat exchanger can be maintained without plant shutdown.

4. Axial fuel shuffling during reloading is planned. This should assist in separation of maximum temperature and burnup fuel from the region of highest power density. Particle failure rates are thus benefited.

5. Separate fissile and fertile fuel elements can be used.

Disadvantages of the WANL concept include:

1. Graphite permeation resistance will not serve to inhibit release of metallic fission products to the primary coolant. The amount of plateout will thus be relatively higher and will offer a higher hazard potential in accidents and for maintenance operations.

2. The matrix will lack the protection of a graphite layer with respect to attack by coolant impurities. The release of particles to high velocity gas could result in serious erosion, localized in undefined areac. 
3. Any sensitivity of the fuel matrix to erosion or corrosion will result in a "dusty" system. Appreciable dust will serve to fix and transport fission products, inhibit primary system maintenance, and increase the hazards associated with a DBDA.

4. Thermal- and irradiation-induced dimensional changes in fuel elements will almost certainly cause. some release of fuel particles to the primary circuit.

5. Any entry of fuel particles into the circulating coolant will distribute all species of fission products into the circuit.

6. BISO-coated fertile particles are used. The fission rate in the particles is increased with burnup when $233 \mathrm{U}$ is produced. Increasing fission rate increases temperature in fertile particles; BISO coatings do not retain barium, strontium, or cesium fission products at temperatures above $1100^{\circ} \mathrm{C}$. However, BISO coatings can be designed and qualified to survive exposure.

7. The directly driven gas turbine will doubtless accumulate plateout and be difficult to maintain directly.

Although the conversion ratio is doubtless highest in the ${ }^{23} \mathrm{U}$ cycle, the possibility of approaching a conversion ratio of 1.0 , much less values in excess of 1.1 (ref. 17), is doubted.

The low cited values of $R / B\left(10^{-6}\right.$ to $\left.2.5 \times 10^{-5}\right)$ for the UHTREX uncoated fuel 18 were not attributed to a specific nuclide or service. As noted earlier, release depends on temperature, age, nuclide, coating, coating faults, external impurity fraction, and other factors. A fuel element bore lining, though helpful, may not be sufficient for the required time and condition of service. The performance of high quality TRISO coatings for both fissile and fertile kernels may be sufficient to maintain the needed fission-product retention characterlstics. A more detailed analysis is needed of the release characteristics and the tolerable release rates with respect to product quality, environmental effects, accident hazard potential, and maintenance of the turbine, and other system components.

The possibility of fission-product (tellurium, cesium, etc.) interaction with turbine materials was not explored.

\section{4 .4 Summary}

All designs anticipate using TRISO-coated fissile kernels and expect or consider the use of TRISO coating of fertile particles (WANL considers BISO). In order to minimize amoeba effects, an effort is made to keep the maximum fuel temperature as low as possible and to minimize the thermal gradient in the fueled region by improving matrix conductivity. These two objectives are met best by the WANL and GE designs. The 
temperature advantage gained in the WANL design by the lack of a graphite sheath over the fueled matrix may be more than offset by loss of the protective qualities of the graphite with respect to fission product release and by attack of the matrix material by exposure to the coolant for an extended period or with abnormal impurities.

The relatively flat shape of the GE core design is more than compensated by the useful effects of the downward passage of fuel, both with respect to separation of high-temperature and high-thermal gradient regions and with respect to the advantages of on-line fueling. However, the low conversion and high inventory of this design are disadvantages.

The use of an intermediate heat transfer loop appears desirable in order to separate fission products from process streams. A purification plant must be assumed for this system. The gas turbine proposed by WANL may encounter significant maintenance problems due to fission product contamination.

The safety analysis of the DBDA by GA assumes sure operation of the auxiliary cooling system, whereas that given by GE does not; they are not directly comparable. No direct analysis was presented by WANL. The fission-product effects, if the auxiliary coolant system is effective, will depend on the amounts of fission products that have been released to the primary coolant system and their location and temperature. In this respect, the GE design may, with equivalent initial fuel quality, be somewhat better than the GA design and appreciably better than the Westinghouse design. Carbonaceous dust is probably greater in the WANL system and least in the General Atomic system.

The evaluation of the respective designs, all of which have merit, depends on the weight, given various advantages, and will include factors not discussed here.

\subsection{Steam Ingress Considerations}

Steam ingress into the primary coolant circuit of an HTGR must be viewed in terms of two time frames. Effects of sudden large in-leakages are generally of a short-term nature. These include possible interactions with exposed fuel, fission products, and coolant circuit surfaces, which could increase gas-borne fission product inventory; reactions with graphite moderator and structural materials, which could result in the generation of explosive concentrations of hydrogen and carbon monoxide and/or result in the loss of structural integrity; and reactions with neutron poisons, such as boron carbide or trifluoride, which could negate the intended shutdown functions of systems using these poisons.

Effects of small, continuous in-leakages, on the other hand, must be regarded over a time period that spans the life of the reactor. Two areas of primary concern in this regard have been identified. One involves the gradual, uniform erosion of structural graphite which can 
result in the sudden collapse of a stressed member, whereas the second concerns the weakening of metallic members through carburization involving reaction product $\mathrm{CO}$ and the consequent large steam ingresses in those cases in which the carburized members isolate the primary coolant from steam.

The steam-graphite reaction is endothermic, hence removal of the source of heat is a most effective technique to limit effects of large steam ingresses. Air oxidation of graphite, on the other hand, is exothermic; as a result, this type of oxidation mechanism is more difficult to control. With respect to the HTGR system, however, air ingress is much less likely than steam in-leakage, and for those cases in which air ingress is possible (all of which involve primary coolant system depressurization), the effects are predominantly determined by the rate of air in-leakage rather than reaction kinetics.

Steam ingress accidents have not been treated in sufficient enough detail in the studies that a fair assessment or comparison of the three systems can be made. Nor is it possible to ascertain which, if any, structural members are susceptible to steam attack. For long-range considerations, it is necessary to establish maximum acceptable continuous steam in-leakage (and duration) and to identify those factors or components that determine this limitation. For considerations of shortterm, massive steam ingresses, it is necessary to establish the maximum possible rate of ingress, the rate at which core cooldown can reasonably be expected to proceed, the rate of steam-graphite reaction, the temperature distribution in the core and core components, and the factors that determine the maximum permissible time interval over which core cooling can be interrupted in the event of massive steam ingress.

\subsubsection{The Westinghouse proposal concept}

Steam ingress in the proposed WANL design is limited to in-leakage from the auxiliary cooling system heat exchanger tubes and possibly also to in-leakage from water bearings on primary coolant circulators and system turbogenerators.

The WANL design eliminates the possibility of steam ingress due to rupture of a steam generator tube and to the corresponding introduction of rather sizeable steam inventories into the coolant circuit. On the other hand, the fuel element design makes no provision for protection of the fuel particles from steam corrosion, and such corrosion can lead to sizeable liftoff of fuel particles and their introduction into the coolant circuit, and from there to the turbogenerator and circulator blades. Moreover, apparently no means are provided for sensing moisture in the primary coolant circuit.

Effects of steam ingresses into the primary coolant of a WANL design HTGR would be most severe of the three designs proposed in terms of 
fuel attack and $\mathrm{H}_{2}$ and $\mathrm{CO}$ production. However, steam inventories available for ingress and the likelihood of steam in-leakages are extremely small for this design.

The WANL design would result in the greatest damage to fuel in the event of air ingress.

\subsubsection{The General Electric proposal concept}

Steam ingress into the primary coolant of the GE design can result from gross failure of helium coolant circulators (leakage from water bearings), from rupture of heat exchanger tubes in the auxiliary cooling system, and from leakage of steam generator tubes.

Effects of steam ingress events in the case of the GE design are probably similar in severity to those that would be encountered in the GA design. However, the GE design may result in a somewhat dustier environment than the GA design, and this could impair the performance of moisture monitors, particularly those which involve light reflection measurements.

It is not clear whether or not structural members are susceptible to steam inleakage or whether or not important structural components can be examined after a massive steam ingress event has occurred. The use of $\mathrm{BF}_{3}$ as a last resort method of reactor shutdown may be ineffective in the case in which shutdown is required as a result of steam ingress.

Shutdown procedures in the event of moisture detection require further classification. For example, since all of the coolant loops are common to the reactor core, it is reasonable to assume that when the moisture monitors on one loop indicate high steam conditions, the monitors on the remaining loops will shortly indicate the same condition. Will this cause all of the loops to be isolated from the core? What would be the sequence of events in the case of an undetected rupture of a heat exchanger tube in the auxiliary cooling system? What effect does massive stcam inleakage have on the primary coolant cleanup system?

Air ingress into the primary coolant system would result in essentially equivalent damage in this design and the GA design, and significantly less damage than would be experienced in the WANL design. This, like steam ingresses of corresponding magnitude, is due primarily to the protection afforded the fuel particles by the graphite materials in which they arc encased.

\subsubsection{The General Atomic Company proposal concept}

As with the GE design, the General Atomic design is subject to steam ingress from water-bearing seal failure, from rupture of heat exchanger tubes in the auxiliary cooling system, and from steam generator inleakage. 
The GA and GE designs are sufficiently similar so that comments made previously in regard to the GE design apply to the GA design, with two exceptions. General Atomic proposes to use boron carbide as a neutron poison; this species is far more stable than the trifluoride in a steam atmosphere. However, the oxide form, $\mathrm{B}_{2} \mathrm{O}_{3}$, is known to react readily with steam at elevated temperatures to yield volatile BOOH.

A second difference between the GA and GE designs concerns the pressure drop across a given fuel element. In the GE design the pressure drop across a given fuel sphere is negligible; a net flow of helium coolant through the sphere can be safely forgotten. In a prismatic fuel element, on the other hand, a small but significant pressure drop exists across all of the coolant channels, and this pressure drop causes the coolant to flow through the channels. This pressure drop gives rise to a corresponding (but smaller) pressure drop in the fuel-filled channels surrounding the coolant passages. As a result, a "transverse" flow of helium into the fuel-filled channels from the coolant passages occurs at the high-pressure end of the fuel element, and a reverse flow (i.e., from the fuel channels to the coolant channels) occurs at the low pressure end. This mechanism allows more steam to enter the fuel channels at the high-pressure end than would occur under strictly constant pressure conditions, and thus permits some localization of corrosion and a lessening of the protection afforded to the fuel by the graphite web in which the particles are encased. Whether or not this would indeed lead to greater or lesser corrosion, when compared with the pebble-bed concept, depends strongly on (1) the temperature distributions along the core and into the fuel elements and (2) the resistances of the graphites involved to gas transport.

\section{5 .4 Summary}

If the WANL design incorporated a steam generator rather than a turbogenerator, it would clearly be an inferior design from the standpoint of minimizing effects of massive steam in-leakage. On the other hand, if the pressures on the water side of the exchanger in the auxiliary cooling system were significantly less than the primary coolant pressure (as with the other two designs), then the WANL version would be clearly superior in terms of minimizing effects of continuous steam in-leakage.

Differences in the effects of steam in-leakage in the GA and GE designs rest primarily on the different temperature characteristics of the two cores; extensive calculations would be required for comparisons on this basis. Such a comparison is further complicated by the existence of a transverse flow mechanism that can be significant in the GA design but not in the GE design. This mechanism may or may not lead to significantly greater corrosion, but this is dependent upon temperature distribution. 
The use of boron trifluoride as a neutron poison in the GE design requires considerable attention because there is reason to believe that the poison could not perform its intended function in a steam atmosphere. Also, it is reasonable to expect the pebble-bed concept to result in a dustier environment than that employing GA-design prismatic fuel elements; this factor may complicate or restrict the selection of moisture monitoring devices. 
THIS PAGE

\section{WAS INTENTIONALLY \\ LEFT BLANK}




\section{FUEL CYCLE COST ANALYSIS}

\subsection{Introduction}

The fuel cycle costs for the various VHTR concepts were compared using a consistent calculational method. These concepts are described in detail in the vendors reports.1,2,3 Some basic information concerning the fuel cycles other than those shown here were presented by the vendors; the ones shown in Table 12 are the only ones for which costs were presented, and therefore are the only ones for which we are making our comparative evaluation.

Table 12. Fuel cycle information

\begin{tabular}{llll}
\hline \multicolumn{1}{c}{ Item } & GA & \multicolumn{1}{c}{ GE } & WANL \\
\hline Feed enrichment, $\%$ & 93 & $8.3-11.9$ & 93 \\
Fertile material & Th & $238 \mathrm{U}$ & Th \\
Recycle & No & No & Yes \\
Refueling period & Annual & Continuous & Annual \\
\hline
\end{tabular}

First, the fuel cycle costs for the various systems were evaluated using the same ground rules that were provided to the vendors. Therefore results from this analysis can be compared directly with results presented by the vendors.

However, for the purposes of our evaluation it appears that some revision of the ground rules is appropriate. Recently there has been significant increases in both the spot and future delivery price of uranium ore. Also estimates of future fuel enrichment costs have increased significantly.

Consequently, the fuel cycle costs for the various systems were evaluated using other estimates for the price of $\mathrm{U}_{3} \mathrm{O}_{8}$ and fuel enrichment than were given in the original ground rules for the studies. These values are given in Table 13.

The value for $\mathrm{U}_{3} \mathrm{O}_{8}$ used in the original ground rules was close to the spot at the time the ground rules were written. There has been a rapid rise in the $\mathrm{U}_{3} \mathrm{O}_{8}$ market price in the ensuing period. Current prices for $\mathrm{U}_{3} \mathrm{O}_{8}$ delivery in the early to mid 1980 s are in the range of $\$ 30-40 / 1 \mathrm{~b}$. These prices are in constant (1975) dollars and are subject to escalation clauses. The current prices are well above current production costs as 
Table 13. Comparison of original and revised ground rules

\begin{tabular}{ccc}
\hline & \multicolumn{2}{c}{ Fissile material value } \\
\cline { 2 - 3 } Item & $\begin{array}{c}\text { Original ground } \\
\text { rules }\end{array}$ & $\begin{array}{c}\text { Revised ground } \\
\text { rules }\end{array}$ \\
\hline $\mathrm{U}_{3} 0_{8}, \$ / 1 \mathrm{~b}$ & 10.0 & 30.0 \\
Enrichment, \$/SWU & 40.0 & 75.0 \\
$233 \mathrm{U}, \$ / \mathrm{g}$ & 17.0 & 38.0 \\
$239-24 \mathrm{Pu}, \$ / \mathrm{g}$ & 6.90 & 27.0 \\
\hline
\end{tabular}

estimated by the ERDA and may include a large provision for future mine and mill development cost as well as exploration expenses. As with any commodity there will be up-and-down fluctuations. The projected expansion of reactors, however, will continue to tax the mining industry for many years to come. The $\$ 30 / 1 b$ for $\mathrm{U}_{3} \mathrm{O}_{8}$ price was chosen as a current reasonably expected uranium price (1975 dollars), once the current supply and demand imbalance levels out. This price is the top ERDA category for estimating U.S. uranium reserves. There appears to be ample reserves available at this cost and we do not expect the price to rise above this level in the intermediate term if ore use proceeds as projected.

The separative work price used in the original ground rules is close to the current value, If the reactor business is to expand, more enrichment capacity than now exists will be needed. Uranium Enrichment Associates has estimated the cost from a privately owned diffusion plant of $\$ 73 /$ SWU (1974 dollars). Other estimates give expected prices of about $\$ 60$ to 80 per separative work unit. The price of $\$ 75$, chosen in the revised cost schedule, therefore, should be thought of as an expected price of enrichment from a privately owned diffusion plant. The successful development of the centrifuge method of enrichment or even laser enrichment could reduce enrichment costs whereas increased electric power costs will raise the price of separative work.

The value for bred fissile material depends on its substitutability in reactors for enriched uranium. Its value is keyed to the value of enriched uranium. In both sets of ground rules, the worth of ${ }^{23} 3 \mathrm{U}$ to enriched uranium is assumed to be at a ratio of 7:6. The original ground rules for fissile plutonium used GE's value of $\$ 6.90$. The revised ground rules evaluate the value of fissile plutonium to the value of enriched uranium at a ratio of 5:6. These ratios have been used in previous ORNL studies. 
Both WANL and GA use a highly enriched uranium feed with thorium as the fertile material. Westinghouse recycles a portion of the bred ${ }^{2} 3{ }^{3} \mathrm{U}$, whereas GA does not recycle in its selected fuel cycles. General Electric uses a low enrichment uranium feed. The fissile plutonium that is bred from the fertile ${ }^{233} \mathrm{U}$ is not recycled. This design features a pebble-bed concept with continuous refueling. The WANL and GA concepts use annual refueling where the fuel is located in large graphite blocks. Both GE and WANL have one design for all process heat temperatures. General Atomic Company considers two fuel cycles, depending on whether the process heat temperature is above or below $1600^{\circ} \mathrm{F}$.

\subsection{Evaluation Methods}

The basic approach used in calculating the fuel cycle cost is similar to that described in the Guide for Economic Evaluation of Nuclear Reactor Plant Design. 19 Average or levelized fuel-cycle costs over the reactor system lifetime are calculated based on present value discounting techniques. The basic ground rule in these calculations is that the income received over the reactor lifetime from the sale of power must be just adequate enough to pay back all capital expended in the fuel cycle, as well as to pay the necessary income taxes and give the specified return on outstanding debt and equity capital.

Direct cash expenditures and incomes are calculated for each accounting period (quarterly) in which fuel cycle expenses or incomes occur. Expenses are charged at the beginning of the period in which they occur. Income from the sale of power and other credits are taken at the end of the period in which it is produced. For income tax purposes, the cost of fresh fuel (ore cost, conversion, enrichment, fabrication, preirradiation shipping) less its salvage value is assumed to be deductible on a pro rata basis with power production. Other expenses (postirradiation shipping, reprocessing, debit for recycled fuel) and incomes (credit for bred fue1) are taken when they occur. Debt and equity are assumed to remain in constant proportion throughout the life of the project.

The fuel cycle cost is made up of two general classes of cost - the direct cost and the indirect charges associated with each item of cost. The direct cost (or credit) of each fuel-cycle cost component is obtained by summing up all costs and credits associated with this item during the reactor history and dividing this by the total energy sold with no discounting, or

$$
D_{m}=\frac{\sum_{n} Z_{m, n}}{\sum_{n} E_{n}},
$$

where

$$
D_{m}=\text { direct cost of item } m \text {, }
$$




$$
\begin{aligned}
Z_{m, n} & =\text { total costs and credits for item } m \text { during period } n, \text { and } \\
E_{n} & =\text { energy produced during period } n .
\end{aligned}
$$

The indirect charges consist of return on outstanding investment, interest payments, taxes, etc., associated with each item of cost. To calculate the indirect charge, we first determine the discounted present value of the direct costs over the reactor lifetime and divide this by the discounted amount of energy delivered, or

$$
T_{m}=\frac{\sum_{n}(1+X)^{-n} z_{m, n}}{\sum_{n}(1+X)^{-n} E_{n}},
$$

where

$$
\begin{aligned}
X & =\text { effective discount factor for each period, and } \\
T_{m} & =\text { total levelized cost of item } m \text {. }
\end{aligned}
$$

For fuel cycle cost components that are credited or expensed for tax purposes at the time the income is received or expense paid (i.e., bred material transactions or reprocessing costs), the indirect cost is simply

$$
I_{m}=T_{m}-D_{m}
$$

For those fuel-cycle cost items that are treated in a pro rata fashion, the indirect charge is this difference multiplied by

$$
\frac{1.0}{(1-t)(1-s)}
$$

or

$$
I_{m}=\left(T_{m}-D_{m}\right) \cdot \frac{1.0}{(1-t)(1-s)},
$$

where

$$
\begin{aligned}
t & =\text { Federal income tax rate, } \\
s & =\text { state income tax rate, and } \\
I_{m} & =\text { indirect cost. }
\end{aligned}
$$


The total fuel cycle cost $\left(C_{f c}\right)$ is the sum of the direct and indirect charges for all fuel cycle items.

$$
C_{f c}=\sum_{m}\left(D_{m}+I_{m}\right)
$$

The discount factor to be used with this procedure is given by

$$
X=(1-b) i_{e}+(1-t)(1-s) \cdot b \cdot i_{b},
$$

where

$$
\begin{aligned}
& b=\text { fraction of capital investment from debt, } \\
& i_{e}=\text { return on equity, and } \\
& i_{b}=\text { interest rate on debt. }
\end{aligned}
$$

This method of analysis gives the same results as the discounted cash flow rate of return (DCFRR) approach for

$$
\operatorname{DCFRR}=(1-b) i_{e}+b i_{b}
$$

In this method the sum of the discounted cash flows, including taxes and all incomes but excluding return on capital, must be zero or

$$
\sum_{n}(1+\mathrm{DCFRR})^{-n} \cdot\left(S_{n}-T_{n}-\sum_{m} Z_{m, n}\right)=0 \text {, }
$$

where

$$
\begin{aligned}
& S_{n}=\text { income from power sales during period } n \text {, and } \\
& T_{n}=\text { taxes paid during period } n
\end{aligned}
$$

\section{3 Mass Balances}

In order to calculate the fuel-cycle costs using the method described above - cycle by cycle - charge-discharge mass balances are needed over the reactor life. Such detailed information was obtained from the vendor only in the case of the WANL design. For the other systems, other sources of information and degrees of approximation had to be used in order to obtain the necessary data in the proper form. 
In the case of the GA designs, although ORNL has received detailed mass balances from GA in the past, the fuel cycles considered here were not included in these. The lifetime fuel cycle for their low-temperature case, however, has been calculated at Oak Ridge. 20 The equilibrium portion of this calculation agrees well with the results presented in the GA report. The Oak Ridge mass balances were used, therefore, in the fuel-cycle cost calculations.

The 30-year lifetime mass balances for the GA high-temperature process heat fuel cycle design were pieced together using various information. The initial core loading was taken from information furnished previously by GA for a fuel cycle similar in equilibrium carbon-to-thorium ratio and power density to that of the reference design. The fuel lifetime in this case was four years instead of three years for the high-temperature reference design, so that other than the initial core loading, the mass balances could not be used directly. The approach to equilibrium in the two cases, however, should be similar. In the equilibrium portion of the fuel cycle, the mass balance used was that presented in the GA report. The approach to equilibrium was based on a modification of the similar four-year fuel lifetime design as was the final mass discharge at the end of life.

General Electric furnished information on the equilibrium mass balance and the equilibrium core fuel composition. In our calculations the initial core was assumed to have the same composition and loading configuration as the final or equilibrium core. The reactor was assumed to be on an equilibrium cycle from first startup until final shutdown.

The GE reactor uses continuous charge and discharge of fuel. In order to fit the quarterly accounting period selected in the comparative evaluation, all material fed to the core during an accounting period was assumed fed at the beginning of the accounting period. All material discharged was assumed to be discharged at the end of the period.

\subsection{Economic Assumptions}

The assumptions used in calculating the fuel-cycle costs, including the original $\mathrm{U}_{3} \mathrm{O}_{8}$ and enrichment costs, are shown in Table 14. The revised ground rules are shown in Table 13. Although each vendor selected a fuel-fabrication unit cost for each of their fuel types, we have chosen one price $(\$ 275 / \mathrm{kg})$ in making the comparison. The effect on the fuelcycle cost results of variations in the unit fabrication price is given in Sect. 3.6. The reference value for fissile plutonium is that used by $\mathrm{GE}$ in its analysis. The discharged thorium and plutonium in the $\mathrm{Th}-{ }^{233} \mathrm{U}$ fuel cycle was assumed valueless.

Two reference sets of economic ground rules were used. These are for a capitalization assumed typical for a utility and for an industrial operation. 
Table 14. Fuel cycle cost assumptions (original ground rules)

\section{Costs and credits}

$\mathrm{U}_{3} \mathrm{O}_{8}$ ore, $\$ / 1 \mathrm{~b}$

10.00

$\mathrm{UF}_{6}$ conversion, $\$ / 1 \mathrm{~b}-\mathrm{U}_{3} \mathrm{O}_{8}$

1.00

Enrichment, \$/SWU

40.00

Fue1 fabrication, $\$ / \mathrm{kg}$

275.00

Fabricated fuel shipping, \$/kg

25.00

Fue1 recovery, $\$ / \mathrm{kg}$

120.00

Shipping to recovery plant, $\$ / \mathrm{kg}$

50.00

$233 \mathrm{U}$ value, $\$ / \mathrm{g}$

17.00

Fissile plutonium value, $\$ / g$

6.90

Thorium, $\$ / \mathrm{kg}-\mathrm{ThO}_{2}$

9.00

$$
\text { Losses, \% }
$$

Preirradiation

0.5

Postirradiation

1.0

Recycled fuel

1.0

Lead and lag times, years

Ore procurement lead

0.75

Conversion lead

0.75

Enrichment lead

0.50

Fabrication lead

0.25

Reprocessing lag

0.50

Fissile recovery lag

0.75

Recycle fuel net lag

1.00

Economic ground rules

$\frac{\text { Financing }}{\text { Utility }}$

Return on equity capital, \%

10

15

Cost of borrowed money, \%

10

10

Fraction of capital from debt

0.55

0.30

Federal income tax rate, \%

48

48

State Income tax rate, \%

3 
Table 14 (continued)

General information

Reactor power, MW(t)

3000

Plant capacity factor, \%

80

Enrichment plant tails assay, \%

0.2

Accounting period

Quarterly

Reactor life, years

30

\subsection{Fue1-Cycle Cost}

The estimated fuel-cycle costs based on original ground rules are given in Table 15. The item called "fuel" includes the uranium ore purchase, its conversion into $\mathrm{UF}_{6}$, and the purchase of thorium (if any). "Fabrication" also includes the preirradiation shipping cost. "Recovery" includes the postirradiation shipping cost as well as the reprocessing and waste disposal.

The three high-temperature $\left(>1600^{\circ} \mathrm{F}\right)$ process heat designs have similar direct costs. The differences in the fuel-cycle costs arise mainly from the indirect charges. Table 16 gives some mass balance information as used in the comparison study. The net resource consumption does not differ appreciably for the various system designs. This is consistent with their similar direct costs. The indirect cost is a function of the time displacement between when money is paid for an item and when money is received for the produced power. A higher loading of fissilc material will result in a higher money payment and therefore a higher indirect charge. Similarly, continuous fueling will result in a shorter averagetime displacement between outlays and income and thus will reduce the indirect charge compared with another system that is fueled annually.

The GE system has the smaller indirect charge since it is both continuously fueled and since it needs a lower charge of fissile material. The lower fissile loading is also an effect of the continuous fueling since less control-rod poisoning is required here than in the cases where the reactor is fueled annually.

For the annually fueled, prismatic fuel cases (GA and WANL), the WANL design has higher fissile loadings than the GA designs. The reason for this can be partially explained by the zonal fuel loading in the WANL design for power flattening purposes. It is also possible that the WANL design is not fully optimized. The net effect is that the WANL system has higher indirect costs than either the GA systems or the GE system. 
Table 15. Fuel costs ( $/$ MBtu)

(original ground rules)

\begin{tabular}{|c|c|c|c|c|c|c|}
\hline \multirow[b]{2}{*}{ Costs } & \multicolumn{4}{|c|}{$\mathrm{GA}$} & GE & WANL \\
\hline & Low & temperature & High & temperature & All temperatures & All temperatures \\
\hline \multicolumn{7}{|l|}{ D1rect costs } \\
\hline Fue1 & & 5.3 & & 5.5 & 5.1 & 5.2 \\
\hline Enrichment & & 9.4 & & 10.0 & 8.2 & 9.4 \\
\hline Fabrication & & 4.3 & & 6.3 & 4.1 & 4.4 \\
\hline Recovery & & 2.4 & & 3.6 & 2.3 & 2.5 \\
\hline Bred fuel credit & & -5.6 & & -6.9 & -0.8 & -2.5 \\
\hline Total & & 15.8 & & 18.5 & 18.9 & 19.0 \\
\hline \multicolumn{7}{|l|}{ Indirect costs } \\
\hline \multicolumn{7}{|l|}{ Utility financing } \\
\hline Fuel & & 2.4 & & 2.9 & 2.0 & 4.1 \\
\hline Enrichment & & 3.7 & & 4.6 & 2.1 & 6.9 \\
\hline Fabrication & & 1.7 & & 1.5 & 1.6 & 1.7 \\
\hline Bred fuel & & 0.8 & & 1.0 & 0.3 & 0.6 \\
\hline Recovery & & -0.3 & & -0.5 & -0.3 & -0.3 \\
\hline Tota1 & & 8.3 & & 9.5 & 5.7 & 13.0 \\
\hline \multicolumn{7}{|l|}{ Industrial financing } \\
\hline Fue1 & & 4.0 & & 4.7 & 3.3 & 7.2 \\
\hline Enrichment & & 6.3 & & 6.5 & 3.4 & 11.7 \\
\hline Fabrication & & 3.0 & & 2.6 & 2.8 & 3.0 \\
\hline Bred fuel & & 1.1 & & 1.5 & 0.4 & 0.7 \\
\hline Recovery & & -0.4 & & -0.7 & -0.3 & -0.4 \\
\hline Total & & 14.0 & & 14.6 & 9.6 & 22.2 \\
\hline \multicolumn{7}{|l|}{ Zotal costs } \\
\hline Utility financing & & 24.1 & & 28.0 & 24.6 & 32.0 \\
\hline Industrial financing & & 29.8 & & 33.1 & 28.5 & 41.2 \\
\hline
\end{tabular}


Table 16. Fuel-cycle mass balance information

\begin{tabular}{|c|c|c|c|c|}
\hline \multirow[b]{2}{*}{ Item } & \multicolumn{2}{|c|}{ GA } & \multirow[b]{2}{*}{$\mathrm{GE}$} & \multirow[b]{2}{*}{ WANL } \\
\hline & $<1600^{\circ} \mathrm{F}$ & $>1600^{\circ} \mathrm{F}$ & & \\
\hline \multicolumn{5}{|l|}{ Lifetime resource consumption } \\
\hline Net $\mathrm{U}_{3} \mathrm{O}_{8}$, tons & 5031 & 5315 & 4952 & 4992 \\
\hline Net separative work, $10^{3} \mathrm{SWU}$ & 5060 & 5356 & 4425 & 5033 \\
\hline Net fissile material produced, $\mathrm{kg}$ & 7093 & 8765 & 2436 & 3091 \\
\hline \multicolumn{5}{|l|}{ Fissile material loadings } \\
\hline Initial core, $\mathrm{kg}$ & 1768 & 1564 & 1267 & 3228 \\
\hline Equilibrium charge, $\mathrm{kg} /$ year & 726 & 959 & 782 & 990 \\
\hline Equilibrium discharge, $\mathrm{kg} /$ year & 302 & 578 & 219 & 449 \\
\hline
\end{tabular}

Estimated fuel cycle costs based on the revised ground rules are shown in Table 17. The comments above relative to cost differences also apply to the costs with revised ground rules.

\subsection{Sensitivity Studies .}

The sensitivity of the fuel cycle cost results to the various economic assumptions for the three high-process heat temperature $\left(>1600^{\circ} \mathrm{F}\right)$ designs was investigated. The original ground rules were used to derive reference values for the sensitivity studies. The unit costs considered were ore, enrichment, fabrication, reprocessing, and bred fuel value. The effect of various tails assays on the resulting costs was also calculated. These calculations were made assuming the industrial financing ground rules. The fuel-cycle cost results, assuming that the fuel cycle working capital is derived entirely from borrowed money at various interest rates, are also included here.

In these sensitivity calculations all parameters, other than the one being varied, are assumed to be at their reference values. In reality there is some interdependence between the various unit costs. The value of the bred fuel will have a relation to the value of enriched uranium, and ideally, the enrichment plant tails assay will be close to the optimum based on the cost of $\mathrm{UF}_{6}$ and the separative work charge.

The results are shown in Figs. 4 through 10 . The fuel-cycle cost is, of course, most sensitive to variations in those components making up the greater part of the overall cost. The fuel-cycle cost, therefore, 
Table 17. Fuel cycle costs, c/MBtu (revised ground rules)

\begin{tabular}{|c|c|c|c|c|c|}
\hline \multirow[b]{3}{*}{ Item } & \multicolumn{2}{|c|}{ GA } & \multirow{2}{*}{\multicolumn{2}{|c|}{$\mathrm{GE}$}} & \multirow{2}{*}{ WANL } \\
\hline & \multirow{2}{*}{$\begin{array}{c}<1600^{\circ} \mathrm{F} \text { process } \\
\text { temperature }\end{array}$} & \multirow{2}{*}{$\begin{array}{c}>1600^{\circ} \mathrm{F} \text { process } \\
\text { temperature }\end{array}$} & & & \\
\hline & & & (a11 & temperatures) & (a11 temperatures) \\
\hline \multicolumn{6}{|c|}{ Direct costs } \\
\hline Fuel & 14.6 & 15.5 & & 14.3 & 14.5 \\
\hline Enrichment & 17.6 & 18.7 & & 15.4 & 17.5 \\
\hline Fabrication & 4.3 & 6.3 & & 4.1 & 4.4 \\
\hline Recovery & 2.4 & 3.6 & & 2.3 & 2.5 \\
\hline Bred fuel & -12.5 & -15.5 & & -3.1 & -5.5 \\
\hline Total & 26.4 & 28.6 & & 33.0 & 33.4 \\
\hline \multicolumn{6}{|c|}{ Indirect costs } \\
\hline Utility finance & 16.8 & 19.9 & & 11.8 & 27.2 \\
\hline Industrial finance & 28.1 & 32.3 & & 19.8 & 46.1 \\
\hline \multicolumn{6}{|c|}{ Total fuel-cycle costs } \\
\hline Utility finance & 43.2 & 48.5 & & 44.8 & 60.6 \\
\hline Industrial finance & 54.5 & 60.9 & . & 52.8 & 79.5 \\
\hline
\end{tabular}




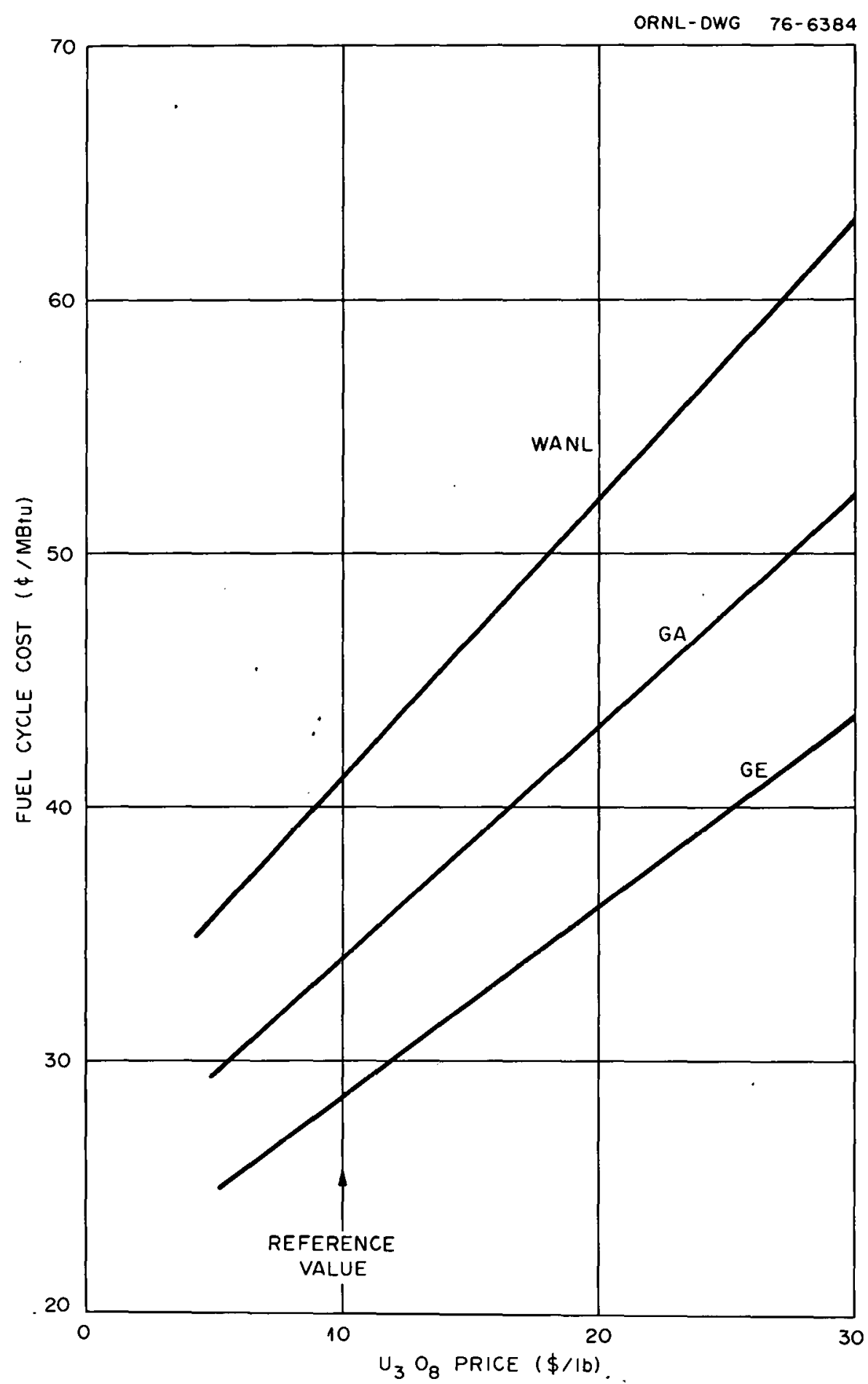

Fig. 4. Fuel cycle cost as a function of uranium ore price. 


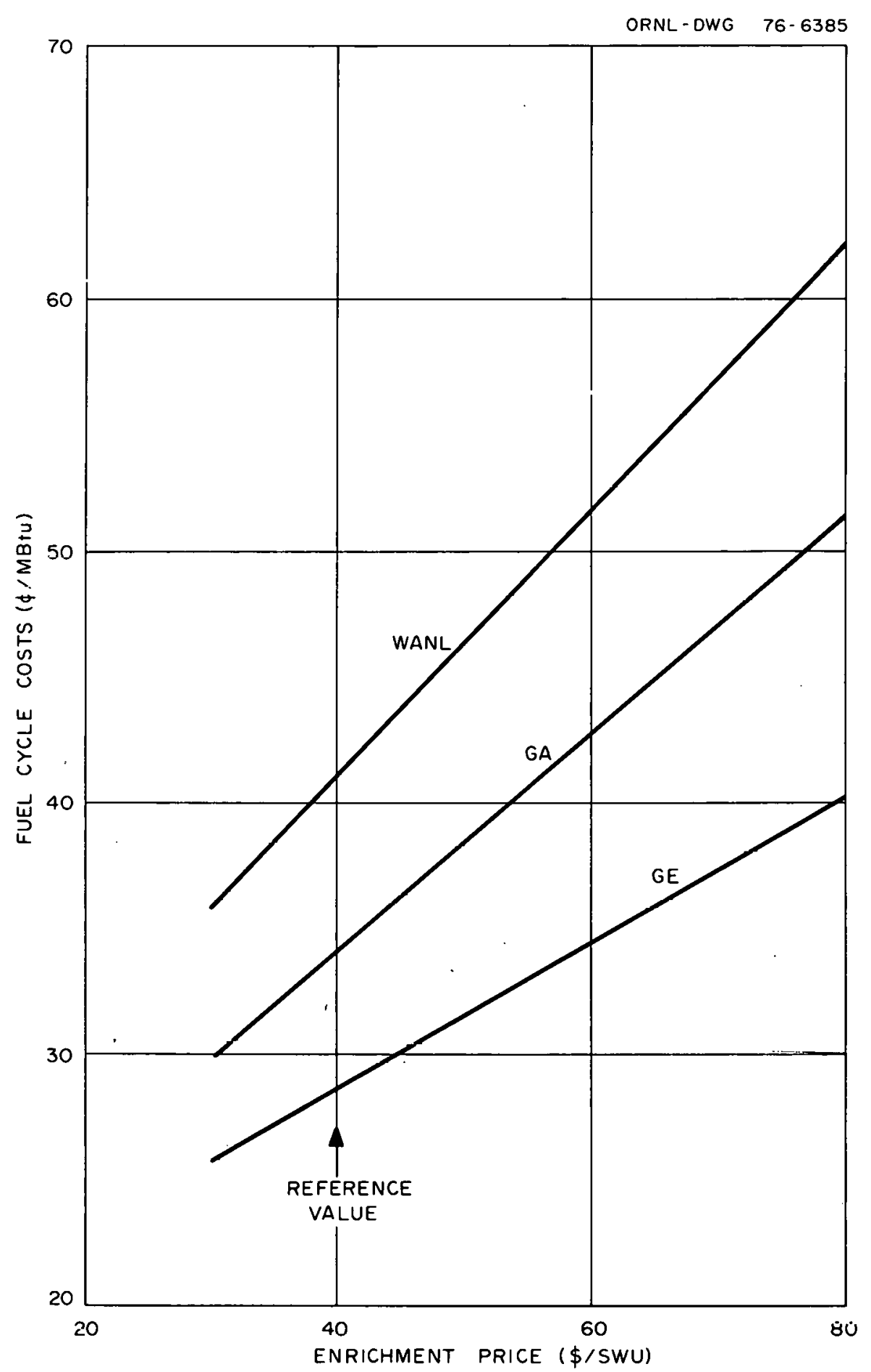

Fig. 5. Fuel cycle cost as a function of enrichment price. 


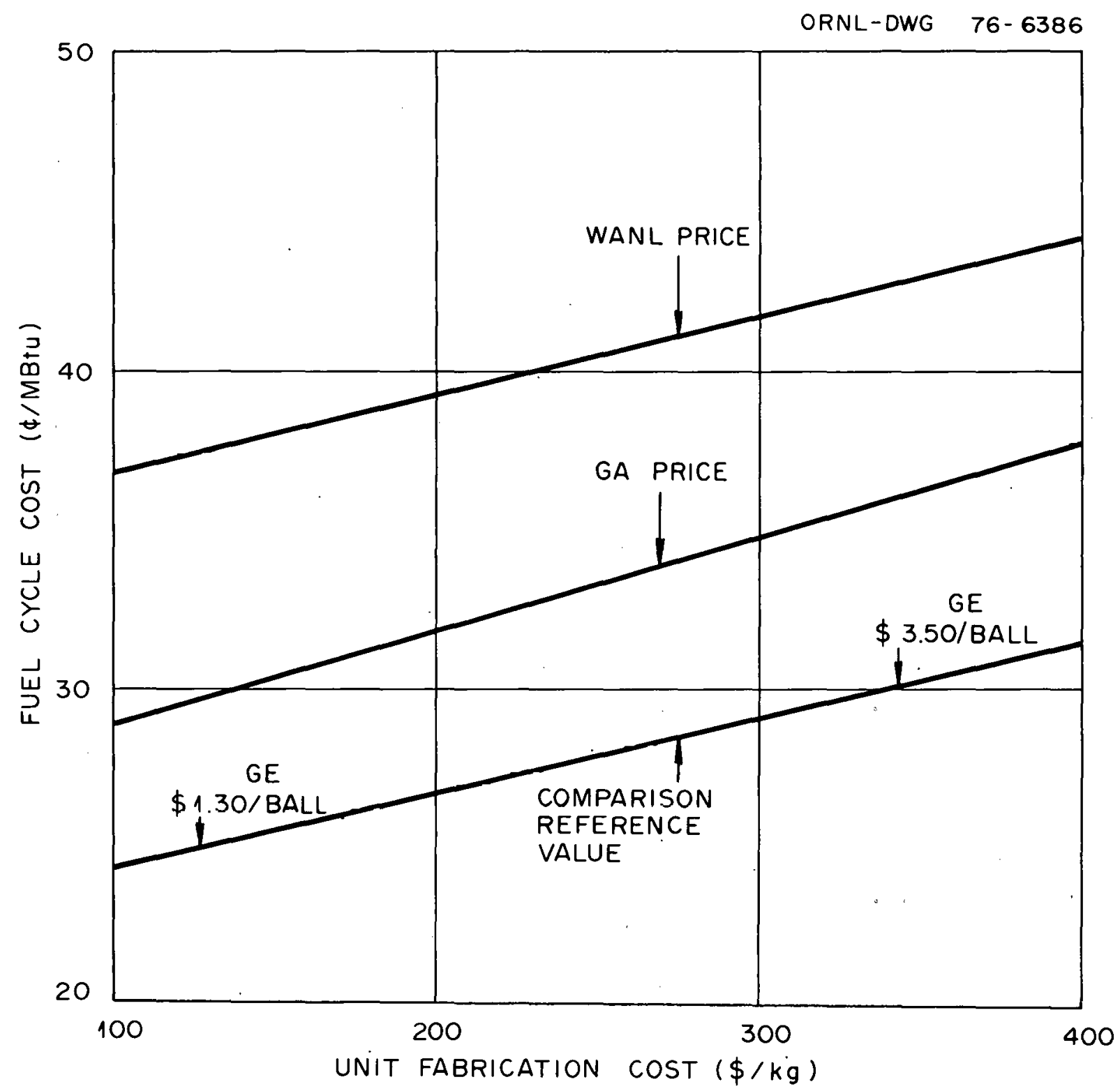

Fig. 6. Fuel cycle cost as a function of unit fabrication cost. 


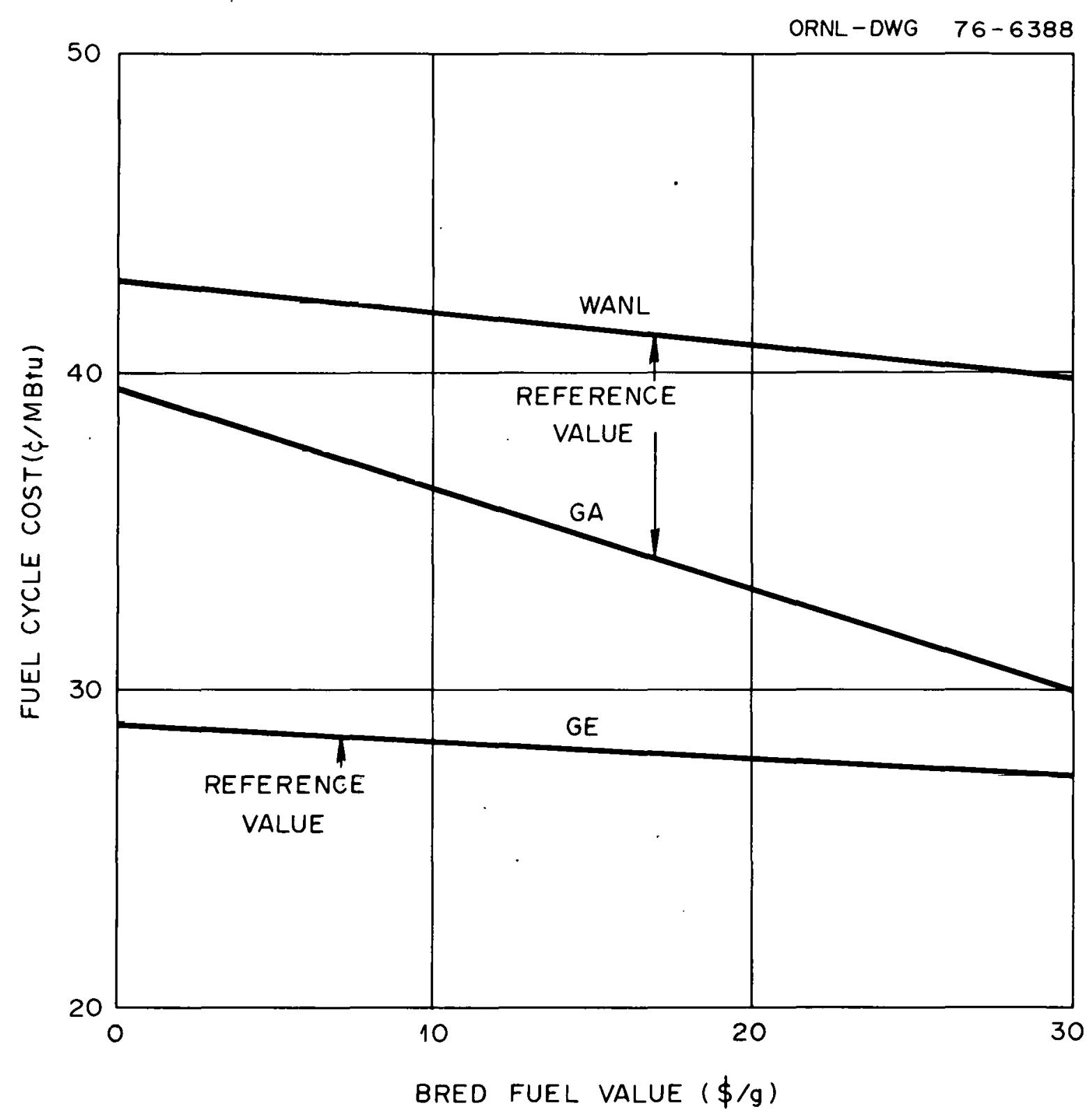

Fig. 7. Fuel cycle cost as a function of bred fuel value. 


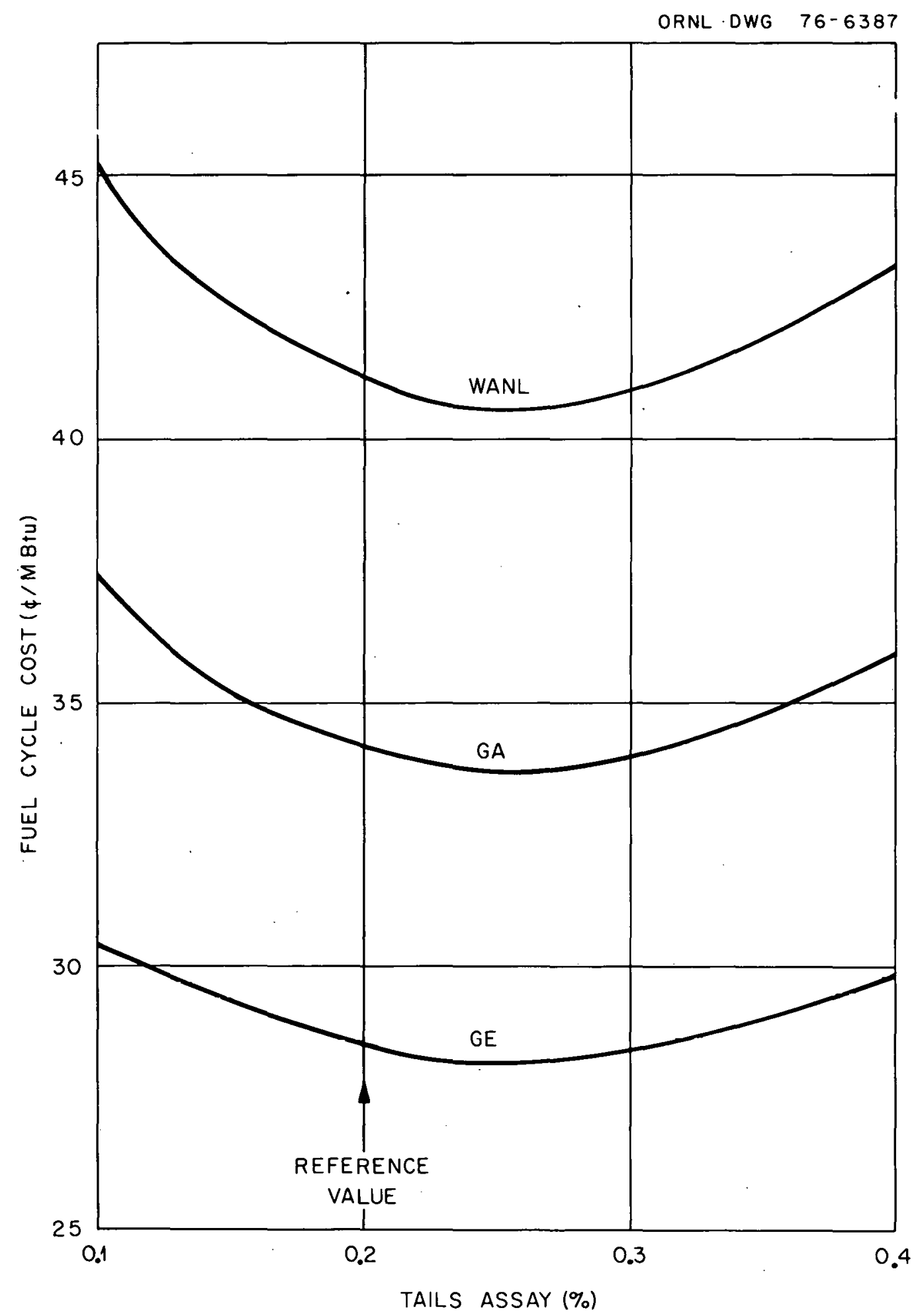

Fig. 8. Fuel cycle cost as a function of enrichment plant tails assay. 


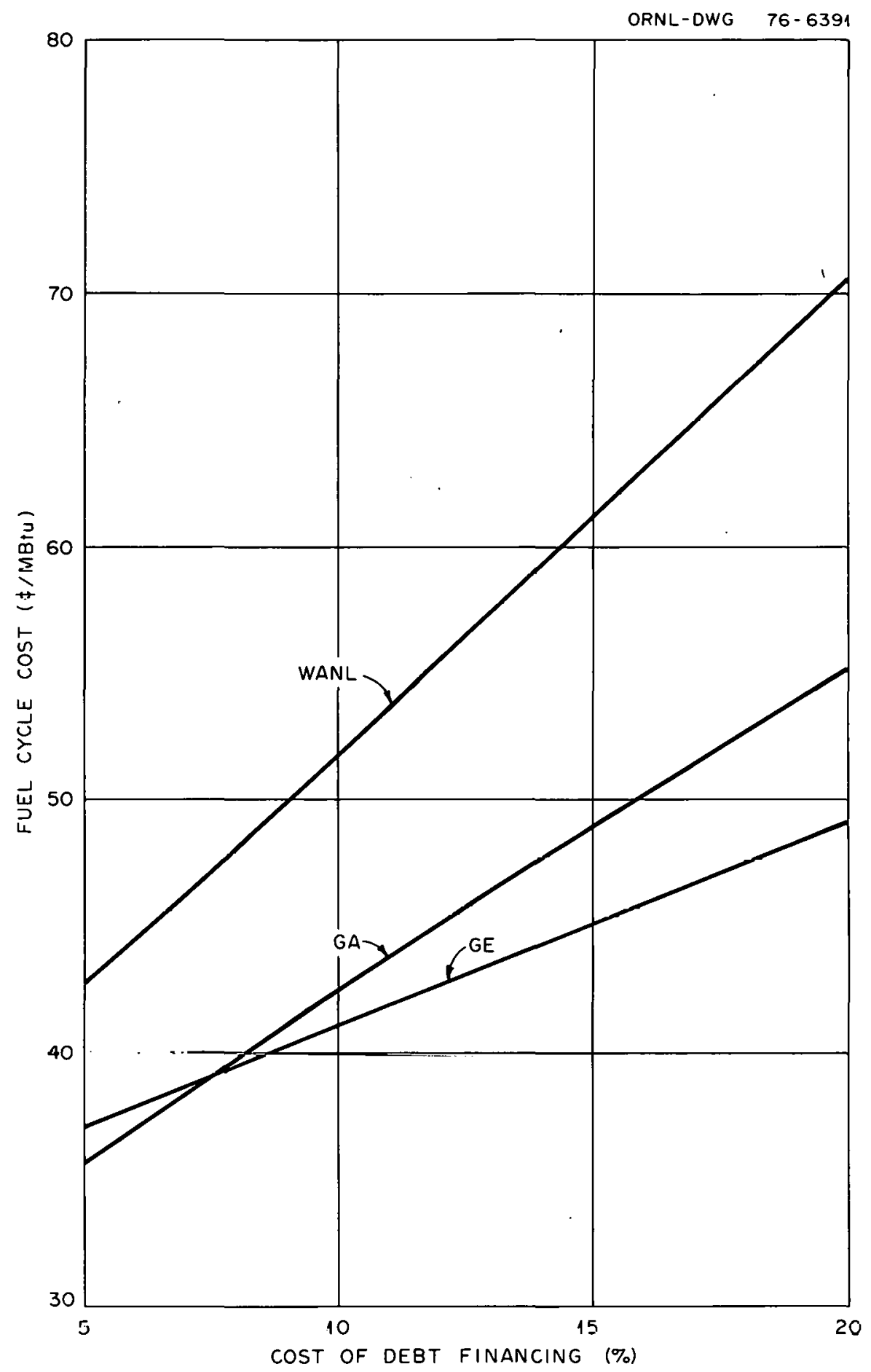

Fig. 9. Fuel cycle cost as a function of interest rate (cost of debt financing). 


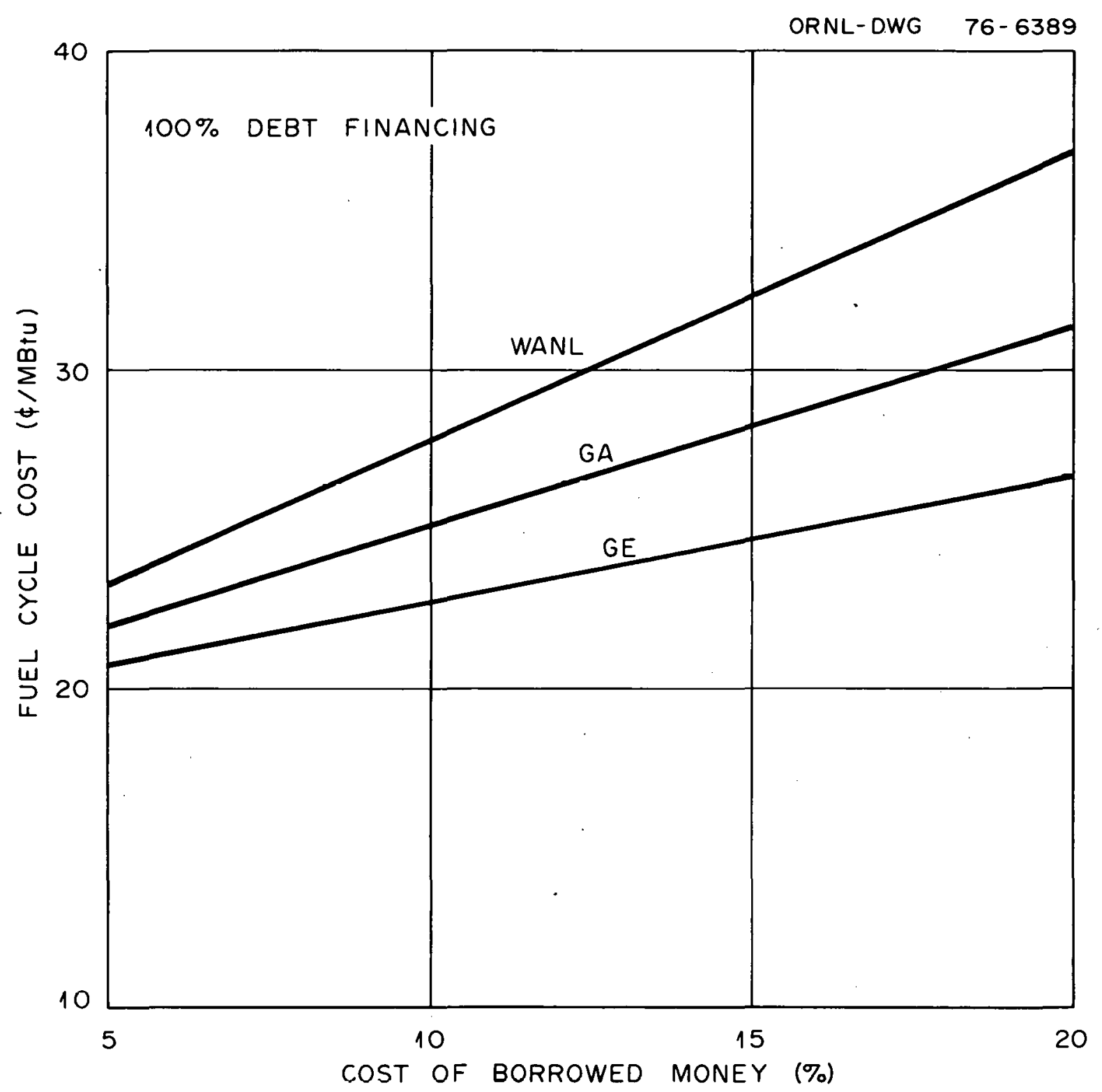

Fig. 10. Fuel cycle cost as a function of interest rate (cost of borrowed money). 
is most sensitive to variations in the separative work and ore price and least sensitive to the reprocessing unit price. The optimum tails assay for our ore and enrichment price is about $0.26 \%$. The $0.2 \%$ value used in the study is worth about $1 / 2 c /$ MBtu in extra fuel-cycle cost. A rise in ore price will shift the minimum to smaller tails assays, whereas a rise in separative work price will shift the optimum to a higher tails assay.

Currently there is a great deal of uncertainty as to the cost of reprocessing spent reactor fuel and recovering the fissile material from it. It now appears that the $\$ 120 / \mathrm{kg}$ used as the reference price in this study is low. However, as shown in Fig. 11, the sensitivity of fuel cost to recovery charge is not very great. Increasing the fuel recovering charge to a more realistic $\$ 200 / \mathrm{kg}$ will increase the fuel-cycle costs less than $2 c / M B t u$ for any of the reference reactor systems.

In the fuel-cycle cost sensitivity to interest rate, as shown in Fig. 10, the equity-debt ground rules were changed from those used for either the utility or industrial financing options. In the case shown here, $100 \%$ debt financing of the fuel cycle was assumed. Since there is no equity involved, there is no profit (other than the lenders) from the fuel cycle and no net income taxes to the project from the fuel-cycle cash flow. The fuel-cycle costs obtained using the utility ground rules may be seen from these curves to correspond to about a $14-1 / 2 \%$ interest rate for this all-debt financing assumption. 


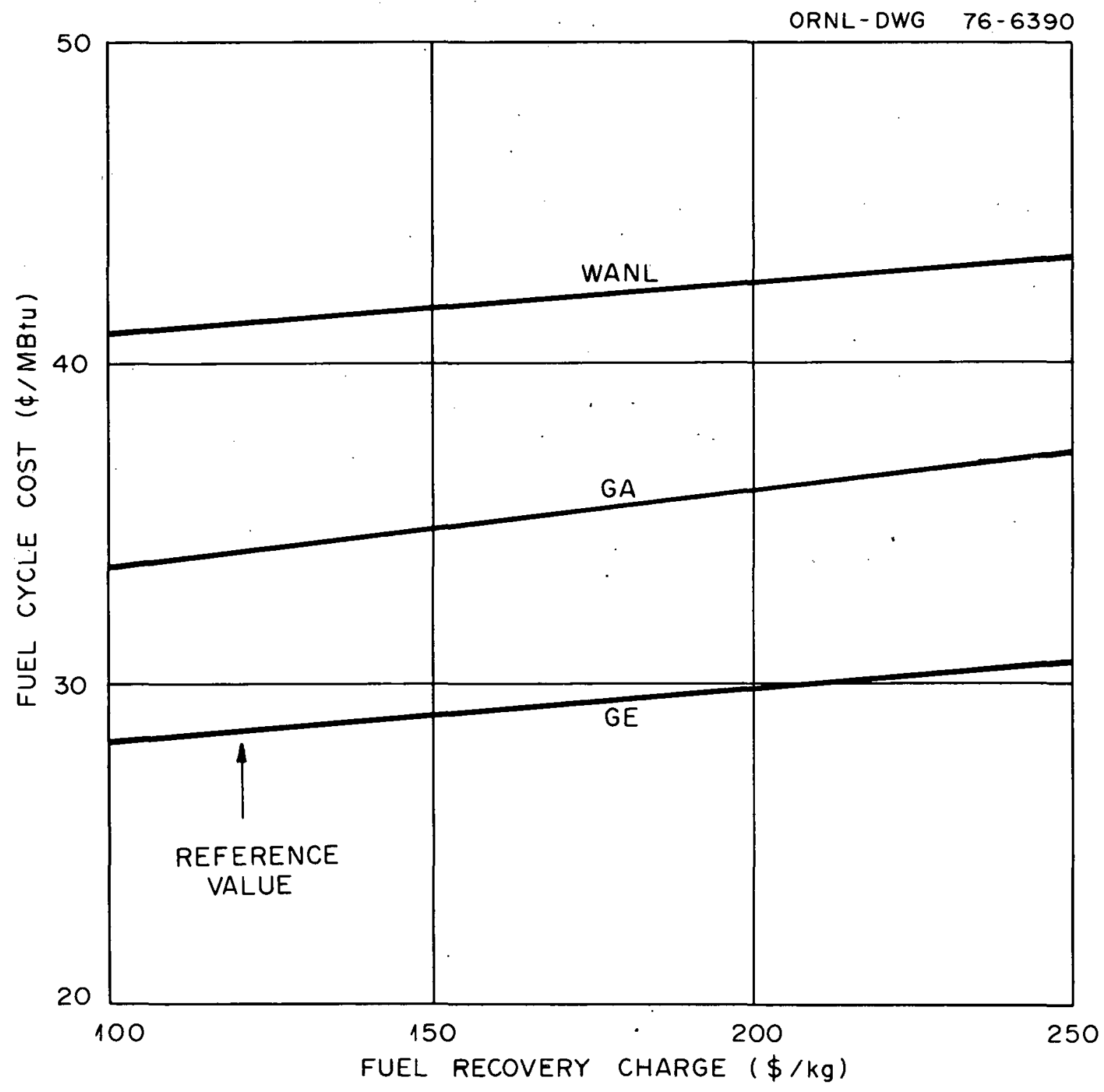

Fig. 11. Fuel cycle cost as a function of fuel recovery charge. 
4. CAPITAL AND OPERATING AND MAINTENANCE (O\&M) COST ANALYSIS

\subsection{Introduction}

\subsubsection{Scope}

United Engineers \& Constructors, Inc. (UE\&C) was requested by the USAEC in November 1974 to prepare an economic comparison of the three conceptual plants under contract number AT(11-1)-2477. The comparison is divided into three tasks:

(1) Develop a balance of plant conceptual design to be combined with the General Atomic Company (GA) concept as a basis for comparison; estimate the cost of the GA/UE\&C concept in July 1974 dollars.

(2) Normalize the overall plant costs for the GA/UE\&C, General Electric (GE) and Westinghouse (WANL) concepts, compare the costs, and identify significant differences between the concepts.

(3) Estimate the operation and maintenance costs for the GA/UE\&C plant and compare with the other concepts.

The results of these tasks are discussed in this Section and in Sects. 2, 3 , and 4 of this report. Section 2 describes the balance of plant which supplements the General Atomic Nuclear Steam Supply System (NSSS). The General Electric and Westinghouse plants and the normalization of the plant costs are described in Sect. 3. Section 4 compares the plant costs and identifies major differences between the plants. Attachment A identifies the interfaces between the nuclear process heat plant and the chemical plant. The chemical plant is not costed.

\subsubsection{UE\&C cost estimation methods}

The total investment cost of a power plant consists of equipment, materials, labor, engineering, construction management, miscellaneous construction expenses, contingency (effects of uncertainty), and the financial costs associated with allocation and disbursement of these funds, which include escalation and interest during construction. The base investment cost of a power plant is defined as the part of the total plant cost that includes the equipment, materials, labor, engineering, construction management, and miscellaneous construction expenses only. This report addresses the base investment cost only. Financial costs are not estimated because the parameters associated with them are too speculative to predict over long periods of time in a highly unpredictable and volatile economy. The effect of the financial costs on the total plant cost is very significant and may exceed $40 \%$ of the total plant cost depending upon the magnitude of the parameters and the length of the project schedule. 
The basis for this cost estimate is the USAEC Report WASH-1230, 770-MWe Central Station Power Plants Investment Cost Study - High-Temperature Gas-Cooled Reactor Plant. 21 The costs contained in that study are based on January 1973 prices. The unit costs of equipment, labor, and materials for this report are adjusted for inflation to July 1, 1974, using the following escalation factors: equipment (20\%), labor (12.5\%), and materials $(20 \%)$.

The cost of the equipment, labor, and materials required are adjusted by analyzing the physical sizes, capacities, and temperature requirements of the equipment and structures, and by adjusting the costs contained in ref. 21. New estimates are prepared for items that are significantly different from those in ref. 21 .

In developing the cost estimates, the following ground rules were observed:

(1) The GA reference design in ref. 1 and supplemented by the system descriptions in ref. 21 is the basis for the conceptual design of the balance of plant.

(2) Changes to the GA reference design were kept to a minimum.

(3) Cost data were based on July 1974 prices. A full complement of licensing and design criteria, circa 1974, was utilized.

(4) The base cost estimate was developed for Middletown, USA, site conditions.

(5) The cost estimate was developed for a single unit.

(6) The base cost was developed in accordance with Appendix B of ref. 19 .

(7) Recent design experience on similar sized HTGR plants is used wherever applicable.

This cost study is based on preliminary, conceptual designs. The costs that are presented may change as a result of further research and development and of more detailed design.

\subsubsection{General Atomic/UE\&C plant description and cost summary}

The nuclear process heat plant that is described and costed in this report is based on a GA 3000-MW(t) HTGR, similar in size and content to the 1160-MW(e) HTGR power plants that are currently being constructed. In the base case, the nuclear reactor systems are modified by GA to include a reformer in the primary coolant loop. This reformer converts a steam-methane mixture to hydrogen and carbon dioxide, with a peak temperature of $1600^{\circ} \mathrm{F}$. 
The nuclear process heat balance of plant (BOP) is essentially the same as the supporting systems and structures for the 1160-MW(e) HTGR, except that electric generation systems are not included. The investment cost study for the 770-MW(e) HTGR ${ }^{21}$ is the basis for definition of the BOP systems, with modifications and additions incorporated as a result of the latest experience with current power plant designs and with recent escalations in labor and materials costs.

The base plant is thus defined as a nuclear reactor (with the necessary BOP-supporting systems and structures) which provides heat to a chemical process in the forms of steam and helium. All electrical needs of the plant are supplied from outside the plant. The costs of the base plant are summarized in Table 18. The chemical plant is not a part of this estimate.

Table 18. Summary of costs for GA/UE\&C base plant (without power generation or intermediate loop) ${ }^{a}$

\begin{tabular}{|c|c|c|c|c|}
\hline \multirow[b]{2}{*}{ Account } & \multirow[b]{2}{*}{ Description } & \multicolumn{3}{|c|}{ Costs (thousands of dollars) } \\
\hline & & BOP total & NSSS total & total \\
\hline 20 & Land and land rights & 1,000 & - & 1,000 \\
\hline 21 & Structure and improvements & 68,872 & - & 68,872 \\
\hline 22 & Reactor plant equipment & 25,322 & 241,879 & 267,201 \\
\hline 24 & Electric plant equipment & 26,597 & - & 26,597 \\
\hline 25 & Miscellaneous plant equipment & 8,774 & - & 8,774 \\
\hline 26 & Special materials & 274 & 271 & 545 \\
\hline 91 & Engineering and construction & 89,083 & - & 89,083 \\
\hline \multirow[t]{2}{*}{99} & Other costs & 7,874 & 24,939 & 32,813 \\
\hline & Total plant costs & 227,796 & 267,089 & 494,885 \\
\hline
\end{tabular}

$a_{\text {This table is derived from Table } 23 .}$

To better isolate the process from the primary coolant, an intermediate helium loop (IHL) is estimated as an addition to the cost of the base plant. This loop minimizes migration of tritium from the primary coolant to the process gas and of hydrogen to the primary coolant. It also relocates the reformers out of the containment building, thereby removing the danger of hydrogen explosions that might affect safety-related systems.

Two electric generation adders are also considered. Generation of $40 \mathrm{MW}(\mathrm{e})$ provides enough power for the nuclear plant equipment plus an allowance for the demand from the chemical processing plant. The generation of $100 \mathrm{MW}(\mathrm{e})$ permits external sale of power. 
The costs of plants with all of these options are summarized in Table 19.

\subsubsection{Comparison summary}

The costs and scopes of supply compared in this Section for the GA/UE\&C, GE, and WANL plants are not directly comparable because of significant differences in the scopes of supply. Table 20 summarizes the costs, and Table 21 summarizes the descriptions of these plants.

The GE plant costs ( $\$ 620$ million) are similar to those for the GA/UE\&C plant, but the GE scope includes fewer structures. The small cost differences between the two concepts, given the uncertainties involved, are not significant.

The WANL plant costs ( $\$ 326$ million) are consistently lower than either of the other estimates. Although differences in some accounts can be explained by different scopes or different structure sizes, WANL estimates of equipment, labor, and material costs for the reactor containment building, administration building, and heat transfer system are lower than would be expected if comparable base costs were used.

\subsubsection{Interfaces with the chemical plant.}

The design of the chemical processing portions of the overall plant requires further definition of the interfaces with the nuclear part of the plant. As a result, UE\&C assumed that:

1. All steam generation by the nuclear plant will be used in the chemiral plant.

2. All boiler feedwater will be supplied by the chemical plant.

3. All makeup water and water conditioning equipment for the steam systems will be supplied by the chemical plant.

4. If a turbine-generator is used, the exhaust system will be used by the chemical plant.

5. The heat sink for the steam cycle, if required, will be supplied by the chemical plant.

6. The electrical demand of the chemical plant is $30 \mathrm{MW}(\mathrm{e})$.

Details of the interfaces between the nuclear and chemical plants are discussed in Appendix A. 
Table 19. GA/UE\&C plant cost with options (July 1974)

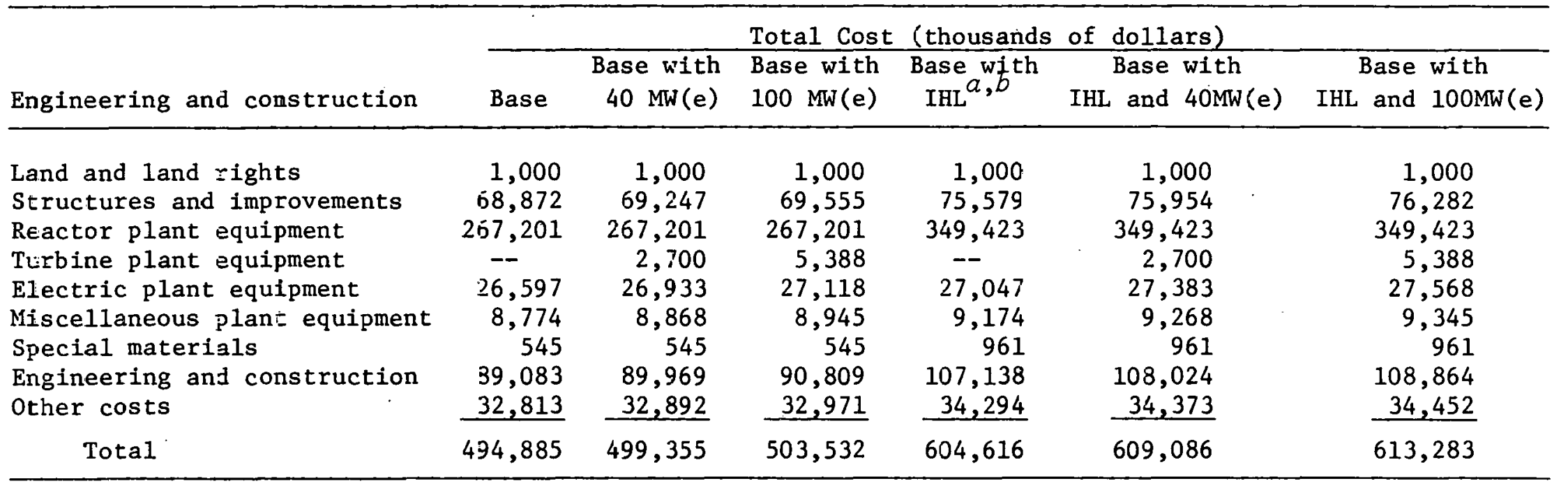

Intermediate Helium Loop.

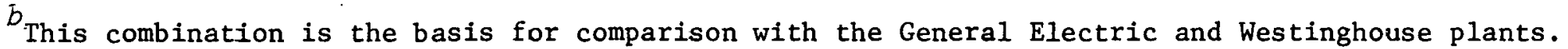

Source: Tables 23, 24, 25, and 26. 
Table 20. Summary of comparison (July 1974) $a, b$

\begin{tabular}{|c|c|c|c|c|}
\hline \multirow[b]{2}{*}{ Account } & \multirow[b]{2}{*}{ Description } & \multicolumn{3}{|c|}{ Total costs (thousands of dollars) } \\
\hline & & GA/UE\&C & GE & WANL \\
\hline 20 & Land and land rights & 1,000 & 2,000 & 800 \\
\hline 21 & Structures and site facilities & 75,579 & 68,986 & 47,551 \\
\hline 22 & Reactor plant equipment & 349,423 & 369,742 & 149,228 \\
\hline 24 & Electric plant equipment & 26,597 & 21,521 & 16,206 \\
\hline 25 & Miscellaneous plant equipment & 8,774 & 9,675 & 6,421 \\
\hline 26 & Special materials & 961 & 840 & 250 \\
\hline \multicolumn{2}{|c|}{ Subtotal (Accounts 21 through 26) } & 462,334 & 472,764 & 220,456 \\
\hline $\begin{array}{l}91 \\
99\end{array}$ & $\begin{array}{l}\text { Engineering and construction costs } \\
\text { Other costs }\end{array}$ & $\begin{array}{r}107,138 \\
34,294 \\
\end{array}$ & $\begin{array}{l}64,134 \\
82,745 \\
\end{array}$ & $\begin{array}{l}57,268 \\
47,820 \\
\end{array}$ \\
\hline \multicolumn{2}{|c|}{ Total costs } & 603,766 & 619,643 & 325,544 \\
\hline \multicolumn{2}{|c|}{ Annual operation and maintenance $\operatorname{costs}^{c}$} & $\begin{array}{r}8,995 \\
\text { to } \\
11,155\end{array}$ & 3,388 & 5,996 \\
\hline
\end{tabular}

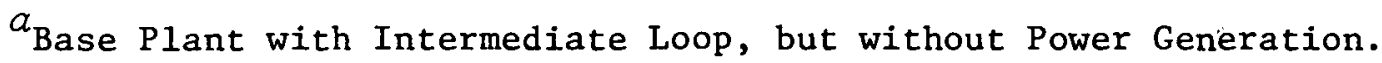

$b_{\text {This }}$ table is derived from Table 31 .

${ }^{c}$ Costs represent different scopes of supply. Direct costs only.

\subsubsection{General comments}

- As a result of this review, several items have been identified which should be investigated in more detail.

\subsubsection{Plant size}

The output of this plant appears to be greater than the demand required by most single potential users. Although it is likely that energy use will become more concentrated in the future as energy production becomes concentrated, the early generation of process heat plants will probably still serve several customers. It is also possible that smaller nuclear heat sources will be applied sooner and more widely than the 3000-MW(t) size. Accordingly, the costs and economic potential should be investigated for plants in the 500 to $2000 \mathrm{MW}(t)$ range. 
Table 21. Comparison of conceptual designs

\begin{tabular}{|c|c|c|c|}
\hline Item & $\begin{array}{c}\mathrm{GA} / \mathrm{UE} \& \mathrm{C}^{a} \\
\text { (comparsion plant) }\end{array}$ & $\mathrm{GE}^{b}$ & WANL $^{c}$ \\
\hline Reference process & $\begin{array}{l}\text { Hydrogen production by } \\
\text { methane reforming }\end{array}$ & $\begin{array}{l}\text { Hydrogen production by } \\
\text { methane reforming }\end{array}$ & $\begin{array}{l}\text { Hydrogen production } \\
\text { by proprietary } \\
\text { steam-electric } \\
\text { process }\end{array}$ \\
\hline $\begin{array}{l}\text { Maximum average pro- } \\
\text { cess temperature }\end{array}$ & $1400^{\circ} \mathrm{F}$ & $1400^{\circ} \mathrm{F}$ & $1400^{\circ} \mathrm{F}$ \\
\hline Nuclear reactor type & $\begin{array}{l}300-\mathrm{MW}(\mathrm{t}) \text { VHTR } \\
\text { (modified HTGR) }\end{array}$ & $\begin{array}{l}\text { 3000-MW(t) VHTR } \\
\text { (similar to German THTR) }\end{array}$ & $\begin{array}{l}3000-M W(t) \text { VHTR } \\
\text { (based on nuclear } \\
\text { rocket technology) }\end{array}$ \\
\hline Reactor core type & $\begin{array}{l}\text { Hexagonal blocks, solid fuel } \\
\text { rods, } 93 \text { without U-235 }\end{array}$ & Pebble bed, Low enriched & $\begin{array}{l}\text { Hexagonal blocks, } \\
\text { hollow cylindrical } \\
\text { fuel rods, } 93 \text { with- } \\
\text { out U- } 235\end{array}$ \\
\hline Reactor coolant & Helium & Helium & Helium \\
\hline Reactor vesse 1 & PCRV & PCRV & PCIV \\
\hline Intermediate loop (IHL) & Yes & Yes & Yes \\
\hline IHL coolant & Helium & Helium & Helium \\
\hline Electric generation & No & No & Yes \\
\hline
\end{tabular}

${ }^{a}$ See Table 28 for plant costs.

$b_{\text {See Table }} 29$ for plant costs.

${ }^{c}$ See Table 30 for plant costs. 


\subsubsection{Power generation}

The incomplete design of the process plant prevents analysis of the amount of energy available for generation of electricity. When the energy demands of the process plants are more clearly defined, a new estimate of electric generation costs should be made.

\subsubsection{Plant configuration}

The nuclear process heat plant described in this report is not an optimum plant. The costs and advantages of different primary/intermediate loop configuration strongly affect the cost of the plant (Table 19). If the intermediate loop is required, significant cost savings in PCRV and containment building costs can be realized if the steam generators are located only in the intermediate loop. However, reactor control should then be very carefully investigated.

\subsubsection{Nuclear plant control}

Although instrumentation and control systems are included in the three conceptual designs, the full scope and complexity of the systems are not documented. Since the problems of nuclear plant control are expected to be extensive, a full investigation of this area should be initiated at an early time.

\subsubsection{Interaction between nuclear and chemical plants}

The nuclear and chemical plants will be highly dependent on each other for electricity, steam, heat, teedwater $r$ coollny walel, dind othcr services which are still undefined. To assure safe operation of the nuclear plant, administrative and technical coordination and interaction must be thoroughly investigated.

\subsection{Description and Cost of General Atomic/United Engineers \& Constructors, Inc. Plant}

\subsubsection{Introduction}

The GA/UE\&C nuclear process heat plant is costed as a base plant with adders for an intermediate heat transfer loop and two electric generation options. Sections 4.2.2-4.2.4 describe the plant and the modifications required for the options.

A chemical plant is associated with the nuclear plant but is not within the scope of this study. Steam is generated by the nuclear plant and supplied to the chemical plant, where it is mixed with methane. The steam-methane mixture is heated in a reformer by helium from the nuclear 
plant to produce a mixture of steam, hydrogen, and carbon dioxide. This is processed by the chemical plant into hydrogen. A flow diagram of a conceptual chemical plant is illustrated in the GA report. ${ }^{22}$

The estimated operating and maintenance cost of the nuclear plant is described in Sect. 4.2.5.

\subsubsection{Base plant}

4.2.2.1 Site

The nuclear process heat plant is assumed to be located at the "Middletown" standard site described in the USAEC Report NUS-531.23 The site was modified for the 770-MW(e) HTGR investment cost study and is described in ref. 21. The sice is on a floodplain next to a river and is about 25 miles from the nearest large city. The site description also includes water, gas, and electric supplies; air, railroad, road, and water access routes; topography, geology, and seismology; meteorological conditions; and waste disposal regulations.

\subsubsection{Nuclear steam supply system}

The nuclear steam supply system (NSSS) is a 3000-MW(e) HTGR supplied by GA. The NSSS consists of the nuclear reactor, control and safety department, the prestressed concrete reactor vessel (PCRV), helium circulators, and the steam generators. For the nuclear process heat plant, the NSSS also includes a methane-to-hydrogen reformer in the primary coolant loop within this PCRV. Other modifications are made to some systems in order to accommodate the required temperatures, which are several hundred degrees hotter than the comparable electric HTGR plant.

General Atomic has investigated the materials and operating problems of the nuclear process heat plant, has estimated the cost of a typical NSSS for process heat, and has recommended a R\&D program. The results and the NSSS description are reported in ref. 1. Process options are discussed, with peak process temperatures from 1200 to $2000^{\circ} \mathrm{F}$. The $1600^{\circ} \mathrm{F}$ case was chosen as the NSSS for definition of the base plant balance of plant because it appears to be the most efficient operating temperature. Serious materials problems exlst at higher temperatures.

A heat balance diagram of the primary cooling system of the base plant is shown in Fig. 12. The hellum is heated in the reactor core and enters the methane reformer at $1800^{\circ} \mathrm{F}$ (average). It passes through the reformer and a steam generator and is then compressed before it reenters the core. Steam generated by the cycle drives the helium circulators and is then used by the chemical process plant, which returns feed water to the system. (Attachment $A$ of this report discusses interfaces with the process plant.) 
ORNL-DWG $76-6395$

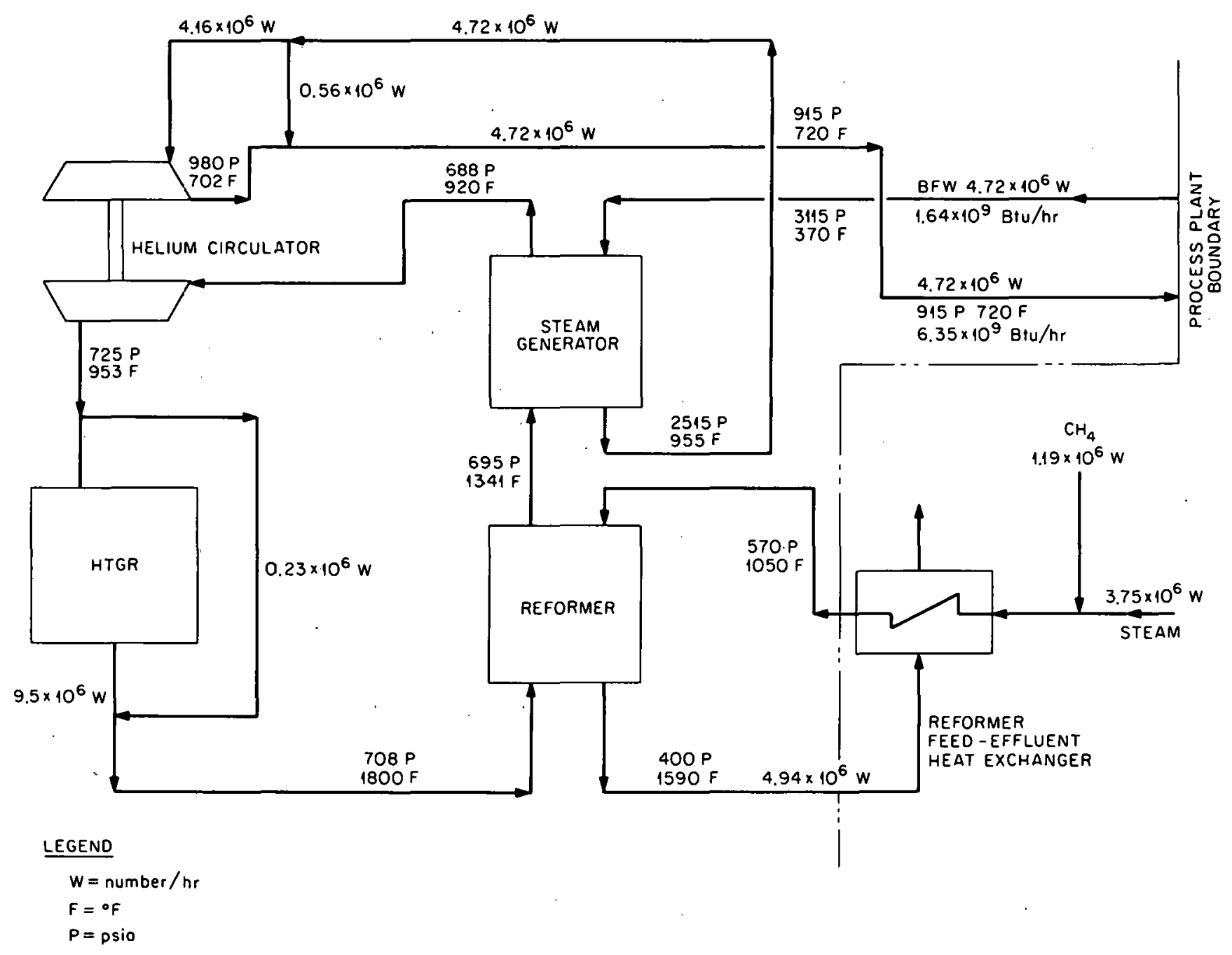

Fig. 12. Heat balance diagram - nuclear process heat reactor. with reformer in PCRV. 
General Atomic quotes their estimate of NSSS costs as adders to their public bid to the Los Angeles Department of Water and Power (LADWP), which was a single-price bid of $\$ 169,358,000$. To bring prices to July 1974 dollars, GA escalated this estimate to $\$ 178,503.300$. In order to compare costs of the plants estimated by GA, GE, and WANL, UE\&C prorated the GA LADWP bid based on the relative values of the appropriate accounts in ref. 21, with modifications and additions resulting from the latest experience with current power plant design, as shown in Table 22. This division of the costs probably does not represent the current cost breakdown from the GA NSSS, but it is the best estimate that can be made without a detailed design and estimate for the NSSS system.

Table 22. NSSS $^{a}$ cost estimated by GA (July 1974)

\begin{tabular}{|c|c|c|c|c|}
\hline \multirow[b]{2}{*}{ Account } & \multirow[b]{2}{*}{ Description } & \multicolumn{3}{|c|}{ Cost (thousands of dollars) } \\
\hline & & $\begin{array}{l}\text { LADWP } \\
\text { bid }\end{array}$ & $\begin{array}{l}\mathrm{NPH}^{C} \\
\text { adder }\end{array}$ & Total \\
\hline 221 & Reactor equipment & 107,594 & 20,323 & 127,917 \\
\hline 222 & Main heat transfer loop & 39,269 & 39,054 & 78,323 \\
\hline 223 & Safeguards cooling system & 7,258 & 12 & 7,270 \\
\hline 224 & $\begin{array}{l}\text { Radioactive waste treatment } \\
\text { and disposal }\end{array}$ & 3,822 & 718 & 4,540 \\
\hline 225 & $\begin{array}{l}\text { Nuclear fuel handling and } \\
\text { storage }\end{array}$ & 13,826 & 516 & 14,342 \\
\hline $\begin{array}{l}226 \\
227\end{array}$ & Other reactor plant equipment & 2,973 & 2,700 & $\begin{array}{l}5,673 \\
3.814\end{array}$ \\
\hline 269 & Initial catalyst filling & $\begin{array}{r}3 \\
0\end{array}$ & 271 & $\begin{array}{r}274 \\
271\end{array}$ \\
\hline 99 & Other costs & 0 & 939 & 939 \\
\hline \multirow[t]{2}{*}{995} & Contingency & $\underline{0}$ & $\underline{24,000}$ & 24,000 \\
\hline & Total & 178,503 & 88,586 & 267,089 \\
\hline
\end{tabular}

$a_{\text {For discussion see Sect. 4,2.2.2. }}$

$b_{\text {Total }}$ bid by GA to Los Angeles Department of Water and Power (LADWP), escalated by GAC to July 1974, and divided into accounts according to recent estimates and the appropriate costs in 770-MW(e) Central Station Power Plarlt Investment Cost Study - High-Temperature Gas-Cooled Reactor Plant, USAEC Report, WASH-1230, vol. V, (January 1973).

${ }^{c}$ Adders for NPH plant from High-Temperature Nucleur Heat source Study (Sect. 8), Report GA-A13158, General Atomic Company, December 1974, with contingency costs removed to separate accounts, in prupurtion to the size of each account. 


\subsubsection{Balance of plant conceptual design}

The conceptual design of the balance of plant is developed from the investment cost summary for the 770-MW(e) HTGR, 21 current experience with similar nuclear power plants, and the GA scope of supply for the NSSS. ${ }^{24}$ The plant costs, including the GA costs, are shown in Table 23.

The layout of the plant site, with all significant structures, is shown in Fig. 13. Sections through the main structures (in Figs. 14 through 17) show the locations of the main systems. The most significant differences between this plant and the one described in ref. 21 are size [ $3000 \mathrm{MW}(\mathrm{t})$ instead of $2000 \mathrm{MW}(\mathrm{t})$ ] ; mixed mean coolant temperature at core outlet ( 1800 vs $1434^{\circ} \mathrm{F}$ ); PCRV contains reformers; and no electric generation equipment, supporting systems, or structures.

The following sections briefly describe the differences between the nuclear process heat balance of plant and the comparable accounts in ref. 21. Where an account is not discussed, the systems are essentially the same as the comparable systems in the 770-MW(e) plant, expanded to $1160 \mathrm{MW}(\mathrm{e})$.

Account 212. Reactor containment building

The containment building and annulus diameters are larger than the comparable structures in ref. 21 because the PCRV diameter is larger. There is sufficient clearance for the removal of the reformers from the PCRV for servicing.

Account 213. Turbine-generator building

This building is not a part of the base plant (see sect. 4.2.4).

\section{Account 214. Water intake structures}

The circulating water intake structure is not a part of the nuclear process heat plant because waste heat dissipation is the responsibility of the chemical plant.

The service water intake structure is scaled up from ref. 21 .

\section{Account 215. Reactor service building}

The services provided are the same as in ref. 21 , but the building size is slightly increased. The cost estimate in ref. 21 was for a reactor service building that serves two reactor units, thus this building would be smaller. However, recent comparable structure designs are considerably larger than the one in ref. 21, thus the net effect is a larger building. 
Tabie 23. Cost of base plant with GA reactor

No intermediate loop, no power generation (July 1974) ${ }^{a}$

\begin{tabular}{|c|c|c|c|c|c|}
\hline \multirow[b]{2}{*}{ Account } & \multirow[b]{2}{*}{ Description } & \multicolumn{4}{|c|}{ Costs (thousands of dollars) } \\
\hline & & $\begin{array}{l}\text { BOP materials } \\
\text { and equipment }\end{array}$ & BOP labor & $\mathrm{GA}$ adder ${ }^{b}$ & Total \\
\hline \multirow{3}{*}{201} & and and land rights & & & & \\
\hline & Land and privilege acquisition & 1,000 & -- & -- & 1,000 \\
\hline & Total for 20 & 1,000 & -- & -- & 1,000 \\
\hline \multirow{11}{*}{$\begin{array}{l}211 \\
212 \\
214 \\
215 \\
218 \mathrm{~A} \\
218 \mathrm{~B} \\
218 \mathrm{C} \\
218 \mathrm{D} \\
218 \mathrm{E}\end{array}$} & ructures and improvements & & & & \\
\hline & Yard work & 1,203 & 1,424 & -- & 2,627 \\
\hline & Reactor containment building & 12,247 & 21,564 & -- & 33,811 \\
\hline & Intake structure & 285 & 127 & -- & 412 \\
\hline & Reactor service juilding & 6,000 & 11,255 & -- & 17,255 \\
\hline & Control building & 1,900 & 4,146 & -- & 6,046 \\
\hline & Diesel generator building & 1,628 & 3,512 & -- & 5,140 \\
\hline & Administration building & 1,200 & 1,372 & -- & 2,572 \\
\hline & Auxiliaries building & 363 & 485 & -- & 848 \\
\hline & Helium storage building & 90 & 71 & -- & 161 \\
\hline & Total for 21 & 24,916 & 43,956 & -- & 68,872 \\
\hline \multirow{11}{*}{$\begin{array}{l}221 \\
222 \\
223 \\
224\end{array}$} & eactor plant equipnent & & & & \\
\hline & Reactor equipment & 104 & 578 & 127,917 & 128,599 \\
\hline & Main heat transfer loop & 318 & 1,146 & 78,323 & 79,787 \\
\hline & Safeguards cooling system & 409 & 259 & 7,270 & 7,938 \\
\hline & Radioactive waste treatment & & & & \\
\hline & and disposal & 239 & 884 & 4,540 & 5,663 \\
\hline & Nuclear fuel handling and & & & & \\
\hline & storage & 254 & 640 & 14,342 & 15,236 \\
\hline & Otier reactor plant equipment & 9,968 & 6,998 & 5,673 & 22,639 \\
\hline & Instrumentation and control & 2,356 & 1,169 & 3,814 & 7,339 \\
\hline & Total for 22 & 13,648 & 11,674 & 241,879 & 267,201 \\
\hline
\end{tabular}


Table 23 (cont'd)

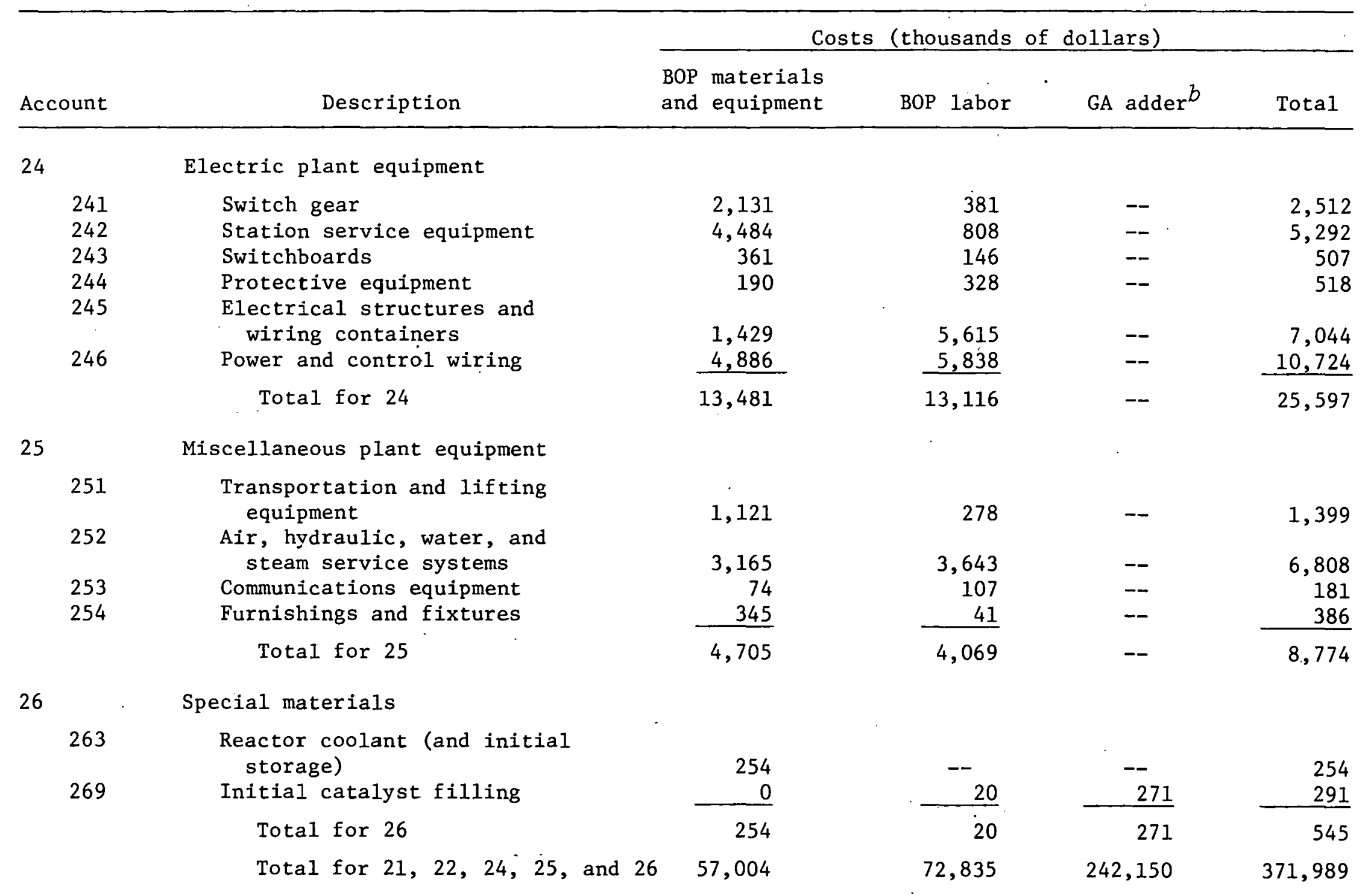


Table 23 (cont'd)

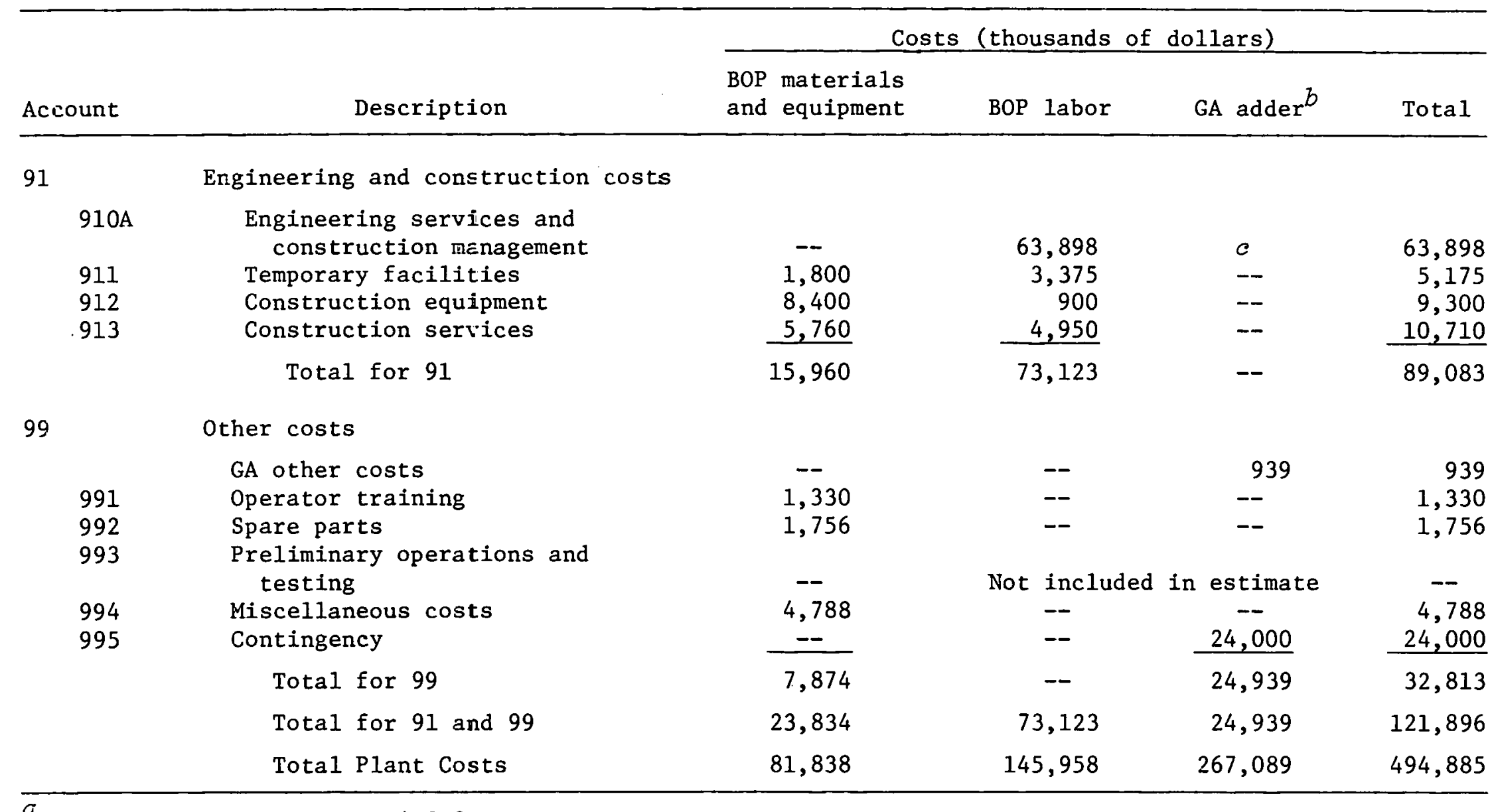

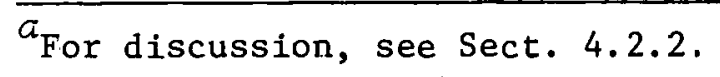

$b_{\mathrm{GA}}$ adders are from ref, 2, Section 8. Contingency costs were separated in proportion to the size of each account. The GA bid for LADWP is taken from Table 22.

$c_{\mathrm{GA}}$ added costs were distributed by GA among other accounts. 

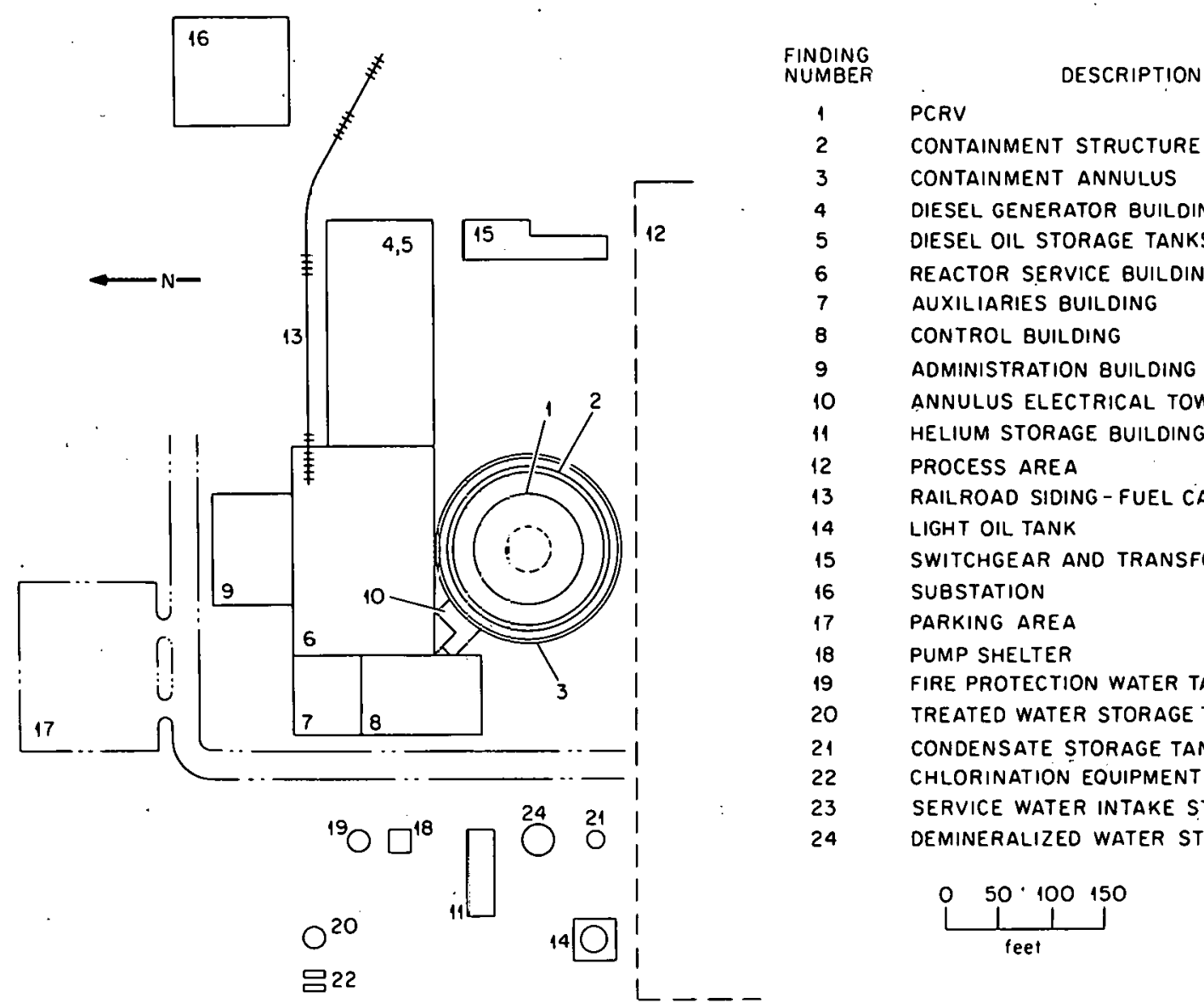

PCRV

CONTAINMENT STRUCTURE

CONTAINMENT ANNULUS

DIESEL GENERATOR BUILDING

DIESEL OIL STORAGE TANKS

REACTOR SERVICE BUILDING

AUXILIARIES BUILDING

CONTROL BUILDING

ADMINISTRATION BUILDING

ANNULUS ELECTRICAL TOWER

HELIUM STORAGE BUILDING

PROCESS AREA

RAILROAD SIDING - FUEL CAR

LIGHT OIL TANK

SWITCHGEAR ANO TRANSFORMER AREA

SUBSTATION

PARKING AREA

PUMP SHELTER

FIRE PROTECTION WATER TANK

TREATED WATER STORAGE TANK

CONDENSATE STTORAGE TANK

CHLORINATION EOUIPMENT

SERVICE WATER INTAKE STRUCTURE

DEMINERALIZED WATER STORAGE TANK
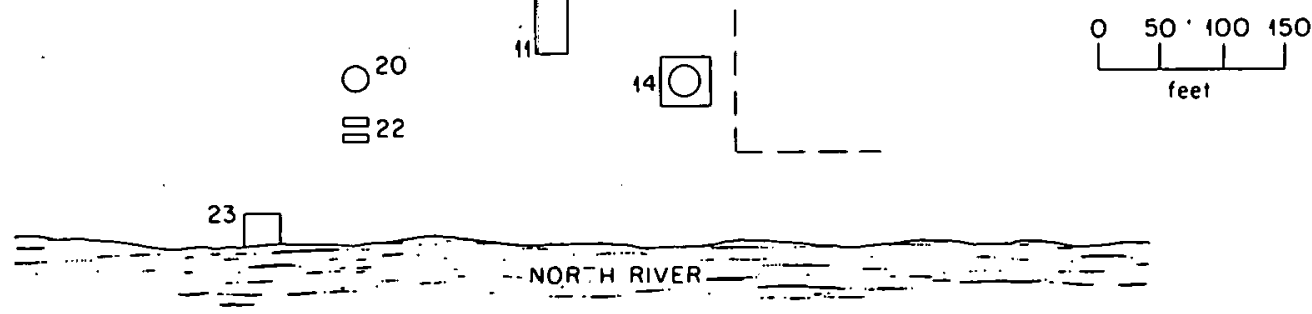

Fig. 13. Plot plan - $3000 \mathrm{MW}(\mathrm{t})$ HTGR [0-MW(e)] for process heat (Middletown hypothetical site). 


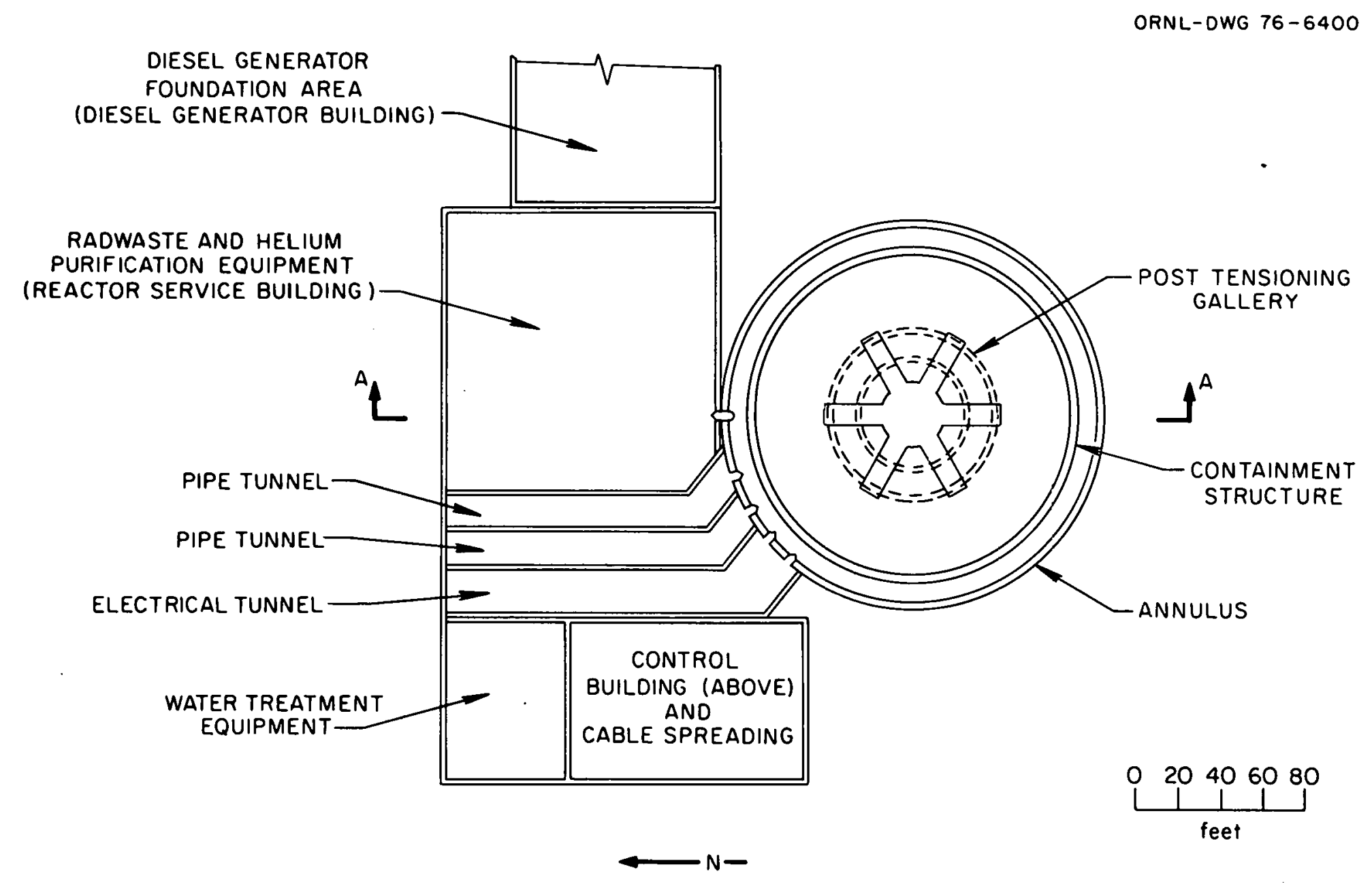

Fig. 14. General arrangement plant (view at elevation $1 \mathrm{ft}-$ 0 in.) - $3000 \mathrm{MW}(\mathrm{t})$ HTGR [0-MW(e)] for process heat (Middletown hypothetical site). 


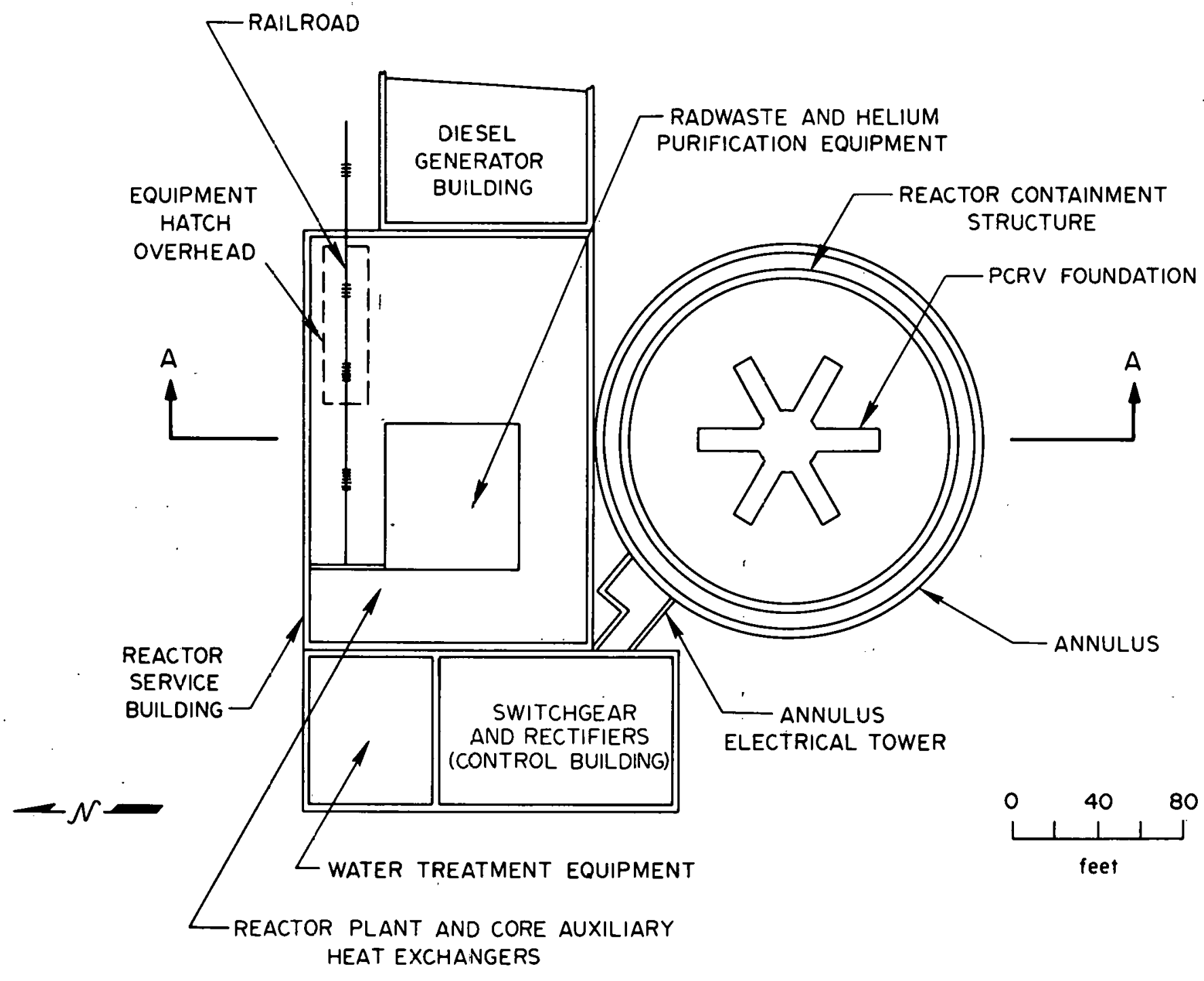

Fig. 15. General arrangement plan (view at elevation $18 \mathrm{ft}-$ 0 in.) - $3000 \mathrm{MW}(\mathrm{t})$ HTGR [0-MW(e)] for process heat (Middletown hypothetical site). 


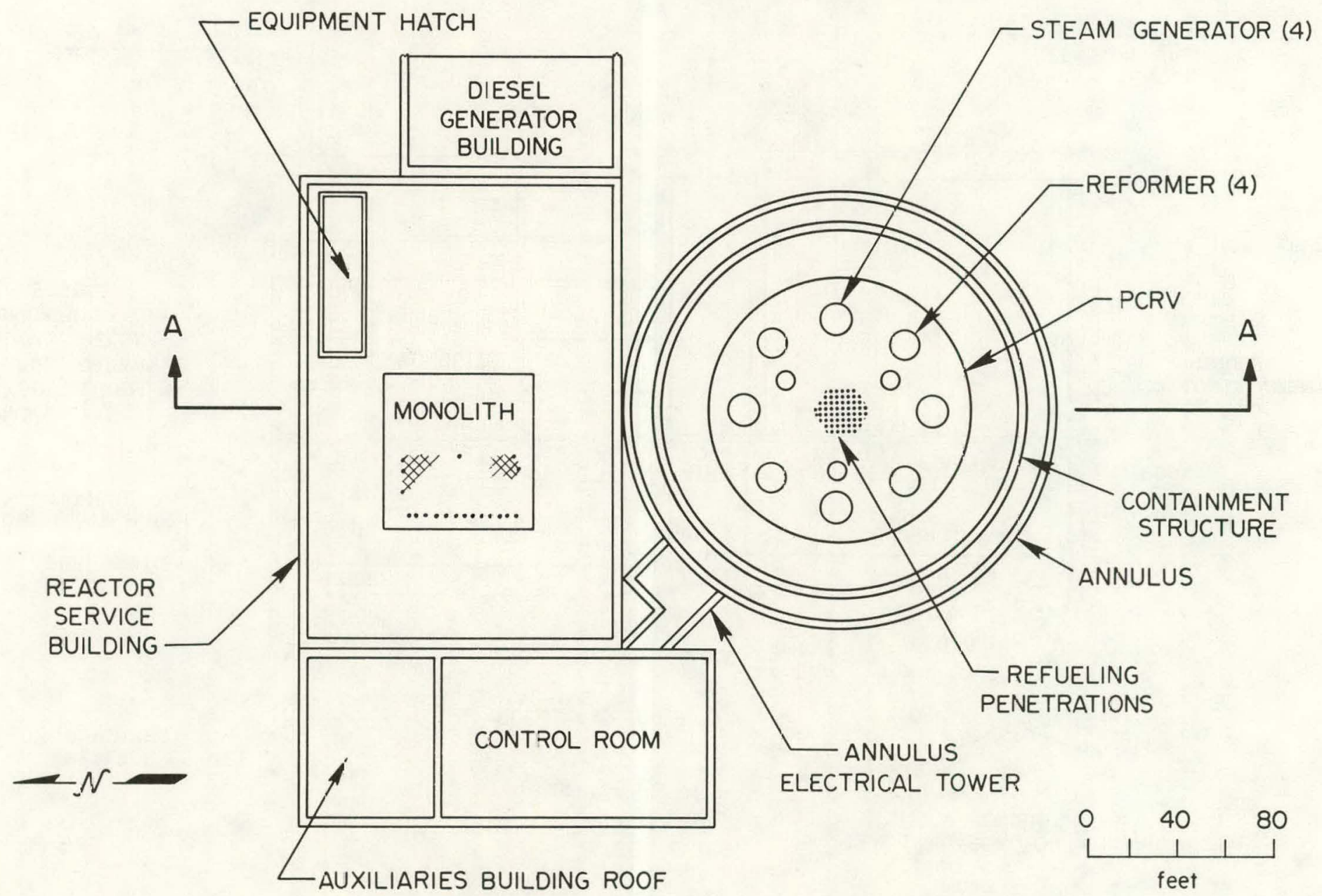

Fig. 16. General arrangement plan (view at elevation $95 \mathrm{ft}-$ 0 in.) - 3000 MW(t) HTGR [0-MW(e)] for process heat (Middletown hypothetical site). 


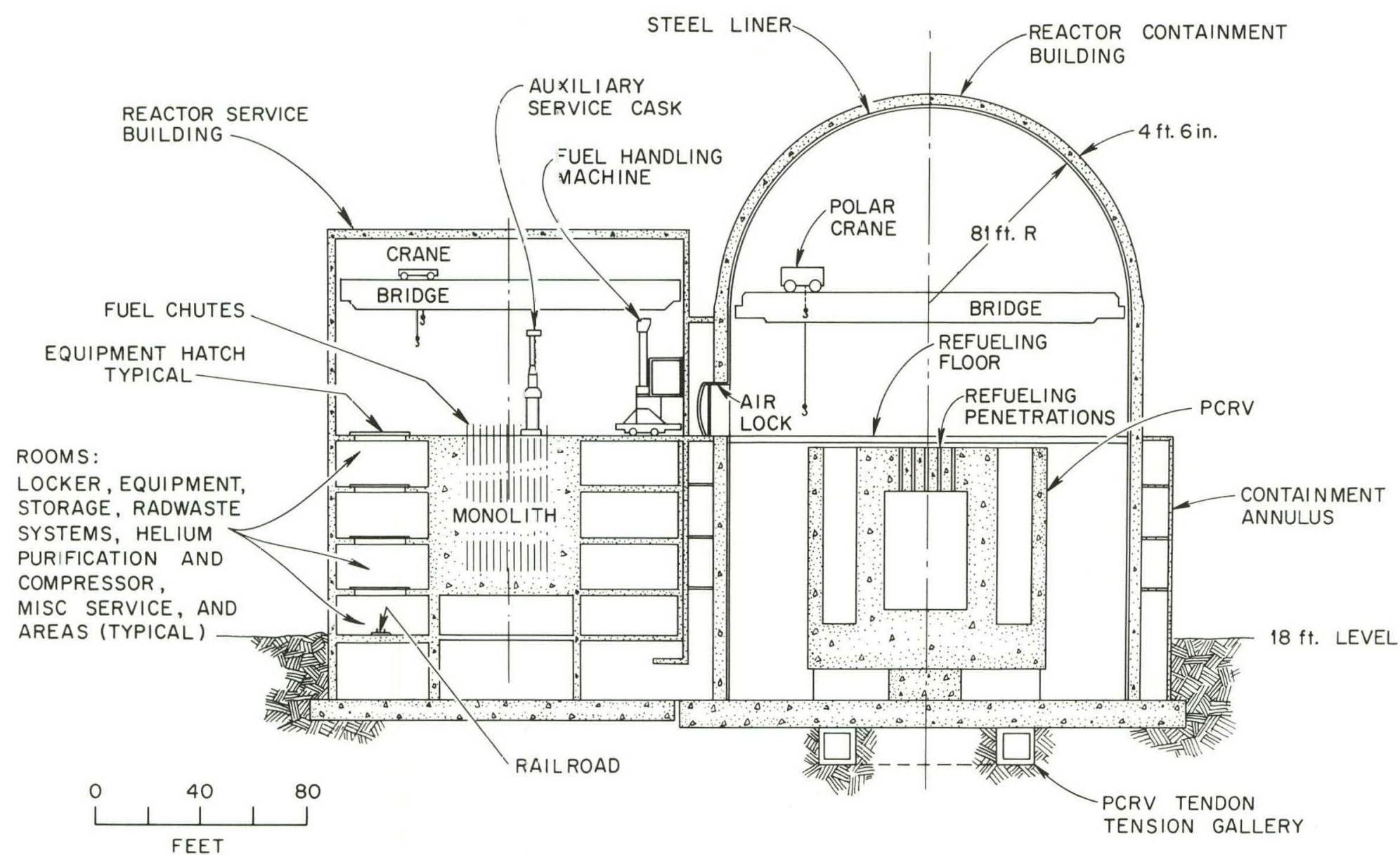

Fig. 17. General arrangement (Sect. AA) - 3000 MW( $t$ ) HTGR [0-MW(e)] for process heat (Middletown hypothetical site). 
Storage space is provided for $40 \%$ of the reactor core, which is appropriate for the 3-year fuel cycle. Because of the more demanding fuel service, it may be desirable to provide storage for the entire core plus a recently discharged batch ( $140 \%$ of core). This option was not estimated.

Major repairs to the steam generators and reformers will be performed offsite. The equipment hatch was enlarged to allow removal of these components by rail to a repair facility.

\section{Account 218A. Control building}

The control building is similar in size and function to the control building for the 1160-MW(e) HTGR. The space allocated in an 1160-MW(e) plant to electrical generation and distribution equipment will be available for process instrumentation.

Account 218C. Administration building

The administration building is the same size as the building for an 1160-MW(e) HTGR single-unit plant. A warehouse and a shop area are included.

\section{Account 218D. Auxiliaries building}

The auxiliaries building houses the auxiliary boilers, water treatment equipment, and associated electrical and instrumentation and control equipment.

Account 222. Main heat transfer and transport systems

Installation of the reformers is added to this account. (Reformer equipment cost is an NSSS cost.)

Account 226. Other reactor plant equipment

A containment inerting system is required to prevent hydrogen explosions that might result from reformer leaks. The cost of this equipment was taken from the GA report. 25

Account 24. Electric plant equipment

The auxiliary power system is comparable to that for a 1160-MW(e) HTGR steam generating station. The safety-related (Class IE) systems are identical. Equipment types in the nuclear process heat plant are similar to those in ref. 21 with the exception of generator related equipment (i.e., switch gear, protective relay panel, and isolated phase bus duct). 
All auxiliary transformers are connected to the offsite power supply (grid) because there is no onsite generation.

The substation and incoming power lines are not included in this estimation.

Account 25. Miscellaneous plant equipment

This account contains essentially the same equipment as in ref. 21 , except that no turbine-generator crane is required. In order to handle a reformer in a shipping cask, the reactor service building crane was increased in size from 100 to 200 tons.

\section{Account 263. Reactor coolant}

This account covers the cost of the initial helium inventory in the reactor, and was not estimated in ref. 1 .

Account 910. Engineering construction management and field supervision

This account is substantially increased relative to ref. 21 because of the recent increases in quality assurance requirements ( 10 CFR 50, Appendix B) and because of anticipated licensing costs for the process heat plant. Quality assurance is assumed to be proportional to the plant size and is estimated to involve a $20 \%$ greater scope. Licensing costs are estimated to be $30 \%$ higher than for an electric power plant of comparable thermal power.

\subsubsection{Intermediate heat transfer loop}

\subsubsection{Summary}

This portion of the study was performed because safety and licensing considerations ${ }^{2}, 3$ may require that an intermediate helium loop (IHL) be inserted between the primary coolant and the process gas. This loop would provide additional isolation between the reactor fission products and the products of the reformer. Although evidence has been found in nuclear explosion experiments which implies that the product gas will not be significantly contaminated, this experience is not directly comparable to the nuclear process heat reactor components. The IHL will reduce the possibility that the public will be exposed to radioactive materials. As a result, a conceptual design was prepared and costs estimated for an intermediate loop. Table 24 shows changes to the costs of the base plant which are required for the installation of an intermediate loop. 
Table 24. Cost adjustments for intermediate loop (July 1974)

\begin{tabular}{|c|c|c|c|c|}
\hline \multirow[b]{2}{*}{ Account } & \multirow[b]{2}{*}{ Description } & \multicolumn{3}{|c|}{ Cost (thousands of dollars) } \\
\hline & & $\begin{array}{l}\text { Equipment } \\
\text { and material }\end{array}$ & Labor & Total \\
\hline 211 & $\begin{array}{l}\text { Yard work } \\
\text { Railroads }\end{array}$ & 29 & 16 & 45 \\
\hline 212D & Intermediate loop building & 3,091 & 3,502 & 6,593 \\
\hline $218 \mathrm{E}$ & Helium storage building & 30 & 39 & 69 \\
\hline 221 & Reactor equipment & -513 & -823 & $-1,336$ \\
\hline $222 B$ & $\begin{array}{l}\text { Intermediate heat transfer loop } \\
\text { Intermediate heat exchanger } \\
\text { Steam generators } \\
\text { Reformers } \\
\text { Circulators } \\
\text { Pressure vessels } \\
\text { Piping and valves }\end{array}$ & 72,626 & 10,186 & 82,812 \\
\hline 226 & $\begin{array}{l}\text { Other reactor plant equipment } \\
\text { Containment inerting equipment } \\
\text { Helium storage and makeup } \\
\text { Helium purification systems }\end{array}$ & 24 & -17 & 7 \\
\hline 227 & Instrumentation and control & 628 & 111 & 739 \\
\hline 241 & Switch gear & 113 & 23 & 136 \\
\hline 245 & $\begin{array}{l}\text { Electrical structures and } \\
\text { wiring containers }\end{array}$ & 45 & 197 & 242 \\
\hline 246 & Power and control wiring & 25 & 47 & 72 \\
\hline 251 & $\begin{array}{l}\text { Transportation and lifting } \\
\text { equipment }\end{array}$ & 310 & 90 & 400 \\
\hline 264 & $\begin{array}{l}\text { Intermediate coolant inventory } \\
\text { (including initial storage) }\end{array}$ & 89 & -- & 89 \\
\hline 269 & IHL initial catalyst filling & 307 & 20 & 327 \\
\hline 910 & $\begin{array}{l}\text { Engineering services and } \\
\text { construction management }\end{array}$ & -- & 15,463 & 15,463 \\
\hline 913 & Construction services & 1,394 & 1,198 & 2,592 \\
\hline 991 & Operator training & 322 & - & 322 \\
\hline 994 & Miscellaneous costs & 1,159 & -- & 1,159 \\
\hline & Total & 79,679 & 30,052 & 109,731 \\
\hline
\end{tabular}

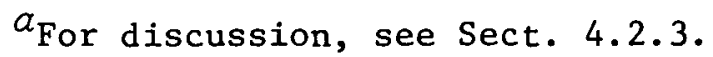

The nuclear reactor portion of the plant is essentially unchanged by the addition of an intermediate loop. The peak coolant temperature is about $1800^{\circ} \mathrm{F}$ in each case. When the IHL is added, the reformers are removed from the PCRV and are replaced by helium-to-helium heat exchangers. As shown in Fig. 18, the IHL directs helium flow from the PCRV and the containment building to the two intermediate loop buildings and then through 


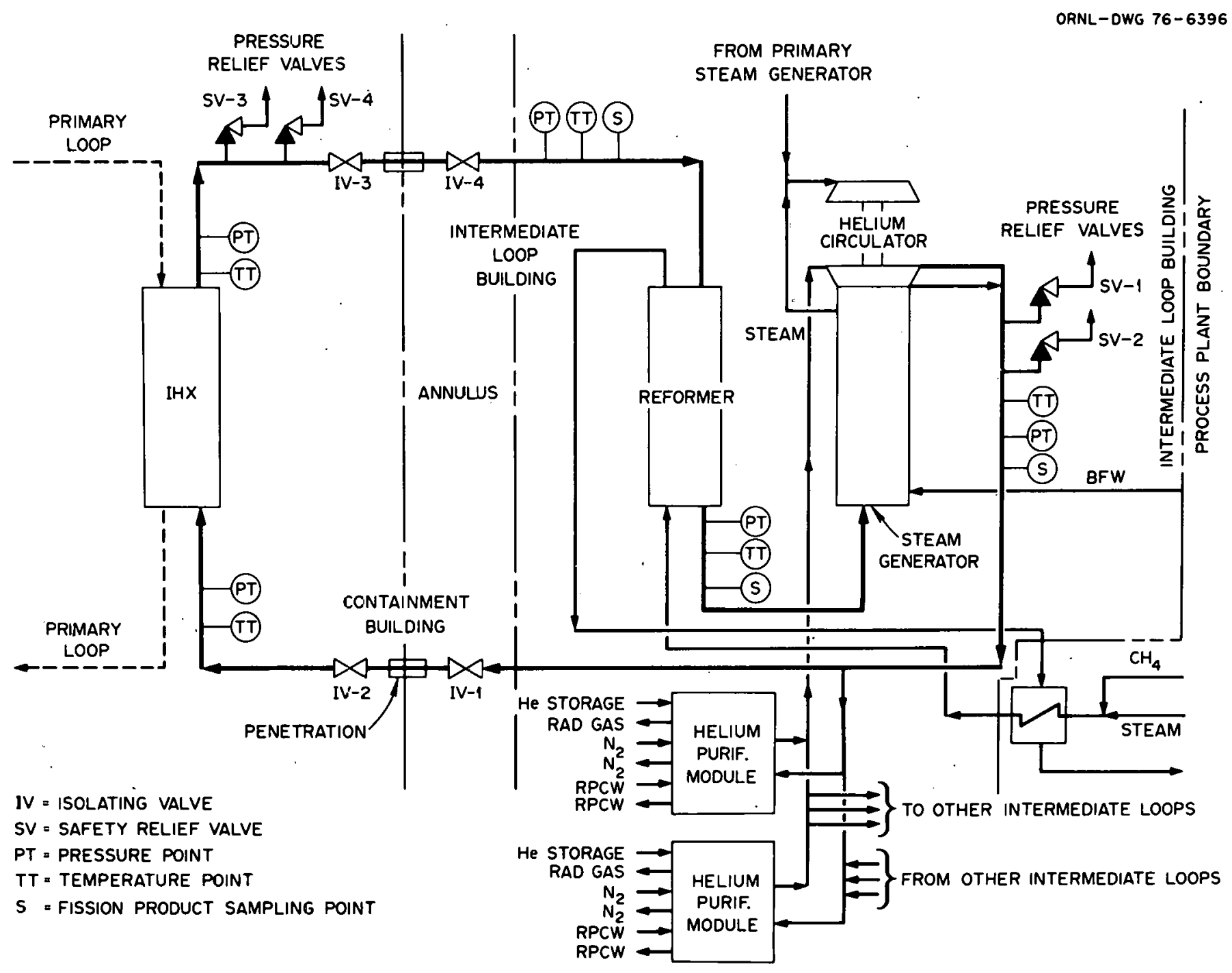

Fig. 18. Schematic diagram intermediate helium loop. 
the reformers, secondary steam generators, steam driven circulators, and finally back to the PCRV. In conceptual design, the plant has four parallel intermediate loops.

The helium is transferred through internally insulated pipes. This insulation is similar to the insulation described in ref. 1 for the hot ducts within the PCRV. Pressure vessels are provided in the intermediate loop buildings for the reformers, steam generators, and circulators. A redundant helium purification system assures that the loop is free of any fission products that may have leaked or migrated through the heat exchangers from the primary coolant loop.

The two intermediate loop buildings are located adjacent to the containment building annulus, as shown in Fig. 19. Details of the buildings are shown in Figs. 20 and 21.

\subsubsection{Intermediate loop conceptual design}

The following paragraphs describe the conceptual design of the intermediate loop.

Account 211. Yard work

Railroad tracks are extended to provide access to both intermediate helium loop buildings in order to facilitate installation, removal, and transport of equipment in loop buildings, such as the reformer, the steam generator, the helium circulator, reformer feed effluent heat exchanger, and other components. Approximately $1100 \mathrm{ft}$ of additional railroad tracks are provided from the base plant spur to the intermediate loop buildings.

Account 212D. Intermediate loop buildings

The two intermediate loop buildings are located adjacent to, and at diametrically opposing positions of, the containment annulus. Each building houses two reformers, two steam generators, and intermediate loop support equipment. Although they are considered part of the containment building, they are structurally independent. Each is $125 \mathrm{ft} \times 95 \mathrm{ft} \times 140 \mathrm{ft}$ high. Both have structural steel frames supported on foundation mats and are enclosed by insulated metal siding, a metal roof deck, and built-up roofing. The below-grade portion of the structures is a basement mat floor with concrete walls up to grade.

Above grade, the buildings are framed with structural steel, and interior structural steel is provided to support the reformers, steam generators, helium circulators, pressure vessels, and the reformer feed effluent heat exchangers housed in the buildings. The integrated heavy interior steel framing is also used to support the intermediate helium loop and associated piping. The interior walls are concrete block, and the floors are 


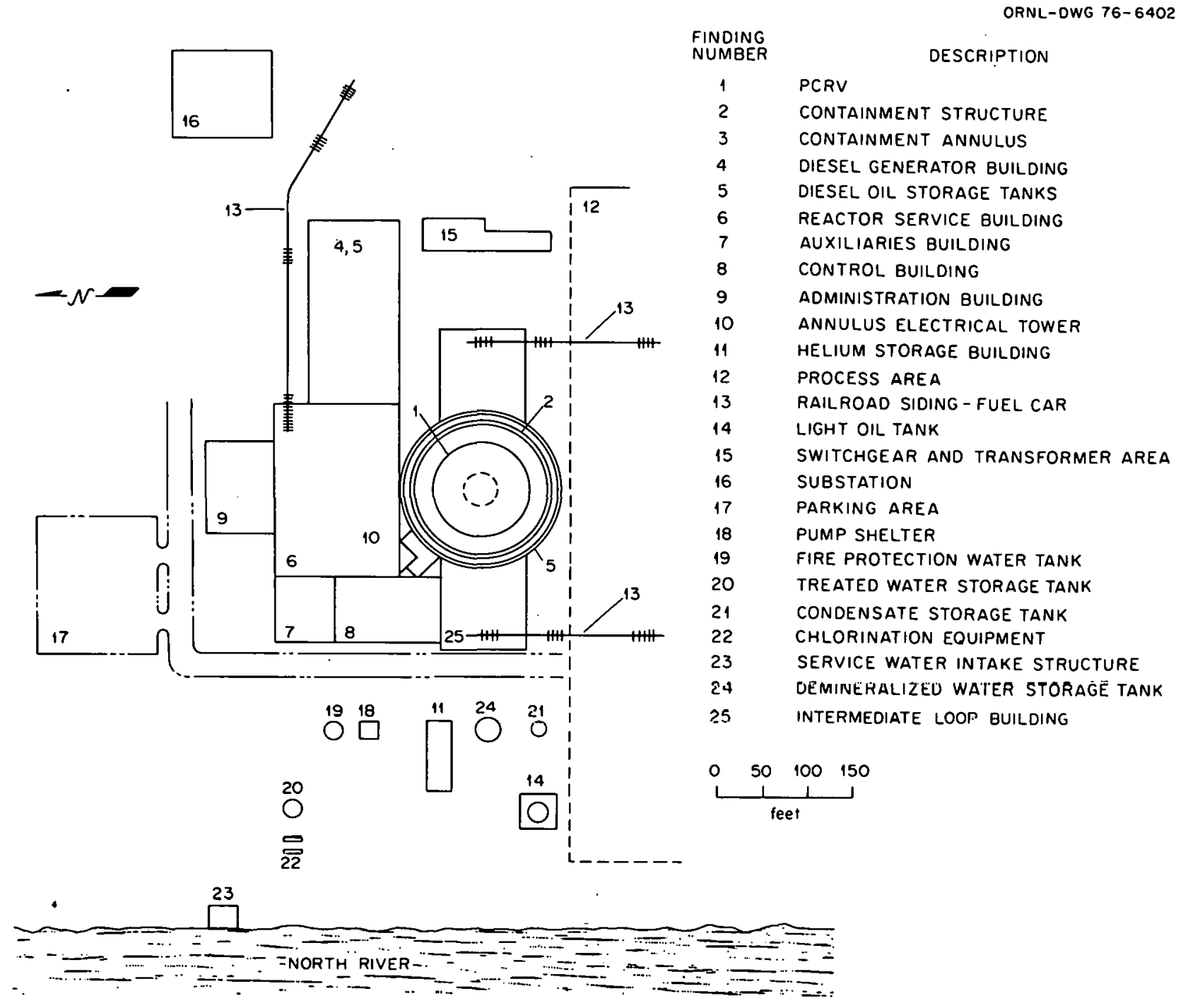

Fig. 19. Plot plan - $3000 \mathrm{MW}(\mathrm{t})$ HTGR [0-MW(e)] intermediate loop building (Middletown hypothetical site). 


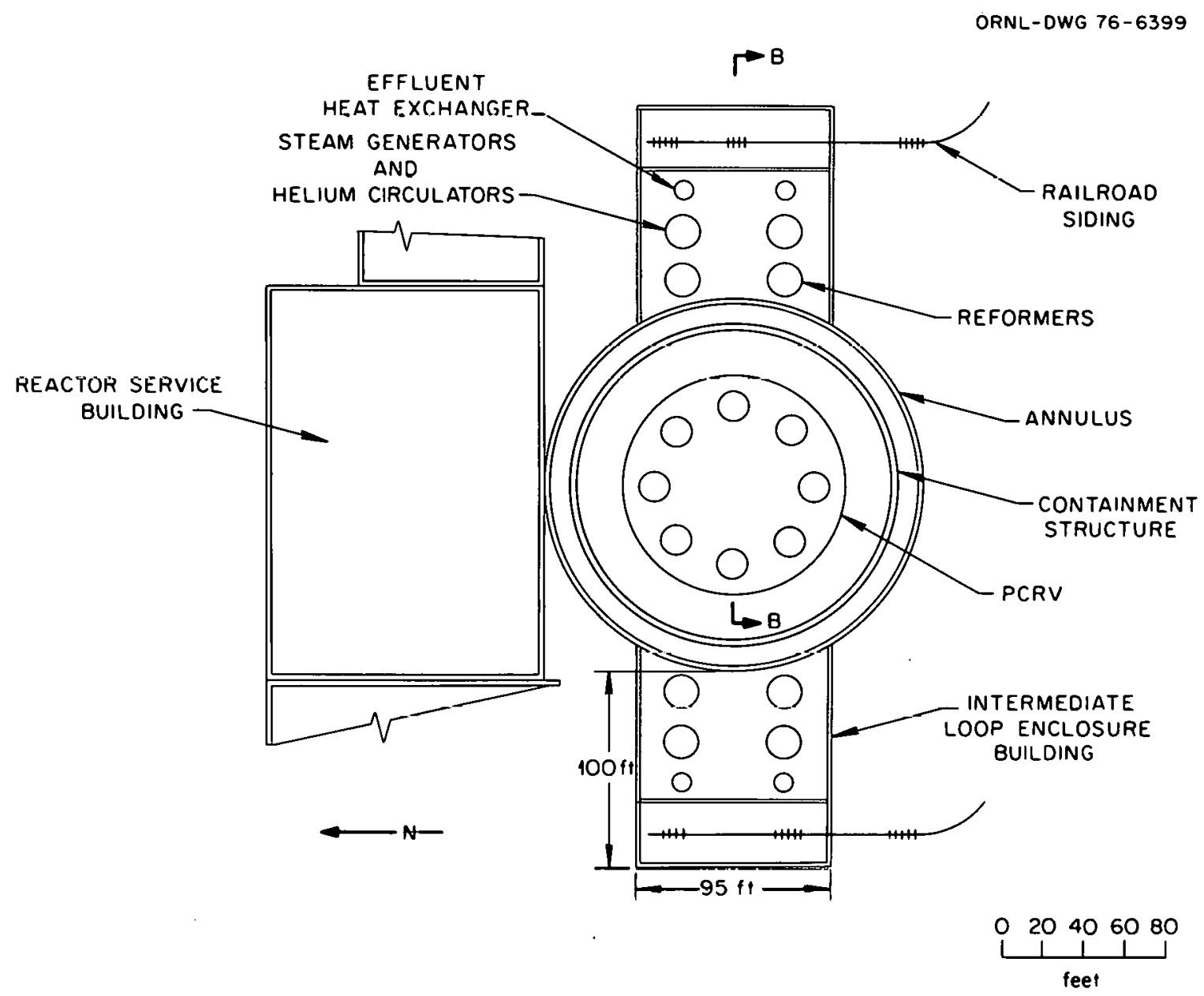

Fig. 20. General arrangement plan (view at elevation $18 \mathrm{ft}-$ 0 in.) - $3000 \mathrm{MW}(\mathrm{t})$ HTGR [0-MW(e)] intermediate loop building (Middletown hypothetical stte). 


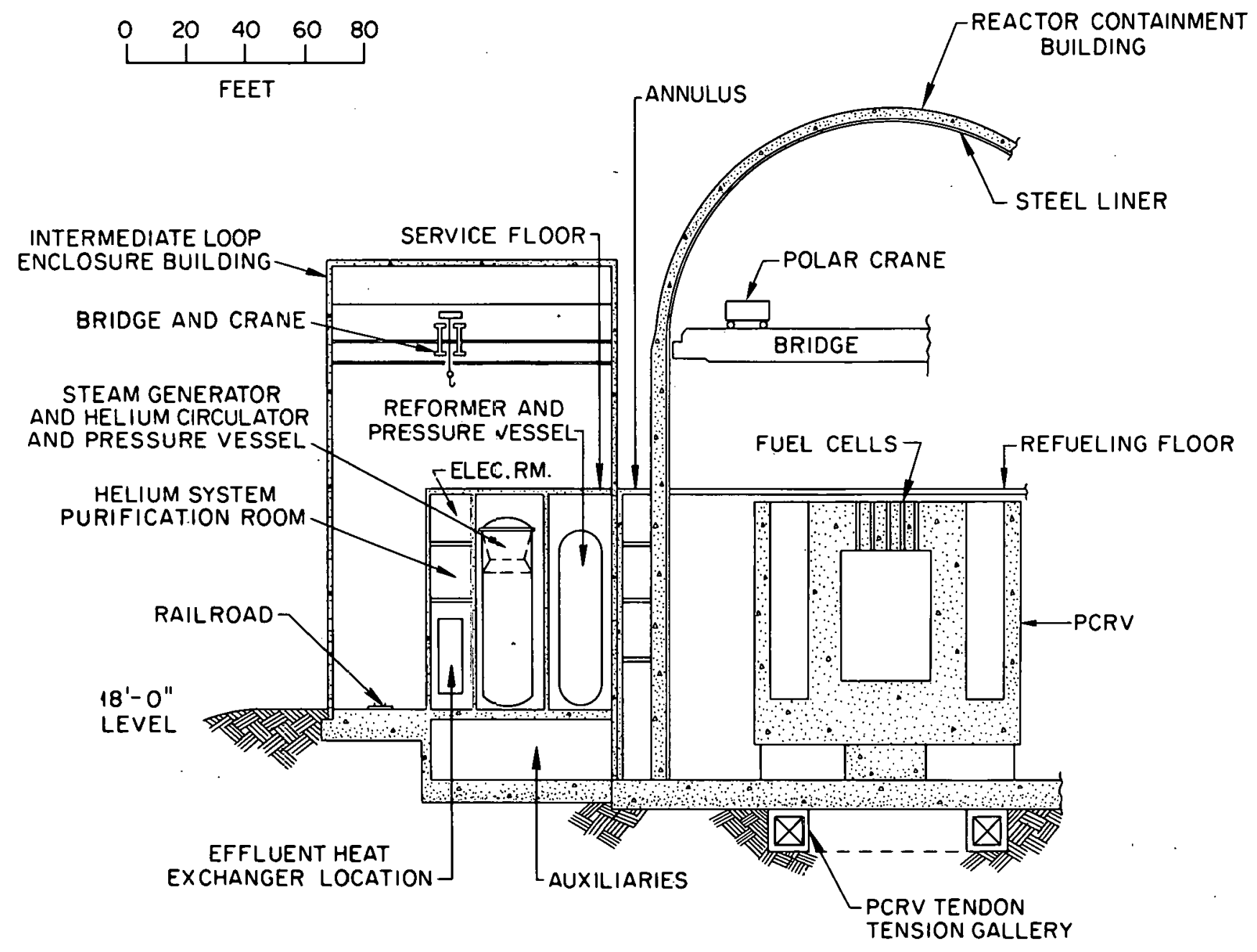

Fig. 21. General arzangement (Sect. BB) - $3000 \mathrm{MW}(t)$ HTGR

[0-MW(e)] intermediate loop building (Middletown hypothetical site). 
concrete slabs supported on steel framing. The building also houses helium purification equipment, switchgear, and intermediate loop instrumentation.

Railroad bays for transport of components are located at the ends of the buildings farthest from the annulus. Overhead traveling cranes ( 85 and 15 ton) located at the top of the buildings serve the railroad bays as well as the operating floor. The buildings are shown in Figs. 20 and 21 .

\section{Account 218E. Helium storage building}

The helium storage facilities for the intermediate helium loop are housed in an extension to the primary loop helium storage building. The enlarged size of the helium storage building was designed to accommodate required added storage capacity. Labor material costs were scaled from the helium storage buildings' costs in ref. 21 .

Account 221. Reactor equipment

The steam generators and intermediate heat exchangers for the primary loop are smaller than the steam generators and reformers in the base plant. As a result, the sizes of the PCRV and the containment building are slightly reduced.

Account 222B. Intermediate heat transfer loop

The intermediate heat exchanger is described and estimated in ref. 1. Installation costs are assumed to be equivalent to the reformer installation costs for the base plant.

The steam generators for the intermediate loop are similar in material and design, but smaller than the steam generators in the base plant. The steam generator costs were assumed to be proportional to the surface area of the equipment.

The reformers are similar to those described in ref. 1 for the $1600^{\circ} \mathrm{F}$ case but larger in diameter to accommodate the larger catalyst surface area that is required at the lower operating temperature of $1400^{\circ} \mathrm{F}$. The equipment cost is taken from the GA report. 25 Labor and material rosts are assumed to he no different than the base plant.

The intermediate loop circulators are described in ref. 1. Equipment costs are also taken from the GA report. 25 Labor and material costs are assumed the same as the circulators for the base plant.

Pressure vessels are used in the intermediate loop to house the reformer and the steam generator-circulator assemblies. They provide strength to resist the hoop and axial stresses that the PCRV provides in the base plant. Costs of the pressure vessels are calculated from a sample design. 
Intermediate loop piping is similar to that described for PCRV hot duct piping. ${ }^{1}$ The 2-1/4 Cr-1 Mo (Type A-335 P11) pipe is suitable for the application and is used as the reference design. Costs for piping are computed on a unit-cost basis. The internal insulation methods (materials and costs for the conceptual design) are described in ref. 1 . It has been found that exterior insulation is unnecessary. A cross section of the hot leg is shown in Fig. 22.

In the conceptual design, 16 isolation valves are necessary. The conceptual design of the valves uses a valve-body outer material of $2-1 / 4$ $\mathrm{Cr}-1$ Mo (Type A-217 WC-6) and an inner material of Incoloy 800 , with compatible seat and stem materials and insulation similar to that used in the piping design. Costs are derived from valve cost data for valves in similar applications.

Hanger and support costs are based on current cost data, as are expansion joints and penetrations.

Account 226. Other reactor plant equipment

Containment inerting equipment. Because the reformers are not located in the containment building, hydrogen leakage does not endanger the integrity of safety-related equipment. The cost of the containment inerting equipment is thus deleted from the account. The equipment cost is taken from the GA report. 25

Helizm storage and makeup. The helium storage capacity is assumed equal to the helium contained in the entire intermediate loop. Costs are based on this capacity although the helium storage and makeup system is housed in a common storage building; this system is completely independent of the primary loop storage and makeup system.

Helizm pumification systems. The helium purification systems are similar to those described in ref. 21. The equipment, however, is assumed to be smaller than comparable primary loop equipment because the fission product concentration will be, at most, equal to one-tenth of the concentration of the primary loop.

There are two independent helium purification trains that tie into a single hydrogen removal module. Waste products are vented to the primary loop radioactive waste systems.

Account 227. Instrumentation and control

Instrumentation and control is assumed similar to the ref. 21 primary loop controls. 
ORNL-OWG $76-6392$

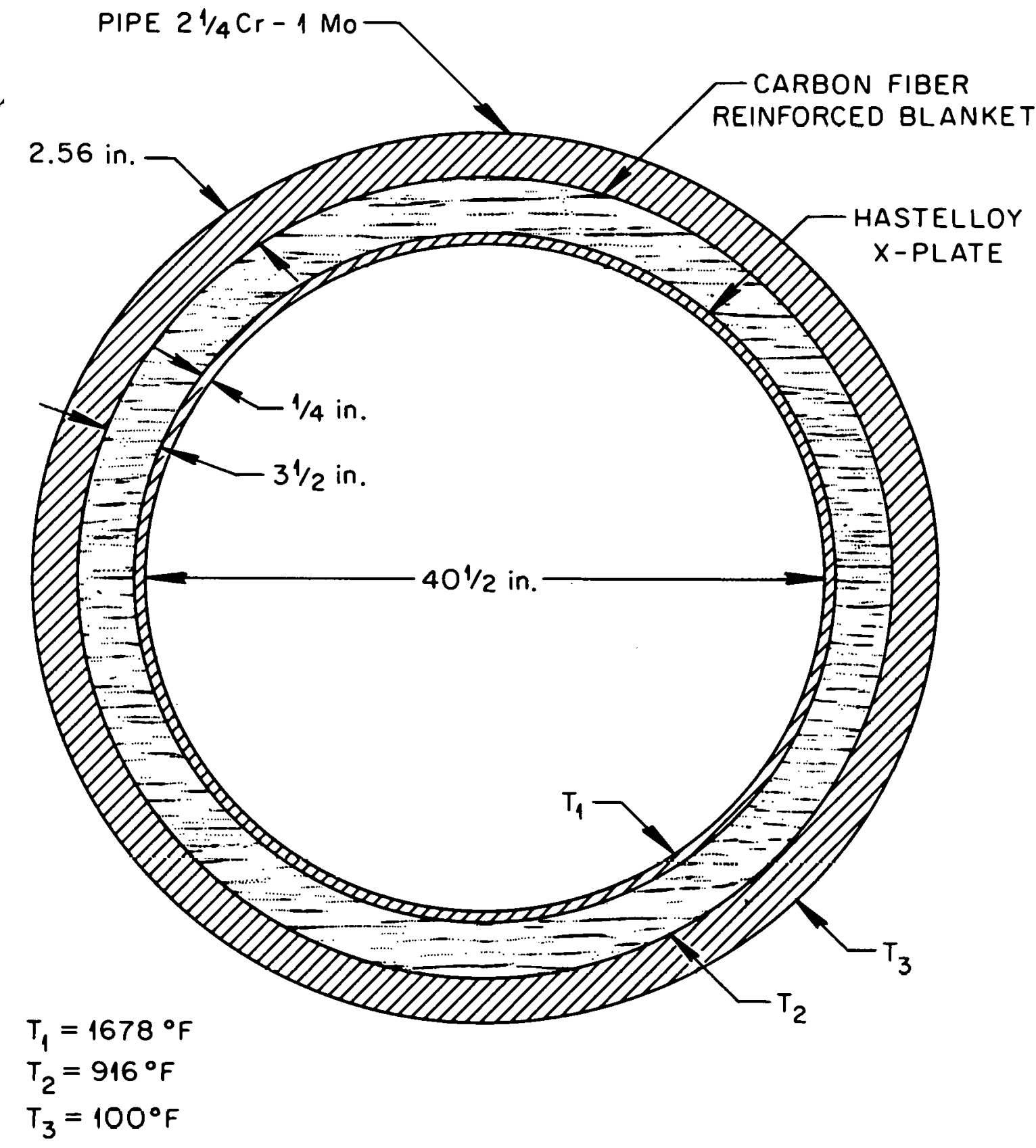

Fig. 22. Cross section of the intermediate loop piping. 


\section{Account 241. Switchgear}

It is assumed that four $5-\mathrm{kV}$ feeder breakers and four $480-\mathrm{V}$ motor control centers are needed for the intermediate loop power train. Costs are based on current data.

Account 245. Electrical structure and wiring containers

Costs for cable trays and conduit for the intermediate loop equipment are based on current unit-cost data.

\section{Account 246. Power and control wiring}

Costs for low-voltage (under $5 \mathrm{kV}$ ) and instrument cables are based on estimated quantities and current unit costs.

Account 251. Transportation and lifting equipment

An 85 and 15 ton overhead traveling crane is required in each intermediate loop building for removal of reformers and steam generators.

Account 264. Intermediate coolant inventory

The initial helium inventory is assumed equal to the intermediate loop working inventory plus initial storage equal to the working inventory.

Accounts 91 and 99 . Indirect costs

Accounts numbered 91 and 99 are assumed to be proportional to the direct total cost of the system.

\subsubsection{Power generation}

\subsubsection{Summary}

The base plant is designed to operate entirely from offsite power with no internal generation (other than emergency) in order to provide a more direct comparison of the costs of supplying process heat.

Additional costs of generating electricity onsite are estimated for two cases. In one, generation is sufficient for internal use on1y, whereas in the other there is excess generation to permit some sale of power. These costs are summarized in Tables 25 and 26. The first case is for the generation of $40 \mathrm{MW}(\mathrm{e})$, which is enough to supply power for the nuclear process heat plant with about $30 \mathrm{MW}(\mathrm{e})$ remaining for the chemical 
Table 25. Cost adjustments for power generation ${ }^{a}$ (July 1974) [40-MW(e) case]

\begin{tabular}{clrrr} 
& & \multicolumn{2}{c}{ Cost (thousands of dollars) } \\
\cline { 3 - 5 } Account & \multicolumn{1}{c}{ Description } & $\begin{array}{c}\text { Equipment and } \\
\text { material }\end{array}$ & Labor & Total \\
\hline 213 & Turbine-generator building & 140 & 235 & 375 \\
231 & Turbine-generator & 2434 & 266 & 2700 \\
241 & Switchgear & 65 & 10 & 75 \\
242 & Station service equipment & -30 & 0 & -30 \\
246 & Power and control wiring & 201 & 90 & 291 \\
251 & Transportation and 1ifting & 73 & 21 & 94 \\
91 & Engineering and construction & & 886 & 886 \\
99 & Other costs & 79 & 1508 & 4470 \\
\hline
\end{tabular}

process plant. The other case is arbitrarily chosen as $100 \mathrm{MW}(\mathrm{e})$, which is sufficient to supply the nuclear and chemical plant needs, with about $60 \mathrm{MW}(\mathrm{e})$ remaining to sell. Incremental generation costs in this range, from 40 to $100 \mathrm{MW}(\mathrm{e})$, are approximately proportional to the incremental power.

The puwer turbine plant io eesentially an additional piece of equipment which draws steam from the main steam supply and exhausts it back to the chemical plant. Figures 23 and 24 show the inlet, outlet, and main steam conditions for each case. The changes in the plant systems to accommodate power generation all occur in the chemical process plant rather than the nuclear plant. Figures 25 and 26 show the location of the turbine building on the plant site.

The chemical plant is expected to supply steam to the turbine and to use the turbine effluent. Support systems necessary for the operation of the turbine are included in this estimate. Because the conditions and equipment of the chemical plant are not yet defined, costs are not estimated for circulating water and water purification systems, condensate and feedwater systems, water intake and outlet structures, and steam piping. Thus, the total cost of generating electricity is not included in these estimates, but the additional systems costs will depend on the chemical plant conceptual design. 
Table 26. Cost adjustments for power generation ${ }^{a}$ (Ju1y 1974) [100 MW(e)-case]

\begin{tabular}{|c|c|c|c|c|}
\hline \multirow[b]{2}{*}{ Account } & \multirow[b]{2}{*}{ Description } & \multicolumn{3}{|c|}{ Cost (thousands of dollars) } \\
\hline & & $\begin{array}{l}\text { Equipment and } \\
\text { material }\end{array}$ & Labor & Total \\
\hline 213 & Turbine-generator building & 262 & 441 & 703 \\
\hline 231 & Turbine-generator & 4854 & 534 & 5388 \\
\hline 241 & Switchgear & 73 & 10 & 83 \\
\hline 242 & Station service equipment & -30 & 0 & -30 \\
\hline 243 & Switchboards & 71 & 14 & 85 \\
\hline 246 & Power and control wiring & 265 & 118 & 383 \\
\hline 251 & $\begin{array}{l}\text { Transportation and lifting } \\
\text { equipment }\end{array}$ & 136 & 35 & 171 \\
\hline 91 & Engineering and construction & & 1726 & 1726 \\
\hline 99 & Other costs & 158 & & 158 \\
\hline \multicolumn{2}{|c|}{ Total } & 5789 & 2878 & 8667 \\
\hline
\end{tabular}

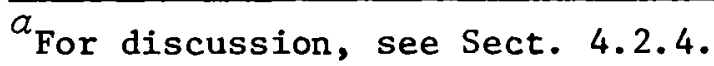

\subsubsection{Power generation plant conceptual design}

The systems and structures required for the power generation are described below by account.

\section{Account 213. Turbine-generator building}

This building is similar in design and construction to the turbinegenerator building described in ref. 24, with the exception that upper floors, walls, and platforms are not required for condensate and feedwater systems, which will be located in the chemical plant.

\section{Account 231. Turbine-generator}

The turbine-generator account includes the turbine-generator, foundation mat, $\mathrm{CO}_{2}$ purge gas system, hydrogen cooling gas system, and the lubricating oil system. 
ORNL-OWG 76-6393

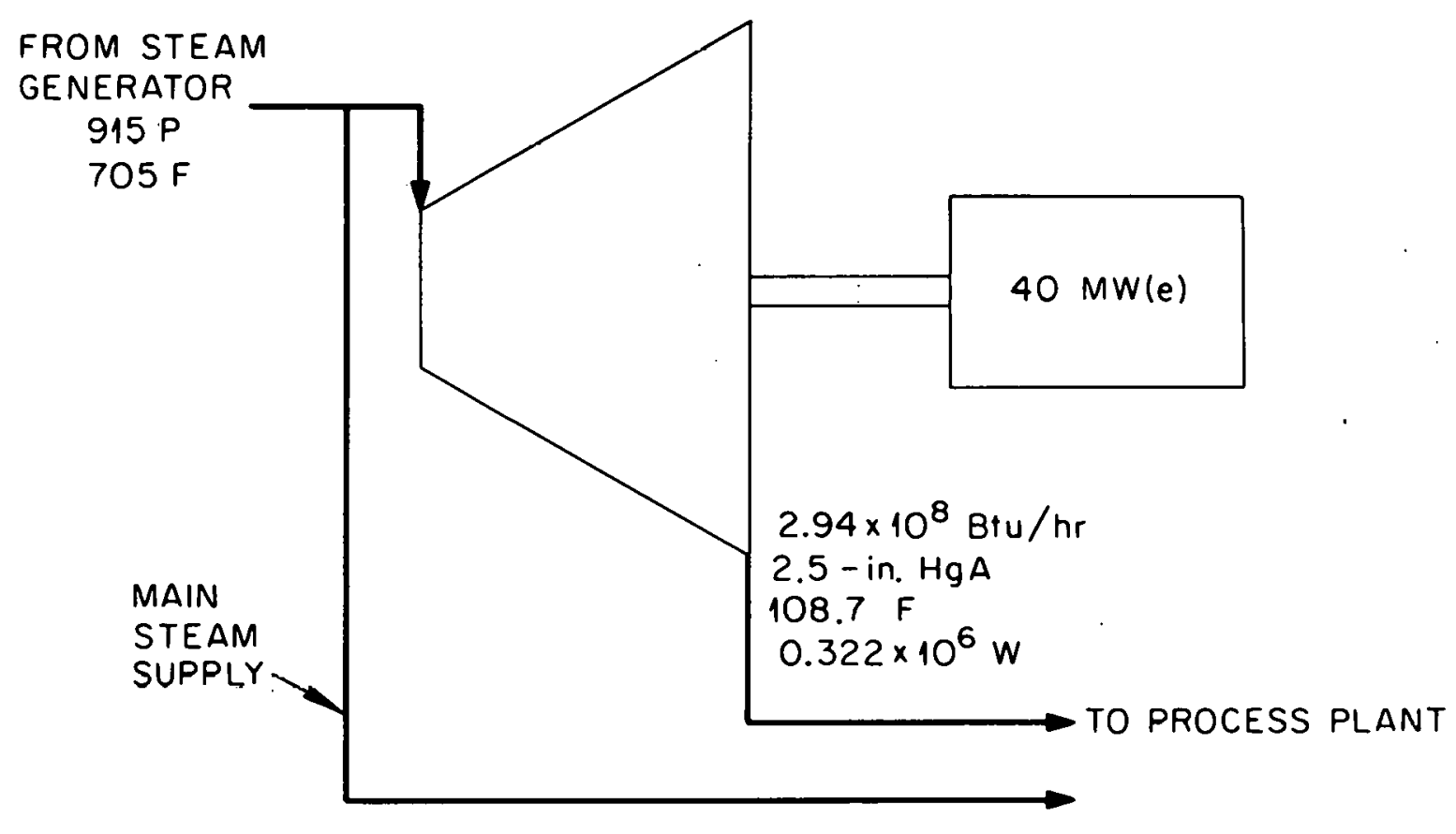

Fig. 23. Heat balance diagram [40-MW(e) turbine]. 
ORNL-DWG 76-6394

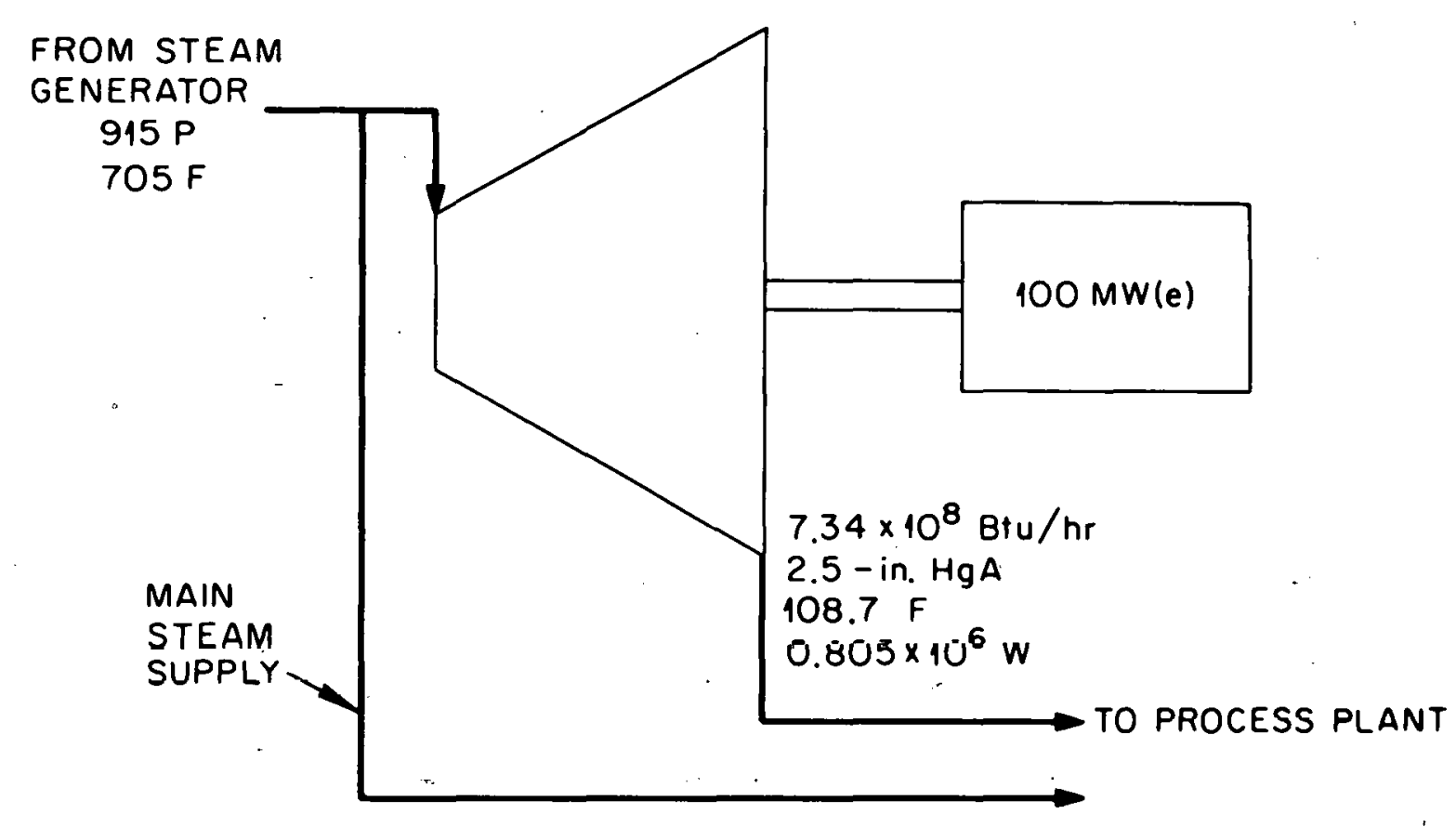

Fig. 24. Heat balance diagram [100-MW(e) turbine]. 


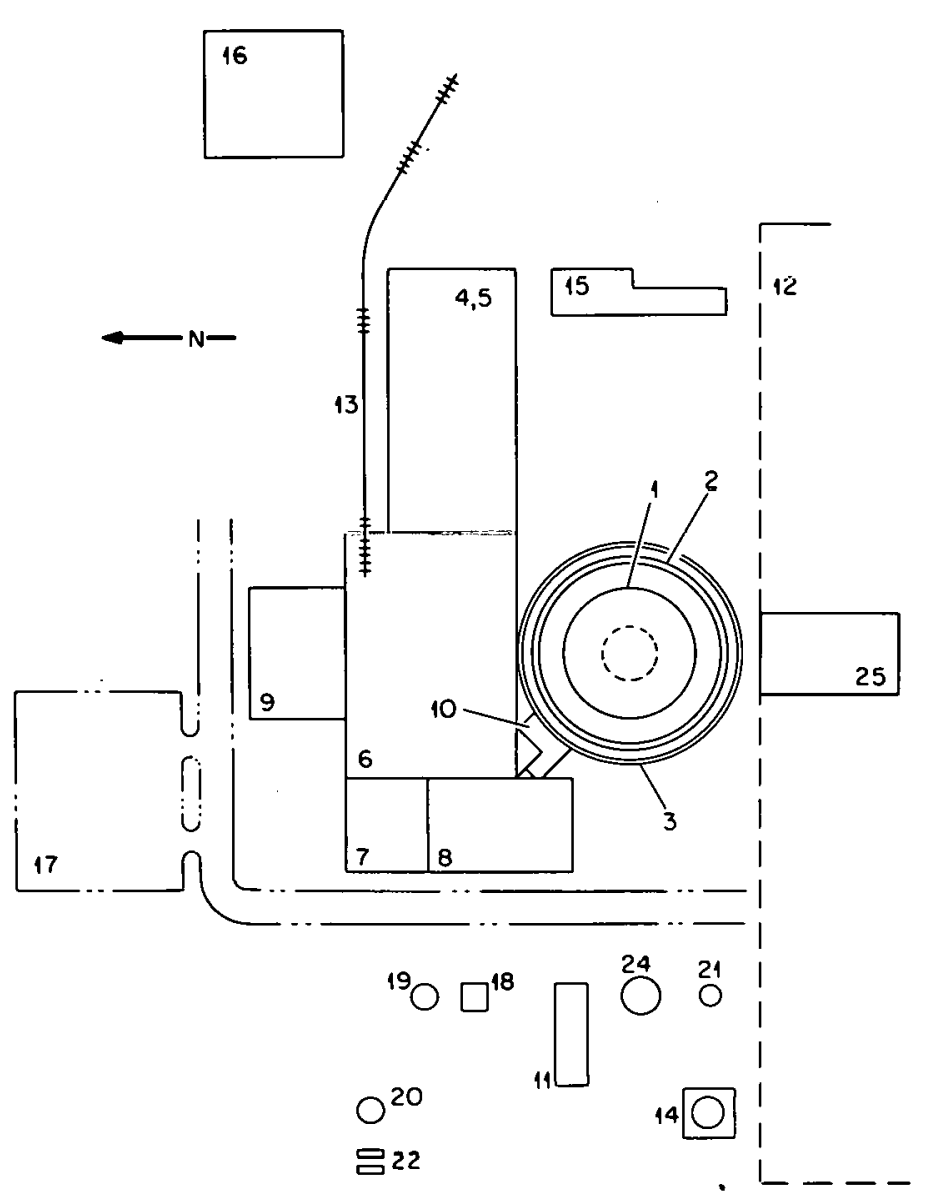

FINDING NUMBER

4

2

3

4

5

6

7

8

9

10

11

12
13

14

15
16

17

18

19

20

21

22

23

24

25
DESCRIPTION

PCRV

CONTAINMENT STRUCTURE CONTAINMENT ANNULUS DIESEL GENERATOR BUILOING DIESEL OIL STORAGE TANKS REACTOR SERVICE BUILDING AUXILIARIES BUILDING CONTROL BUILOING ADMINISTRATION BUILDING ANNULUS ELECTRICAL TOWER HELIUM STORAGE BUILOING PROCESS AREA RAILROAD SIDING - FUEL CAR LIGHT OIL TANK SWITCHGEAR AND TRANSFORMER AREA SUBSTATION PARKING AREA PUMP SHELTER FIRE PROTECTION WATER TANK TREATED WATER STORAGE TANK CONDENSATE STORAGE TANK CHLORINATION EQUIPMENT SERVICE WATER INTAKE STRUCTURE DEMINERALIZED WATER STORAGE TANK TURBINE BUILDING

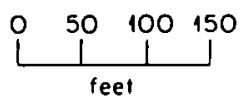

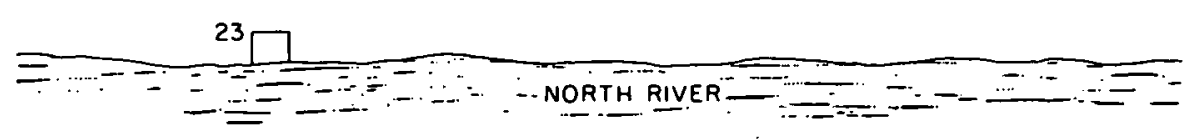

Fig. 25. Plot plan - $3000 \mathrm{MW}(t)$ HTGR [0-MW(e)] for process heat with turbine (Middletown hypothetical site). 


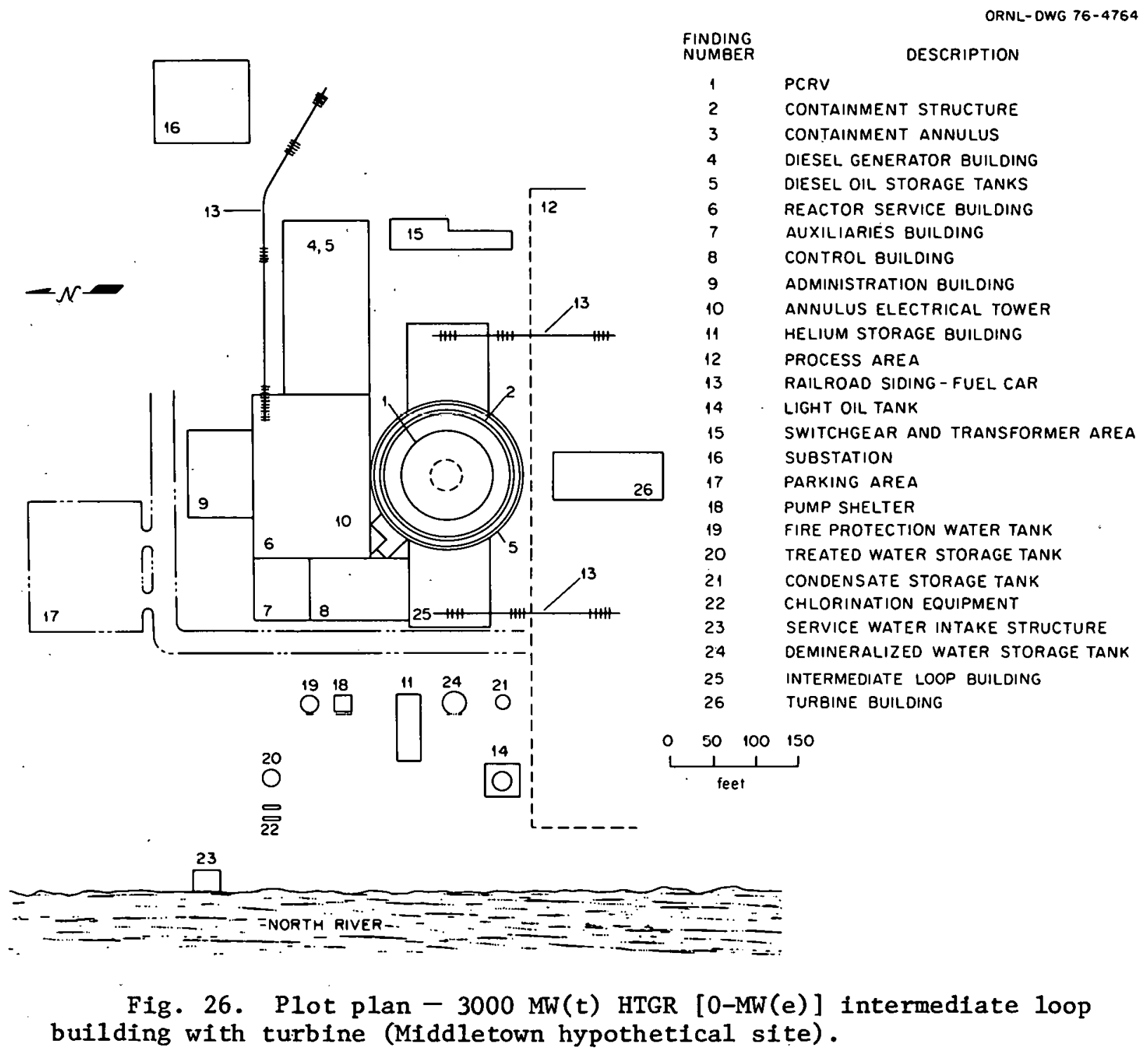


Account 24. Electric plant equipment

This account includes the generator switchgear and the generator bus duct to the main plant switchgear. The 100-MW(e) case also includes a generator protective relay panel.

Account 251. Transportation and lifting equipment

The turbine building is supplied with a 40-ton crane for the 40-MW(e) case and a 75-ton crane for the 100-MW(e) case.

Accounts 91 and 99. Indirect costs

Accounts 91 and 99 are proportional to the total plant cost.

\subsubsection{Operating and maintenance}

The annual operating and maintenance (O\&M) charges for the nuclear process heat (NPH) plant estimated by $\mathrm{GA}^{\mathrm{l}}$ are in general agreement with the O\&M costs for similar sized power reactor plants. Table 27 shows the O\&M costs estimated by UE\&C for plants with and without an intermediate loop and with and without power generation.

The GA's fixed maintenance charges seem unusually low when compared with power reactors. Fixed maintenance is defined as mechanical equipment servicing and building maintenance. Power industry experience for these costs ranges between $\$ 1.5$ and $\$ 2.5$ million per year. The majortty of this expense is incurred in heat exchanger maintenance.

The base NPH plant has four steam generators and four reformers which represent a total of two more heat exchangers than in an 1160-MW(e) HTGR. When the intermediate loop is added, there are eight steam generators, four reformers, and four intermediate heat exchangers which represent ten more heat exchangers than in a comparable electric plant. In addition, the reformers and intermediate heat exchangers operate at higher temperatures than standard steam generators, and are thus expected to require more maintenance. Additional maintenance will be necessary if the systems are not kept free of dust and impurities, which cause hot spots in the heat exchangers.

The fixed maintenance costs for the NPH plant are thus likely to be about $\$ 1.5$ to $\$ 2.5$ million per year, which is in the same range as for a comparable power plant. These costs will be increased by about 1.0 to 1.5 million dollars if an intermediate loop is added. 
Table 27. Annual operating and maintenance costs (thousands of dollars) (July 1974)

\begin{tabular}{|c|c|c|c|c|c|c|c|}
\hline Item & Base plant & $\begin{array}{r}\text { Base } \\
\text { Interme }\end{array}$ & $\begin{array}{l}\text { e plant } t \\
\text { ediate loop }\end{array}$ & $\begin{array}{c}\text { Base } \\
\text { power }\end{array}$ & $\begin{array}{l}\text { plant }+ \\
\text { generation }\end{array}$ & $\begin{array}{l}\text { Bas } \\
\text { power } \\
\text { interm }\end{array}$ & $\begin{array}{l}\text { e plant }+ \\
\text { generation }+ \\
\text { ediate loop }\end{array}$ \\
\hline Station staffing & 1800 & \multicolumn{2}{|r|}{1960} & \multicolumn{2}{|r|}{1880} & \multicolumn{2}{|r|}{2040} \\
\hline Fixed maintenance & 1500 to 2500 . & 2500 & to 4000 & 1500 & to 2500 & 2500 & to 4000 \\
\hline $\begin{array}{l}\text { Variable maintenance (including } \\
\text { catalyst costs) }\end{array}$ & 960 & \multicolumn{2}{|r|}{1320} & \multicolumn{2}{|r|}{960} & \multicolumn{2}{|r|}{1320} \\
\hline Supplies and expenses & 140 to 300 & 160 & to 820 & \multicolumn{2}{|c|}{150 to 810} & \multicolumn{2}{|c|}{170 to 830} \\
\hline Coolant makeup purchase & 65 & \multicolumn{2}{|r|}{125} & \multicolumn{2}{|r|}{65} & \multicolumn{2}{|r|}{125} \\
\hline Electric power purchased & 2080 & \multicolumn{2}{|r|}{2080} & \multicolumn{2}{|r|}{0} & \multicolumn{2}{|r|}{0} \\
\hline Insurance & 390 & \multicolumn{2}{|r|}{390} & \multicolumn{2}{|r|}{390} & \multicolumn{2}{|r|}{390} \\
\hline Annual license fee & 200 & \multicolumn{2}{|r|}{200} & \multicolumn{2}{|r|}{200} & \multicolumn{2}{|r|}{200} \\
\hline Administrative and general & 260 & \multicolumn{2}{|r|}{260} & \multicolumn{2}{|r|}{260} & \multicolumn{2}{|r|}{260} \\
\hline Total & 7395 to 9055 & 8995 & to 11,155 & 5405 & to 7065 & 7005 & to 9165 \\
\hline
\end{tabular}

This plant is the basis for comparison with the GE and WANL plants. 


\subsubsection{Comparison plant}

The comparison plant is the combination of the base plant (Sect. 4.2.2) and the intermediate loop (Sect. 4.2.3). It is the basis for comparing the GA/UE\&C conceptual design and cost estimate with the estimates provided by $G E$ and WANL. Section 4.4 compares these estimates.

As shown in Fig. 19, the comparison plant is essentially the same as the base plant, except that additional facilities have been added to house and service the intermediate loop. Table 28 combines the costs that will be compared with the other estimates.

\subsection{Description and Costs of General Electric and Westinghouse Plants}

Generai Electric and Westinghouse Astronuclear Laboratory each prepared a description and cost estimate for a nuclear hydrogen production facility. Each concept has significant unique features, and each cost estimate is quoted in a slightly different format. This section contains brief summaries of the conceptual plant designs and presents the GE and WANL cost estimates in a consistent format.

\subsubsection{GE description and cost}

\subsubsection{Plant description}

The GE conceptual, design ${ }^{2}$ used as a comparison plant in this report is a 3000-MW(t) VHTR that employs the concept of an intermediate loop connecting the reactor and the hydrogen reformers. The reactor is a heliumcooled pebble-bed reactor, developed by the German KFA, ${ }^{\star}$ delivering $3000 \mathrm{MW}(t)$. It provides a total of $900 \mathrm{MW}(t)$ to five process loops each at $1400^{\circ} \mathrm{F}$ outlet temperature, $1640 \mathrm{MW}(t)$ to five primary loop steam generators which can deliver up to $600 \mathrm{MW}(\mathrm{e})$ of electric power, and $460 \mathrm{MW}(\mathrm{t})$ to five intermediate loop steam generators, as discussed in "Systems Concepts Topical Report." 26

The reactor is located in an integrated PCRV that contains all of the primary loop components. The five intermediate heat exchangers and five steam generators are located in separate cavities in the PCRV as discussed in "Systems Concepts Topical Report."27

The five independent primary loops transport the reactor coolant (helium) to intermediate heat exchangers and through transverse ducts to the steam generators. The helium is then transported up along the wall of the steam

\footnotetext{
${ }^{*}$ Institut fur Reaktorentwicklung Kernforschungsanlage, Julich.
} 
Table 28. Comparison plant costs - GA/UE\&C (July 1974)

\begin{tabular}{|c|c|c|c|c|}
\hline \multirow[b]{2}{*}{ Account } & \multirow[b]{2}{*}{ Description } & \multicolumn{3}{|c|}{ Costs (thousands of dollars) } \\
\hline & & $\begin{array}{l}\text { Base } \\
\text { plant }\end{array}$ & $\begin{array}{l}\text { IHL } \\
\text { adder }\end{array}$ & Total \\
\hline \multirow{3}{*}{201} & Land and land rights & & & \\
\hline & Land and private acquisition & 1,000 & & 1,000 \\
\hline & Total for Account 20 & 1,000 & & 1,000 \\
\hline \multirow{13}{*}{$\begin{array}{ll}21 & \\
211 \\
212 \\
212 \mathrm{D} \\
214 \\
215 \\
217 \\
218 \mathrm{~A} \\
218 \mathrm{~B} \\
218 \mathrm{C} \\
218 \mathrm{D} \\
218 \mathrm{E}\end{array}$} & Structures and improvements & & & \\
\hline & Yard work & 2,627 & 45 & 2,672 \\
\hline & Reactor containment building & 33,811 & & 33,811 \\
\hline & Intermediate loop building & & 6,593 & 6,593 \\
\hline & Intake structures & 412 & & 412 \\
\hline & Reactor service building & 17,255 & & 17,255 \\
\hline & Fuel storage building ${ }^{a}$ & & & \\
\hline & Control building & 6,046 & & 6,046 \\
\hline & Diesel generating building & 5,140 & & 5,140 \\
\hline & Administration building & 2,572 & & 2,572 \\
\hline & Auxiliaries buildịng & 848 & & 848 \\
\hline & Helium storage building & 161 & 69 & 230 \\
\hline & Total for Account 21 & 68,872 & 6,707 & 75,579 \\
\hline \multirow{9}{*}{$\begin{array}{ll}22 & \\
221 \\
222 \\
223 \\
224\end{array}$} & Reactor plant equipment & & & \\
\hline & Reactor equipment & 128,599 & $-1,336$ & 127,263 \\
\hline & Heat transfer system & 79,787 & 82,812 & 162,599 \\
\hline & Safeguards cooling system & 7,938 & & 7,938 \\
\hline & $\begin{array}{l}\text { Radioactive waste treatment and } \\
\text { disposal }\end{array}$ & 5,663 & & 5,663 \\
\hline & $\begin{array}{l}\text { Nuclear fuel handling and } \\
\text { storage }\end{array}$ & 15,236 & & 15,236 \\
\hline & Other & 22,639 & 7 & 22,646 \\
\hline & $I \& C$ & 7,339 & 739 & 8,078 \\
\hline & Total for Account 22 & 267,201 & 82,222 & 349,423 \\
\hline \multirow{8}{*}{$\begin{array}{ll} & \\
& 24 \\
& 24 \\
& \end{array}$} & Electric plant equipment & & & \\
\hline & Switchgear & 2,512 & 136 & 2,648 \\
\hline & Station service equipment & 5,292 & & 5,292 \\
\hline & Switchboards & 507 & & 507 \\
\hline & Protective equipment & 518 & & 518 \\
\hline & $\begin{array}{l}\text { Electric structure and wiring } \\
\text { container }\end{array}$ & 7,044 & 242 & 7,286 \\
\hline & Power and control wiring & 10,724 & 72 & 10,796 \\
\hline & Total for Account 24 & 26,597 & 450 & 27,047 \\
\hline
\end{tabular}


Table 28 (continued)

\begin{tabular}{|c|c|c|c|c|}
\hline \multirow[b]{2}{*}{ Account } & \multirow[b]{2}{*}{ Description } & \multicolumn{3}{|c|}{ Costs (thousands of dollars) } \\
\hline & & $\begin{array}{l}\text { Base } \\
\text { plant }\end{array}$ & $\begin{array}{l}\text { IHL } \\
\text { adder }\end{array}$ & Total \\
\hline \multirow{5}{*}{$\begin{array}{rr}25 & \\
251 \\
252\end{array}$} & Miscellaneous plant equipment & & & \\
\hline & $\begin{array}{l}\text { Transporting and lifting } \\
\text { Air, hydraulic, water and } \\
\text { steam }\end{array}$ & $\begin{array}{l}1,369 \\
6,808\end{array}$ & 450 & $\begin{array}{l}1,799 \\
6,808\end{array}$ \\
\hline & Communications & 181 & & 181 \\
\hline & Furnishings and fixtures & 386 & & 386 \\
\hline & Total for Account 25 & 8,774 & 400 & 9,174 \\
\hline \multirow{6}{*}{$\begin{array}{r}26 \\
2 \\
2 \\
2\end{array}$} & Special materials & & & \\
\hline & Reactor coolant $t^{b}$ & 254 & & 254 \\
\hline & Intermediate coolant ${ }^{b}$ & & 89 & 89 \\
\hline & Initial, catalyst filling & 291 & 327 & 618 \\
\hline & Total for Account 26 & 545 & 416 & 961 \\
\hline & Subtotal (Accounts 21 through 26) & 371,989 & 90,195 & 462,184 \\
\hline \multirow{6}{*}{919} & Engineering and construction costs & & & \\
\hline & $\begin{array}{l}\text { Engineering services and } \\
\text { construction management }\end{array}$ & 63,898 & 15,463 & 79,361 \\
\hline & Temporary facilities & 5,175 & & 5,175 \\
\hline & Construction equipment & 9,300 & & 9,300 \\
\hline & Construction services & 10,710 & 2,592 & 13,302 \\
\hline & Total for Account 91 & 89,083 & 18,055 & 107,138 \\
\hline \multirow{10}{*}{99} & Other costs & & & \\
\hline & Operator training & 1,330 & 332 & 1,652 \\
\hline & Spare parts & 1,756 & & 1,756 \\
\hline & $\begin{array}{l}\text { Preliminary operating and } \\
\text { testing }\end{array}$ & & & \\
\hline & Miscellaneous costs & 4,788 & 1,159 & 5,947 \\
\hline & Contingency & 24,000 & & 24,000 \\
\hline & $\operatorname{IDC}^{c}$ & & & \\
\hline & GA-other costs (undistributed) & 939 & & 939 \\
\hline & Total for Account 99 & 32,813 & 1,491 & 34,294 \\
\hline & Totals of all costs & 494,885 & 109,741 & 604,616 \\
\hline \multicolumn{2}{|c|}{$\begin{array}{l}{ }^{a} \text { Functions included in reactor service buildir } \\
b \text { Includes } 100 \% \text { reserve in storage. } \\
\text { Not estimated. } \\
\text { Source: This table is derived from Tables } 2.2\end{array}$} & $(A c c o r$ & 215) & \\
\hline
\end{tabular}


generator cavities to the circulators, which return it to the reactor core. The primary loop helium ducting has internal insulation as discussed in the GE report. 28

The high-temperature secondary loop helium is transported from the intermediate heat exchangers to the reformers. The helium is then ducted to the nearby reheater and circulator, all located in bays adjacent to the process building. The secondary loop consists of five independent loops, one from each of the five intermediate heat exchangers to the five reformers. The secondary loop piping is internally insulated. The hot leg is $4 \mathrm{ft}$ in diameter.

The GE conceptual design of the reformer is similar to the EinzeeSpaltrohr-Versuchsanlage (EVA) design used by KFA. Each of the five reformers is housed in a single shell. The GE reference design is discussed in the GE report 29 and shown in "Systems Concepts Topical Report."30

The secondary loop coolant circulates on the shell side of the reformer unit, which reforms a methane and steam mixture into hydrogen. The product is then passed through a series of heat exchangers and a chemical converter to permit maximal recovery of sensible heat for input stream preheating. Of this process equipment, only the reformers are considered in the GE conceptual design scope and cost estimate.

The plant arrangement of the GE conceptual design is shown in their report. ${ }^{31}$ The PCRV is contained by a 156-ft-diam containment building that is surrounded by a penetration building $216 \mathrm{ft}$ in diameter and 116 ft high. Around these central structures are located:

(1) the reactor service building,

(2) the core auxiliary cooling systems building,

(3) the helium storage building,

(4) the control building,

(5) the process heat exchanger building (which houses the reformers),

(6) the diesel generator building,

(7) the auxiliary boilers building,

(8) the administration building, and

(9) the radwaste building.

A turbine building is shown by GE, 31 but the turbine building and turbine plant equipment are not included in the GE scope of design or cost estimate. 


\subsubsection{Costs}

GE presents the plant costs divided into descriptive categories but without account numbers. ${ }^{32}$ This cost breakdown was slightly reorganized and was assigned account numbers in accordance with the NUS-53119 system. The costs are shown by account in Table 29 and correspond fairly closely to the listing in the GE report. ${ }^{32}$ This cost breakdown was slightly reorganized and was assigned account numbers in accordance with the NUS-53119 system. The costs are shown by account in Table 29 and correspond fairly closely to the listing in the GE report. ${ }^{32}$

Account 20 (Land and land rights) is taken from the GE report. 33

To allow comparison of similar cases, the costs of Account 222 (Heat transfer loops) were adjusted in accordance with a table in the GE Report. ${ }^{34}$ The cost adjustments for the $\mathrm{P} 14\left(1400^{\circ} \mathrm{F}\right.$ peak average process gas temperature) case were used. The adjustments total $-\$ 2,760,000$ for the primary loop and $+\$ 23,329,900$ for the intermediate loop.

\subsubsection{Westinghouse description and cost}

\subsubsection{Plant description}

The Westinghouse conceptual plant ${ }^{3}$ is a VHTR providing $3000 \mathrm{MW}(\mathrm{t})$ of energy, in the form of electric power and heat, to a chemical process operating with a peak temperature of $1400^{\circ} \mathrm{F}$. The reactor is a heliumcooled graphite moderated unit employing the high-temperature fuel technology derived from the NERVA nuclear rocket program. The reactor is housed in a PCIV in which are also located the helium circulators, turbomachinery, and high and low-temperature intermediate heat exchangers. An intermediate heat transport loop isolates the reactor from the process and enhances the operability, maintainability, and licensability of the nuclear heat source.

The reactor and its coolant loops are contained within a multicavity PCIV, whose design is based on work by the German firm Siempalkamp. ${ }^{6}$ Housed in cavities within the vessel walls are five high-temperature heat exchangers and circulators and five turbogenerators and low-temperature intermediate heat exchangers. Reactor helium coolant enters and discharges from the cavities through coaxial piping at the upper end of the cavity, while the intermediate helium coolant is introduced and leaves through the bottom of the cavities. The function of the five parallel high-temperature intermediate heat exchanger loops is to transfer heat from the reactor core to the high-temperature process equipment.

The proprietary WANL process uses steam and electricity to generate hydrogen. No process equipment is included in the cost estimate.

The WANL arrangement of plant structures on the site is shown in their report. 35 The major buildings are the reactor containment, the reactor 
Table 29. Interpreted accounts summary - General Electric (July 1974)

\begin{tabular}{|c|c|c|c|c|}
\hline \multirow[b]{2}{*}{ Account } & \multirow[b]{2}{*}{ Description } & \multicolumn{3}{|c|}{ Costs (thousands of dollars) } \\
\hline & & $\begin{array}{l}\text { Material/ } \\
\text { equipment }\end{array}$ & Labor & Total \\
\hline \multirow[t]{2}{*}{20201} & $\begin{array}{l}\text { Land and land rights } \\
\text { Land and privilege } \\
\text { Acquisition }\end{array}$ & & & \\
\hline & Total for Account 20 & 2,000 & & 2,000 \\
\hline 21 & Structures and site facilities & & & \\
\hline 211 & Yard work & 2,000 & 3,000 & 5,000 \\
\hline 212 & Reactor containment building & 13,250 & 26,242 & 39,492 \\
\hline 213 & Turbine generator building ${ }^{a}$ & & & \\
\hline 214 & Intake structures ${ }^{a}$ & 3,048 & 7,839 & 10,887 \\
\hline 215 & Reactor service building & & & \\
\hline 217 & Fuel storage building & 1,608 & 2,745 & 4,353 \\
\hline $218 \mathrm{~A}$ & Control building & 1,689 & 4,566 & 6,255 \\
\hline $218 \mathrm{~B}$ & Diesel generator building & 644 & 1,931 & 2,575 \\
\hline $218 \mathrm{C}$ & Administration building ${ }^{a}$ & & & \\
\hline $218 D$ & Auxiliaries building ${ }^{a}$ & & & \\
\hline \multirow[t]{2}{*}{$218 \mathrm{E}$} & Helium storage building & 178 & 246 & 424 \\
\hline & Total for Account 21 & 22,417 & 46,569 & 68,986 \\
\hline 22 & Reactor plant equipment & & & \\
\hline $\begin{array}{l}221 \\
222 \mathrm{~A}\end{array}$ & $\begin{array}{l}\text { Redicur equipment } \\
\text { Primary heat transfer system }\end{array}$ & $\begin{array}{l}62,022 \\
24,445\end{array}$ & $\begin{array}{r}38,163 \\
8,468\end{array}$ & $\begin{array}{r}100,185 \\
32,913\end{array}$ \\
\hline $222 B$ & $\begin{array}{l}\text { Intermediate heat transfer } \\
\text { system }\end{array}$ & 129,406 & 58,441 & 187,847 \\
\hline 223 & Safeguards cooling systems & 1,977 & 248 & 2,225 \\
\hline 224 & $\begin{array}{l}\text { Radioactive waste treatment and } \\
\text { disposal }\end{array}$ & 2,027 & 1,045 & 3,072 \\
\hline 225 & $\begin{array}{l}\text { Nuclear fuel handling and } \\
\text { storage }\end{array}$ & 10,409 & 1,561 & 11,970 \\
\hline 226 & Other reactor plant equipment & 12,821 & 6,971 & 19,792 \\
\hline \multirow[t]{2}{*}{227} & Instrumentation and control & 9,767 & 1,971 & 11,738 \\
\hline & Total for Account 22 & 252,874 & 116,868 & 369,742 \\
\hline 23 & $\begin{array}{l}\text { Turbine plant equipment } \\
\text { Heat rejection systems } a\end{array}$ & & & \\
\hline
\end{tabular}

232 Total for Account 23 
Table 29 (continued)

\begin{tabular}{|c|c|c|c|c|}
\hline \multirow[b]{2}{*}{ Account } & \multirow[b]{2}{*}{ Description } & \multicolumn{3}{|c|}{ Costs (thousands of dollars) } \\
\hline & & $\begin{array}{l}\text { Material/ } \\
\text { equipment }\end{array}$ & Labor & Total \\
\hline \multirow{8}{*}{$\begin{array}{r} \\
241 \\
242 \\
243 \\
244 \\
245\end{array}$} & Electric plant equipment & & & \\
\hline & Switchgear & 732 & 175 & 907 \\
\hline & Station service equipment & 3,538 & 933 & 4,471 \\
\hline & Switchboards & 623 & 225 & 848 \\
\hline & Protective equipment & 200 & 250 & 450 \\
\hline & $\begin{array}{l}\text { Electric structure and wiring } \\
\text { container }\end{array}$ & 975 & 5,150 & 6,125 \\
\hline & Power and control wiring & 3,525 & 5,195 & 8,720 \\
\hline & Total for Account 24 & 9,593 & 11,928 & 21,521 \\
\hline \multirow{6}{*}{$\begin{array}{ll}25 & \\
& 251 \\
& 252\end{array}$} & Miscellaneous plant equipment & & & \\
\hline & Transportation and lifting & 1,120 & 325 & 1,445 \\
\hline & $\begin{array}{l}\text { Air, hydraulic, water and } \\
\text { steam }\end{array}$ & 3,659 & 3,796 & 7,455 \\
\hline & Communications & 104 & 154 & 258 \\
\hline & Furnishings and fixtures & 457 & 59 & 516 \\
\hline & Total for Account 25 & 5,340 & 4,334 & 9,674 \\
\hline \multirow{6}{*}{$\begin{array}{ll} & \\
263 \\
264 \\
269\end{array}$} & Special materials & & & \\
\hline & Reactor coolant $b$ & 240 & & 240 \\
\hline & Intermediate coolant ${ }^{b}$ & & & \\
\hline & Initial catalyst filling & 600 & & 600 \\
\hline & Total for Account 26 & 840 & & 840 \\
\hline & Subtota1 (Accounts 21 through 26) & 291,064 & 179,699 & 470,763 \\
\hline \multirow{6}{*}{91910} & Engineering and construction costs & & & \\
\hline & $\begin{array}{l}\text { Engineering services and } \\
\text { construction management }\end{array}$ & & 42,830 & 42,830 \\
\hline & Temporary facilities & 1,911 & 4,687 & 6,598 \\
\hline & Construction equipment & 6,445 & & 6,445 \\
\hline & Construction services & 1,543 & 6,718 & 8,261 \\
\hline & Total for Account 91 & 9,899 & 54,235 & 64,134 \\
\hline
\end{tabular}


Table 29 (continued)

\begin{tabular}{|c|c|c|c|c|}
\hline \multirow[b]{2}{*}{ Account } & \multirow[b]{2}{*}{ Description } & \multicolumn{3}{|c|}{ Costs (thousands of dollars) } \\
\hline & & $\begin{array}{l}\text { Material/ } \\
\text { equipment }\end{array}$ & Labor & Total \\
\hline \multirow{8}{*}{$\begin{array}{ll}99 & \\
991 \\
992 \\
993\end{array}$} & Other costs & & & \\
\hline & Operator training ${ }^{a}$ & & & \\
\hline & Spare parts ${ }^{a}$ & & & \\
\hline & $\begin{array}{l}\text { Preliminary operating and } \\
\text { testing }\end{array}$ & 468 & 1,312 & 1,780 \\
\hline & Miscellaneous costs ${ }^{a}$ & & & \\
\hline & Contingency & 44,758 & 36,207 & 80,965 \\
\hline & Total for Account 99 & 45,226 & 37,519 & 82,745 \\
\hline & Totals of all costs & 348,189 & 271,453 & 619,642 \\
\hline
\end{tabular}

auxiliary building, the control and electrical building, the diesel generator building, the administration service building, and the helium storage building.

\subsubsection{2 $\underline{\text { Costs }}$}

For the most part, the plant costs given by WANL ${ }^{36}$ are in the format established for Table 29 of this report. These costs are shown in Table 30 .

The only areas rearranged by UE\&C are in the 90 s accounts, whereas WANL uses account number designations outside of the NUS-531 report ${ }^{19}$ system. Specifically, the WANL Accounts 92 and 94 become Accounts $910 \mathrm{~A}$ and 996, respectively, of Table 30, without change of description. Westinghouse Account 93 (Other costs) becomes in Table 29 Account 994 (Miscellaneous costs). One WANL entry, Account 91 (Construction, facilities, equipment and services), covers the scope of the following Table 30 entry listings, without any information to permit a distribution among them: Account 910B - Construction management and field supervision, Account 911 - Temporary facilities, Account 912 Construction equipment, and Account 913 - Construction services.

Spare parts costs, entered in Table 30 as Account 992, represent a value accumulated from spare parts costs given individually under the following WANL accounts: Account 22 - Reactor plant equipment, Account 24 - Electric plant equipment, and Account 25 - Miscellaneous plant equipment. 
Table 30. Interpreted accounts summary - Westinghouse (July 1974)

\begin{tabular}{|c|c|c|c|c|}
\hline \multirow[b]{2}{*}{ Account } & \multirow[b]{2}{*}{ Description } & \multicolumn{3}{|c|}{ Costs (thousands of dollars) } \\
\hline & & $\begin{array}{l}\text { Material/ } \\
\text { equipment }\end{array}$ & Labor & Total \\
\hline \multirow{3}{*}{201} & Land and land rights & & & \\
\hline & $\begin{array}{l}\text { Land and privilege } \\
\text { acquisition }\end{array}$ & $\underline{800}$ & & 800 \\
\hline & Total for Account 20 & 800 & & 800 \\
\hline \multirow{13}{*}{$\begin{array}{ll}21 & \\
211 \\
212 \\
213 \\
214 \\
215 \\
217 \\
218 \mathrm{~A} \\
218 \mathrm{~B} \\
218 \mathrm{C} \\
218 \mathrm{D} \\
218 \mathrm{E}\end{array}$} & Structures and site facilities & & & \\
\hline & Yard work & 1,041 & 1,293 & 2,334 \\
\hline & Reactor containment building & 5,463 & 9,509 & 14,972 \\
\hline & Turbine generator building ${ }^{a}$ & & & \\
\hline & Intake structures & 183 & 551 & 734 \\
\hline & Reactor service building & 6,453 & 16,575 & 23,028 \\
\hline & Fuel storage building ${ }^{a}$ & & & \\
\hline & Control building & 1,141 & 2,606 & 3,747 \\
\hline & Diesel generator building & 486 & 1,293 & 1,779 \\
\hline & Administration building & 359 & 431 & 790 \\
\hline & Auxiliaries building $a$ & & & \\
\hline & Helium storage building & 73 & 94 & 167 \\
\hline & Total for Account 21 & 15,199 & 32,352 & 47,551 \\
\hline \multirow{10}{*}{$\begin{array}{l}221 \\
222 \mathrm{~A} \\
222 \mathrm{~B}\end{array}$} & Reactor plant equipment & & & \\
\hline & Reactor equipment & 46,218 & 6,797 & $53,01.5$ \\
\hline & Primary heat transfer system & 54,272 & 1,585 & 55,857 \\
\hline & $\begin{array}{l}\text { Intermediate heat transfer } \\
\text { system }\end{array}$ & 2,769 & 2,800 & 5,569 \\
\hline & Safeguards cooling system & 3,054 & 1,155 & 4,209 \\
\hline & $\begin{array}{l}\text { Radioactive waste treatment and } \\
\text { disposal }\end{array}$ & 1,351 & 634 & 1,985 \\
\hline & $\begin{array}{l}\text { Nuclear fuel handling and } \\
\text { storage }\end{array}$ & 10,140 & 859 & 10,999 \\
\hline & Other reactor plant equipment & 7,547 & 2,659 & 10,206 \\
\hline & Instrumentation and control & 6,084 & 1,304 & 7,388 \\
\hline & Total for Account 22 & 131,435 & 17,793 & 149,228 \\
\hline
\end{tabular}

Turbine plant equipment

Heat rejection systems $a$

Total for Account 23 
Table 30 (continued)

\begin{tabular}{|c|c|c|c|c|}
\hline \multirow[b]{2}{*}{ Áccount } & \multirow[b]{2}{*}{ Description } & \multicolumn{3}{|c|}{ Costs (thousands of dollars) } \\
\hline & & $\begin{array}{l}\text { Material/ } \\
\text { equipment }\end{array}$ & Labor & Total \\
\hline \multirow{8}{*}{$\begin{array}{ll}24 & \\
241 \\
242 \\
243 \\
244 \\
245\end{array}$} & Electric plant equipment & & & \\
\hline & Switchgear & 1,121 & 173 & 1,294 \\
\hline & Station service equipment & 2,825 & 452 & 3,277 \\
\hline & Switchboards & 521 & 132 & 653 \\
\hline & Protective equipment & 110 & 171 & 281 \\
\hline & $\begin{array}{l}\text { Electric structure and wiring } \\
\text { container }\end{array}$ & 591 & 2,441 & 3,032 \\
\hline & Power and control wiring & 3,378 & 4,291 & 7,669 \\
\hline & Total for Account 24 & 8,546 & 7,660 & 16,206 \\
\hline \multirow{6}{*}{$\begin{array}{l}25 \\
251 \\
252\end{array}$} & Miscellaneous plant equipment & & & \\
\hline & Transportation and lifting & 947 & 250 & 1,197 \\
\hline & $\begin{array}{l}\text { Air, hydraulic, water and } \\
\text { steam }\end{array}$ & 2,128 & 2,614 & 4,742 \\
\hline & Communications equipment & 60 & 97 & 157 \\
\hline & Furnishings and fixtures & 288 & 337. & 325 \\
\hline & Total for Account 25 & 3,423 & 2,998 & 6,421 \\
\hline \multirow{6}{*}{$\begin{array}{rr}26 & \\
263 \\
264 \\
269\end{array}$} & Special materials & & & \\
\hline & Reactor coolant ${ }^{c}$ & 250 & & 250 \\
\hline & Intermediate coolant & & & \\
\hline & Initial catalyst filling ${ }^{a}$ & & & \\
\hline & Total for Account 26 & 250 & & 250 \\
\hline & Subtotal (Accounts 21 through 26) & 158,853 & 60,803 & 219,656 \\
\hline \multirow{6}{*}{$\begin{array}{l}911 \\
912 \\
913\end{array}$} & Engineering and construction costs & & & \\
\hline & $\begin{array}{l}\text { Engineering services and } \\
\text { construction management }\end{array}$ & 40,800 & & 40,800 \\
\hline & Temporary facilities & 16,468 & & 16,468 \\
\hline & Construction equipment ${ }^{a}$ & & & \\
\hline & Construction services ${ }^{a}$ & & & \\
\hline & Total for Account 91 & 57,268 & & 57,268 \\
\hline
\end{tabular}


Table 30 (continued)

\begin{tabular}{|c|c|c|c|c|}
\hline \multirow[b]{2}{*}{ Account } & \multirow[b]{2}{*}{ Description } & \multicolumn{3}{|c|}{ Costs (thousands of dollars) } \\
\hline & & $\begin{array}{l}\text { Material/ } \\
\text { equipment }\end{array}$ & Labor & Total \\
\hline \multirow{8}{*}{$\begin{array}{ll}99 & \\
991 \\
992 \\
993\end{array}$} & Other costs & & & \\
\hline & Operator training ${ }^{a}$ & & & \\
\hline & Spare parts & 1,391 & & 1,391 \\
\hline & $\begin{array}{l}\text { Preliminary operating and } \\
\text { testing }\end{array}$ & & & \\
\hline & Miscellaneous costs & 12,700 & & 12,700 \\
\hline & Contingency & 27,649 & 6,080 & 33,729 \\
\hline & Total for Account 99 & 41,740 & 6,080 & 47,820 \\
\hline & Totals of al1 costs & 258,661 & 66,883 & 325,544 \\
\hline
\end{tabular}
4.4 Summary of Scope and Costs of General Atomic/UE\&C, General
Electric, and Westinghouse Conceptual Designs

\subsubsection{Bases for summary}

Three conceptual designs have been estimated. A General Atomic NSSS with a UE\&C BOP is described in Sect. 4.2 and is summarized in Table 28. Summaries of the GE and WANL plants are presented in Sect. 4.3 and are shown in Tables 29 and 30 . The costs are presented in Table 31, and technical parameters are shown in Table 32. Section 4.2 discusses the differences between the concepts in detail.

Operating and maintenance costs are presented in Sect. 4.3.

Several ground rules were established for the evaluation:

(I) All costs are quoted in July 1974 dollars.

(2) All finance charges (interest, cost of money, etc.) are ignored because they are percentages of the capital cost of the plant.

(3) No electricity is generated (although turbine-generators are included in the WANL estimate). 
Table 31. Summary of costs of VHTR nuclear process heat plants ${ }^{a}$ as supplied in the contractor reports (July 1974)

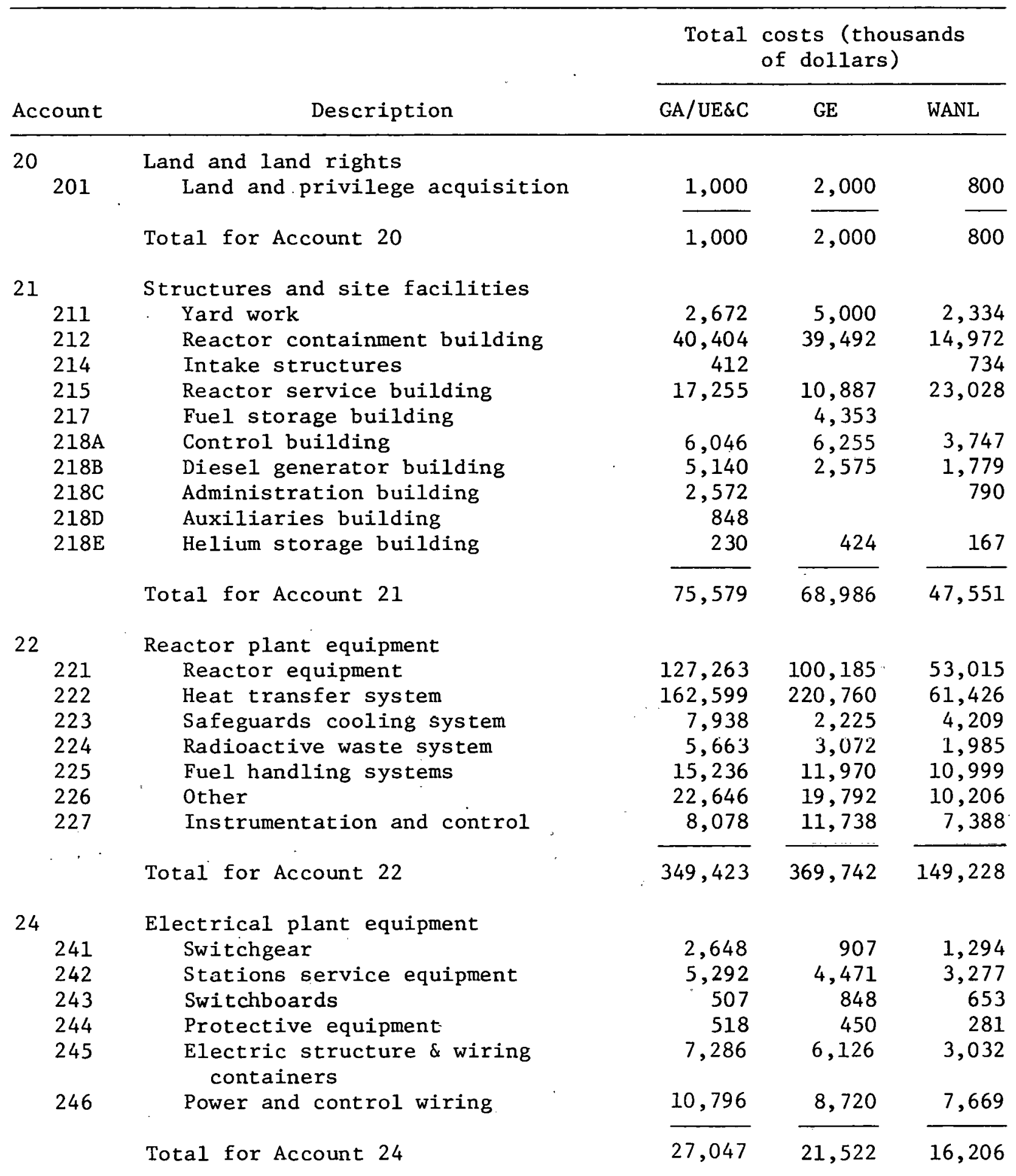


Table 31 (continued)

\begin{tabular}{|c|c|c|c|c|}
\hline \multirow[b]{2}{*}{ Account } & \multirow[b]{2}{*}{ Description } & \multicolumn{3}{|c|}{$\begin{array}{c}\text { Total costs (thousands } \\
\text { of dollars) }\end{array}$} \\
\hline & & GA/UE\&C & GE & WANL \\
\hline \multirow{6}{*}{$\begin{array}{r}25 \\
251 \\
252\end{array}$} & Miscellaneous plant equipment & & & \\
\hline & Transporting and lifting & 1,799 & 1,445 & 1,197 \\
\hline & $\begin{array}{l}\text { Air, hydrogen, water and steam } \\
\text { service }\end{array}$ & 6,808 & 7,455 & 4,742 \\
\hline & Communications equipment & 181 & 258 & 157 \\
\hline & Furnishings and fixtures & 386 & 516 & 325 \\
\hline & Total for Account 25 & 9,174 & 9,674 & 6,421 \\
\hline \multirow{6}{*}{26263} & Special materials & & & \\
\hline & Reactor coolant & 254 & 240 & 250 \\
\hline & Intermediate coolant & 89 & & \\
\hline & Initial catalyst filling & 618 & 600 & \\
\hline & Total for Account 26 & 961 & 840 & 250 \\
\hline & Subtotal (Accounts 21 through 26) & 462,184 & 470,764 & 219,656 \\
\hline \multirow{6}{*}{91910} & Engineering and construction costs & & & \\
\hline & $\begin{array}{l}\text { Engineering services and } \\
\text { construction management }\end{array}$ & 79,361 & 42,830 & 40,800 \\
\hline & Temporary facilities & 5,175 & 6,598 & 16,468 \\
\hline & Construction equipment & 9,300 & 6,445 & \\
\hline & Construction services & 13,302 & 8,261 & \\
\hline & Total for Account 91 & 107,138 & 64,134 & 57,268 \\
\hline \multirow{9}{*}{99} & Other costs & & & \\
\hline & Operator training & 1,652 & & \\
\hline & Spare parts & 1,136 & & 1,391 \\
\hline & Preliminary operating and testing & & 1,780 & \\
\hline & Miscellaneous costs & 5,947 & & \\
\hline & Contingency & 24,000 & 80,965 & 33,729 \\
\hline & $\mathrm{GA}$ - other costs (undistributed) & 939 & & \\
\hline & Total for Account 99 & 34,294 & 82,745 & 47,820 \\
\hline & Totall costs ${ }^{a}$ & 604,616 & 617,643 & 325,544 \\
\hline
\end{tabular}

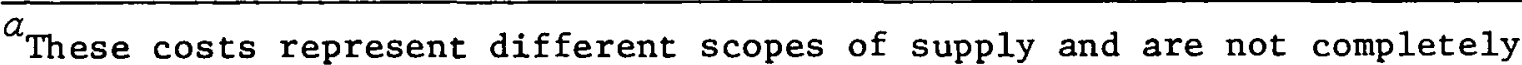
comparable. Significant, indentifiable differences are discussed in Chapter 4.

Source: This table is derived from Tables 28-30. 
Table 32. Comparison of significant design parameters

\begin{tabular}{|c|c|c|c|}
\hline Item & $\mathrm{GA} / \mathrm{UE} \& \mathrm{C}^{a}$ & $\mathrm{GE}^{b}$ & WANL $^{c}$ \\
\hline \multicolumn{4}{|l|}{$\begin{array}{l}\text { Building sizes (length } \times \text { width } \times \\
\text { height, } f t)\end{array}$} \\
\hline Containment building & 162 Diam $\times 240$ high & 156 Diam $\times 188$ high & 110 Diam $\times 250$ high \\
\hline Intermediate loop building & $125 \times 95 \times 140$ & $d$ & $d$ \\
\hline Reactor service building & $240 \times 135 \times 140$ & $80 \times 313 \times 80$ & $\begin{array}{r}130 \times 100 \times 160 \\
\text { and } \\
90 \times 130 \times 89\end{array}$ \\
\hline Control building & $110 \times 50 \times 130$ & $80 \times 150 \times 125$ & $80 \times 160$ \\
\hline Diesel generator building & $90 \times 210$ & $80 \times 120$ & $60 \times 90$ \\
\hline Administration building & $134 \times 170$ & $60 \times 150^{d}$ & $50 \times 100$ \\
\hline \multicolumn{4}{|l|}{ Heat transfer systems } \\
\hline \multicolumn{4}{|l|}{ Reactor vessel } \\
\hline Type & PCRV. & PCRV & PCIV \\
\hline Dimensions & 106 Diam $\times 84.3 \mathrm{H}$ & 116 Diam $\times 82 \mathrm{H}$ & 66 Diam $\times 110 \mathrm{H}$ \\
\hline \multicolumn{4}{|l|}{ Primary steam generators } \\
\hline Number & 4 & 5 & 0 \\
\hline Total area, $f t^{2}$ & 30,000 & 25,000 & \\
\hline $\operatorname{MW}(t)$ & 1374 & 1640 & \\
\hline \multicolumn{4}{|l|}{ Intermediate heat exchangers } \\
\hline Number & 4 & 5 & 5 \\
\hline Total area, $\mathrm{ft}^{2}$ & 175,000 & 123,000 & 157,000 \\
\hline $\operatorname{MW}(t)$ & 1626 & 1360 & 1555 \\
\hline
\end{tabular}


Table 32 (continued)

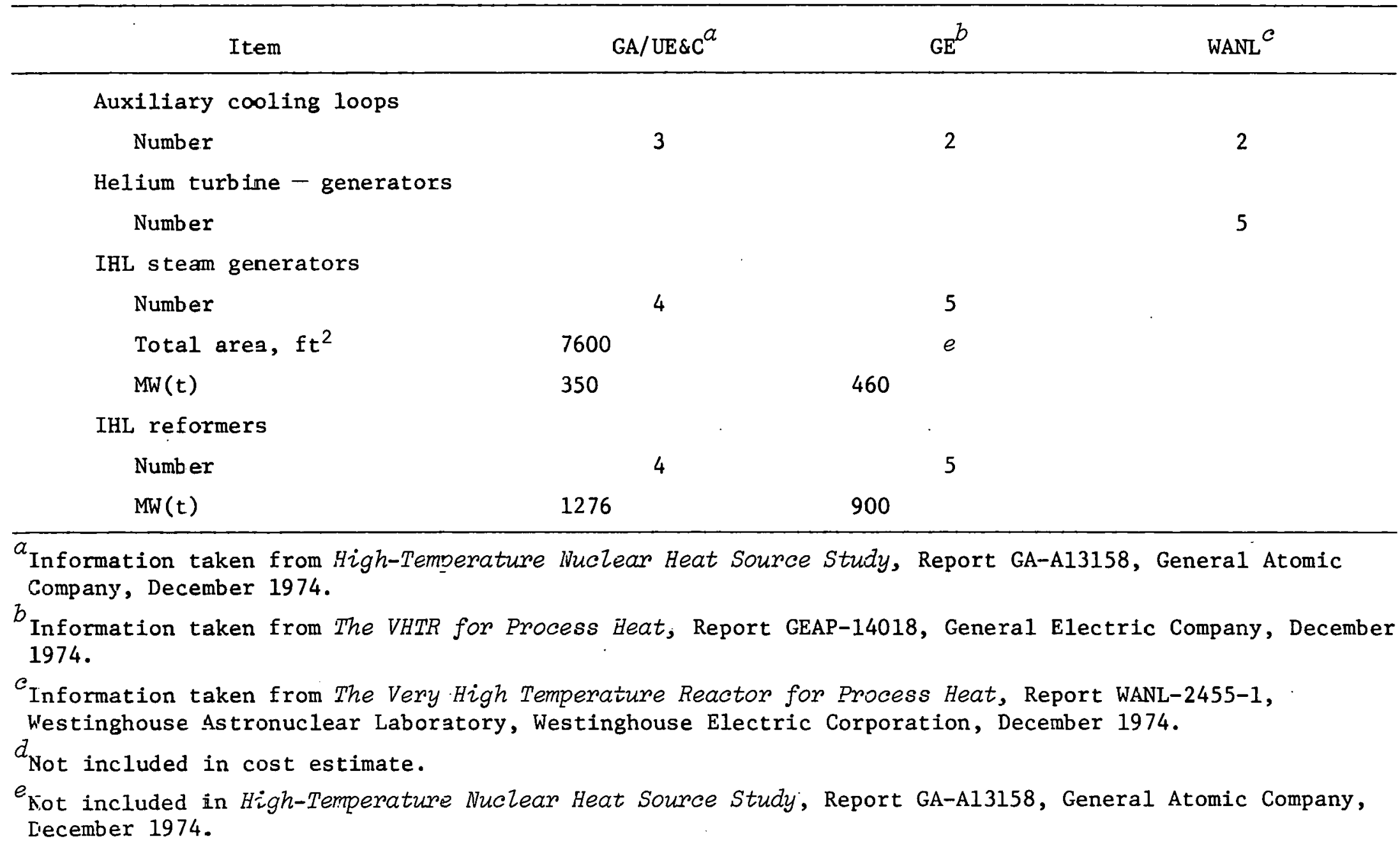


(4) Costs quoted in refs. 1, 2, and 3 are adjusted as described in Sects. 4.2 and 4.3, using adders from the references to allow comparison of plants with similar operating conditions.

Costs are stated in a consistent code of accounts.

\subsubsection{Plant cost and scope}

\subsubsection{Major differences}

There are significant differences among the three estimates presented in this report, both in scope of supply and in the types of equipment used. The costs for the three plants shown in Table 31 are thus not directly comparable. Although gross differences in the scope can explain differences in cost, a complete evaluation of the accuracy of the cost estimate is not, in general, possible. Because the WANL and GE design is based on a somewhat less developed technology, the uncertainty in their estimate is somewhat higher than that for the GA/UE\&C estimate. The WANL estimate is based on the least developed technology and, in addition, provides little detailed breakdown.

The prestressed cast iron reactor vessel (PCIV) proposed by WANL is a significant, imaginative innovation. Potentially, the PCIV can cause reductions in construction time, reactor vessel cost, and BOP cost. However, the concept is still in the early stages of development. Any estimate of costs and cost savings must be considered highly speculative.

The pebble-bed reactor, which is the basis for the GE estimate, is presently being developed in Germany. A small prototype reactor (AVR) has operated for several years, and a large [300 MW(e)] demonstration plant is under construction. Fuel has been tested extensively but not under commercial operating conditions. The pebble bed appears competitive with the GA HTGR, but a detailed cost comparison is not possible with the data provided in refs. 1 and 2 .

The fuel used in the WANL reactor is similar to fuel that was studied early in the HTGR fuel development program. An extensive research, development, and testing program is required. The WANL fuel is the least developed and thus the most uncertain of the three concepts.

\subsubsection{Detailed summary}

Table 31 presents the summary of the costs of the GA/UE\&C, GE, and WANL plants. A comparison of the costs is superficial because the differences in scope of supply are not shown. Table 32 shows some of the technical characteristics of the plants. This section discusses the details of the differences in scopes and comments on obvious cost differences. The discussion is arranged by accounts: 
Account 212. Reactor containment building

The GA/UE\&C plant includes the reactor containment, annulus, annulus electrical tower, and two intermediate loop buildings.

General Electric has included a somewhat smaller reactor containment and a containment annulus. The process heat exchanger building of the GE conceptual design is analogous to the intermediate loop buildings of the GA/UE\&C concept but is not included in the GE cost estimate. If an allowance is included for the cost of the intermediate loop building, the GE estimate will be somewhat higher than the GA/UE\&C estimate.

The containment structure of the WANL concept is much smaller than the GA/UE\&C or GE designs. This is due to the much smaller reactor vessel (PCIV) in the WANL concept and results in a significant reduction in cost.

\section{Account 213. Turbine generator building}

None of the conceptual designs includes a turbine-generator building in the base cost estimates. The GA/UE\&C design shows this as an optional. adder in Tables 25 and 26.

\section{Account 214. Intake structures}

A service water intake structure to provide plant and safety-related cooling water is costed by the GA/UE\&C and WANL estimates, but the GE concept does not include any cooling for those purposes. All these conceptual designs do not include a circulating water intake structure because waste heat dissipation is the responsibility of the chemical plant.

\section{Account 215. Reactor service building}

A reactor service building is included in all three concepts. The GE design of this building is somewhat smaller in size than the other two concepts and is costly.

Account 217. Fuel storage building

A fuel storage building is costed only by $\mathrm{GE}$, but no separate building appears on GE's plant arrangement drawing. ${ }^{37}$ General Atomic Company/UE\&C and WANL include fuel storage in the reactor service building.

Account 218A. Control building

A control building is included in all three concepts. The WANL concept describes a much smaller size building, resulting in much lower cost. 
Account 218B. Diesel generator building

The diesel generator building of the GA/UE\&C design is much larger in size and cost than the GE or WANL concepts due to recent licensing criteria stipulating that three diesel generators and three 30-day oil storage tanks must be provided.

\section{Account 218C. Administration building}

An administration building is not included in the GE estimate; ${ }^{38}$ however, GA/UE\&C and WANL have included this structure. The WANL estimate is considerably less than the GA/UE\&C estimate, although the physical size and function are comparable. The GA/UE\&C estimate is based on current UE\&C experience.

Account 218D. Auxiliaries building

An auxiliaries building, which houses auxiliary boilers, water treatment equipment, and miscellaneous plant auxiliaries, is included in the GA/UE\&C estimate. General Electric shows an auxiliary boiler building and a machine shop building on their plant arrangement drawing, 37 but the costs of these buildings are not identified. ${ }^{39}$ Westinghouse does not include an auxiliaries building or similar type structure in their design or estimate.

Account 218E. Helium storage building

All three concepts include a helium storage building. However, the WANL estimate is lower and the GE estimate is higher, both for no obvious reason.

\section{Account 221. Reactor equipment}

The PCRV sizes are essentially comparable; however, the GA/UE\&C PCRV incorporates eight major cavities, and the GE PCRV incorporates ten. Costs quoted for the GA PCRV are somewhat higher than for GE.

Due to the dramatically different PCIV design that WANL incorporates, the estimated cost is considerably lower and contributes significantly to the difference in total plant cost.

\section{Account 222. Heat transfer system}

Physical data for the heat transfer systems appear in Table 32. The WANL estimate includes intermediate loop equipment only within the containment building. It is not clear whether isolation valves (a considerable expense) are included. The large difference between GA/UE\&C and GE 
heat transfer system costs seems to be due to a very high GE cost for intermediate loop piping. The layout of the GE intermediate loop requires $3370 \mathrm{ft}$ of intermediate loop piping, compared to $1160 \mathrm{ft}$ required for the GA/UE\&C configuration.

Account 223. Safeguards cooling system

Differences in costs of the safeguards cooling system cannot be explained based on the information provided in refs. 1, 2, and 3. The heat loads on the systems are not likely to be significantly different.

\section{Account 224. Radwaste system}

The low cost of radwaste systems in the WANL estimate may be due to a lower flow through the radwaste system (because of smaller total helium loop inventory) than in the other designs. However, the low GE estimate cannot be supported by this reasoning.

\section{Account 225. Fuel handling and storage}

The GA/UE\&C cost is based on current UE\&C experience and is higher than the WANL estimate. Because of the different fuel concept, the GE estimate is not comparable.

Account 226. Other reactor plant equipment

The Westinghouse estimate is considerably lower than GE or GA/UE\&C, in part because of smaller coolant storage and makeup, purification, and treatment systems required by the WANL conceptual design. However, the higher GA/UE\&C and GE estimates appear close to applicable recent experience.

Account 227. Instrumentation and contro1

Instrumentation and control requirements and costs are generally equivalent.

Account 24. Electric plant equipment

The costs in these accounts are generally comparable. The higher costs in some accounts of the GA/UE\&C estimate are caused by. provisions in this account to supply $30 \mathrm{MW}(\mathrm{e})$ from the grid to the chemical process plant. 
Account 251. Miscellaneous plant equipment

The costs for this account are comparable.

Account 252. Air, water and steam services

The Westinghouse estimate is probably slightly lower due to smaller overall building sizes.

Accounts 910-913. Engineering and construction costs

Engineering costs have risen significantly due to new quality assurance requirements affecting not only construction costs but also engineering costs. The UE\&C estimate is probably conservative.

\subsubsection{Adjusted cost of the three VHTR concepts}

In an effort to determine the most realistic costs for the three concepts, an at tempt was made to normalize, wherever possible, the balance of plant costs for the GE and WANL concepts to those developed by UE\&C. This resulted in an adjusted cost presented in Table 33. This tabulation is based on various assumptions and interpretations about the extent and detail of the GE and WANL estimates and design.

The GA/UE\&C cost estimates are believed to be the most reliable because they are based on the most completely defined design and the most developed technology. The GE estimates provide a great deal of detail cost breakdown and backup material, resulting in a very thorough cost estimate based on somewhat less developed technology. The Westinghouse estimates do not include detailed equipment lists and cost breakdowns. Likewise, the technology presented is the least developed and the most speculative. Although the costs presented by WANL are much lower, it is our judgment that they are less reliable because of the state of the technology and the lack of detail presented. Therefore, the WANL costs were not considered in evaluating the economic potential of the VHTR concept. The costs for the three concepts would have to be very similar because so much of the major equipment systems are common to all. Therefore, the GA/UE\&C and GE costs will be considered representative for the concept.

Some structures, such as the intake structure, diesel generator building, and the auxiliaries building, are essentially independent of the type of facility considered. The estimates prepared by UE\&C for these structures are based on recent power plant experience and thus assigned to each of the three concepts. The GE fuel storage building cost is combined with the cost of their reactor service building.

The costs of an intermediate loop and associated equipment and structures are shown in Table 24. These costs are added to the appropriate accounts 
Table 33. Adjusted costs of VHTR nuclear process heat plants (July 1974)

\begin{tabular}{|c|c|c|c|c|}
\hline \multirow[b]{2}{*}{ Account } & \multirow[b]{2}{*}{ Description } & Total costs & \multicolumn{2}{|c|}{ (millions of dollars) $^{a}$} \\
\hline & & GA/UE\&C & GE & WANL \\
\hline 20 & Land and land rights & & & \\
\hline 201 & Land and privilege acquisition & 1.0 & 1.0 & 1.0 \\
\hline 21 & Structures and site facilities & & $\cdot$ & \\
\hline $\begin{array}{l}211 \\
212 \\
214 \\
215 \\
218 \text { A } \\
218 B \\
218 C \\
218 D \\
218 E\end{array}$ & $\begin{array}{l}\text { Yard work } \\
\text { Reactor containment building } \\
\text { Intake structures } \\
\text { Reactor service and fuel storage building } \\
\text { Control bullding } \\
\text { Diesel gencrator building } \\
\text { Administration building } \\
\text { Auxiliartes bullding } \\
\text { Helium storage building }\end{array}$ & $\begin{array}{r}2.7 \\
40.4 \\
.4 \\
17.2 \\
6.0 \\
5.1 \\
2.6 \\
.8 \\
.2 \\
\end{array}$ & $\begin{array}{r}5.0 \\
46.1 \\
.4 \\
15.2 \\
6.2 \\
5.1 \\
2.6 \\
.8 \\
.4 \\
\end{array}$ & $\begin{array}{r}2.4 \\
21.6 \\
.4 \\
23.0 \\
3.7 \\
5.1 \\
.8 \\
.8 \\
.2 \\
\end{array}$ \\
\hline & Total for Account 21 & 75.4 & 81.8 & 58.0 \\
\hline 22 & Reactor plant equipment & v & & \\
\hline $\begin{array}{l}221 \\
222 \\
223 \\
224 \\
225 \\
226 \\
227\end{array}$ & $\begin{array}{l}\text { Reactor equipment } \\
\text { Heat transfer system } \\
\text { Safeguards cooling system } \\
\text { Radioactive waste system } \\
\text { Fuel handling systems } \\
\text { Other } \\
\text { Instrumentation and control }\end{array}$ & $\begin{array}{r}127.3 \\
162.6 \\
7.9 \\
5.7 \\
15.2 \\
22.6 \\
8.1 \\
\end{array}$ & $\begin{array}{r}100.2 \\
220.8 \\
2.2 \\
3.1 \\
12.0 \\
20.9 \\
12.5 \\
\end{array}$ & $\begin{array}{r}53.0 \\
102.8 \\
4.2 \\
2.0 \\
11.0 \\
11.3 \\
8.1 \\
\end{array}$ \\
\hline & Total for Account 22 & 349.4 & 371.7 & 192.4 \\
\hline 24 & Electrical plant equipment & & & \\
\hline $\begin{array}{l}241 \\
242 \\
243 \\
244 \\
245 \\
246\end{array}$ & $\begin{array}{l}\text { Undistributed cost } \\
\text { Switch gear } \\
\text { Station service equipment } \\
\text { Swltchboards } \\
\text { Protective equipment } \\
\text { Electrical structure and wiring containers } \\
\text { Power and control wiring }\end{array}$ & $\begin{array}{r}2.5 \\
5.3 \\
.5 \\
.5 \\
7.0 \\
10.7 \\
\end{array}$ & $\begin{array}{r}.4 \\
.9 \\
4.5 \\
.8 \\
.5 \\
6.1 \\
8.7\end{array}$ & $\begin{array}{r}.4 \\
1.3 \\
3.3 \\
.7 \\
.3 \\
3.0 \\
7.7 \\
\end{array}$ \\
\hline & Tútal for Account 24 & 26.5 & 21.9 & 16.7 \\
\hline 25 & Miscellaneous plant equipment & & & \\
\hline $\begin{array}{l}251 \\
252 \\
253 \\
251\end{array}$ & $\begin{array}{l}\text { Transporting and lifting } \\
\text { Air, hydraulic, water, and steam service } \\
\text { Communlcations equipment } \\
\text { Eurnichingo and firturco }\end{array}$ & $\begin{array}{r}1.4 \\
6.8 \\
.2 \\
.4 \\
\end{array}$ & $\begin{array}{r}1.8 \\
7.5 \\
.3 \\
.5 \\
\end{array}$ & $\begin{array}{r}1.6 \\
4.7 \\
.2 \\
.3 \\
\end{array}$ \\
\hline & Total for Account 25 & 8.8 & 10.1 & 6.8 \\
\hline 26 & Special materials & & & \\
\hline $\begin{array}{l}263 \\
264 \\
269\end{array}$ & $\begin{array}{l}\text { Reactor coolant } \\
\text { Intermediate coolant } \\
\text { Initial catalyst filling }\end{array}$ & $\begin{array}{l}.3 \\
.1 \\
.6 \\
\end{array}$ & $\begin{array}{r}.3 \\
.3 \\
.6 \\
\end{array}$ & $\begin{array}{r}.3 \\
.1 \\
.6 \\
\end{array}$ \\
\hline & Total for Account 26 & 1.0 & 1.2 & 1.0 \\
\hline 91 and $99^{2}$ & . & 141.0 & 147.0 & 105.0 \\
\hline & Total adjusted costs & 603 & 635 & 381 \\
\hline
\end{tabular}

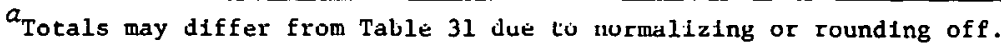
Source: Table 31 . 
in the GE and WANL estimates where it appears that the costs are not previously estimated.

The three adjusted cost estimates differ significantly in only three accounts. The WANL estimate for the containment building cost is much lower than the GA/UE\&C and GE costs and appears to be based on a lower estimate of construction and material costs.

The reactor equipment account shows major differences between the estimates for the GE and WANL concepts and the GA/UE\&C plant, which is based on the commercial HTGR. Past experience indicates that the costs of new technologies (such as the pebble-bed reactor, PCIV, and NERVA-type fue1) will increase considerably before they become commercial. The concept with the lowest cost (WANL) is also the least developed and can thus be expected to increase the most.

The major difference between the GA/UE\&C and the GE estimate for the heat transfer system account is the length of the IHL piping. The GE cost could probably be considerably reduced by building more than one IHL building and reducing the IHL piping length. The WANL estimate for this account (Table 31) is apparently based on the costs of the intermediate heat exchanger, IHL piping within the containment building, and the isolation valves, as well as the systems normally contained in this account for an HTGR. This estimate is unreasonably low.

\subsubsection{Summary of operating and maintenance costs}

Operating and maintenance $(O \& M)$ costs were compiled from refs. 2 and 3 for the GE and WANL plants and in Sect. 2.5 for the GA/UE\&C plant. These costs are presented in Table 34. Only direct O\&M costs are included in the summary; interest and finance charges are excluded because they are merely percentages of direct costs which are compared.

The total O\&M costs given in Table 34 are not comparable because not all categories of $O \& M$ were estimated in each report. However, the costs for each category that is quoted in more than one estimate are essentially the same in each estimate. Thus, assuming that the items missing from estimates will also be comparable when included, it is reasonable to expect an annual direct $0 \& M$ cost of about $\$ 9$ million for each of the concepts being compared.

The GA/UE\&C estimate for station staffing is higher than the other estimates. This difference is due to the additional staff required for the intermediate loop building and other structures not estimated for the other plants.

It is difficult to accurately estimate materials, supplies, and outside services without detailed design and operating experience. Within the accuracy of this comparison, the costs presented are not significantly different. 
Table 34. Summary of annual direct operating and maintenance costs [without electrical generation (July 1974)]

\begin{tabular}{|c|c|c|c|}
\hline \multirow[b]{2}{*}{ Item } & \multicolumn{3}{|c|}{ Annual direct costs (thousands of dollars) } \\
\hline & GA/UE\&C & GE & WANL \\
\hline Station staffing & 1,960 & 1,544 & 1,698 \\
\hline Materials, supplies and outside services & $\begin{array}{r}160 \\
\text { to } \\
820\end{array}$ & 1,160 & 520 \\
\hline Coolant makeup purchases & 125 & 120 & 135 \\
\hline Electric power purchases & 2,080 & & \\
\hline Fixed maintenance & $\begin{array}{c}2,500 \\
\text { to } \\
4,000\end{array}$ & & 2,920 \\
\hline $\begin{array}{l}\text { Variable maintenance (including catalyst } \\
\text { costs) }\end{array}$ & 1,320 & & \\
\hline General and administrative & 260 & 174 & 333 \\
\hline $\begin{array}{l}\text { Nuclear liability insurance (including } \\
\text { commercial and government) }\end{array}$ & 390 & 390 & 390 \\
\hline Annual license fee & 200 & & \\
\hline Total annual costs ${ }^{a}$ & $\begin{array}{c}8,995 \\
\text { to } \\
11,155\end{array}$ & 3,388 & 5,996 \\
\hline
\end{tabular}

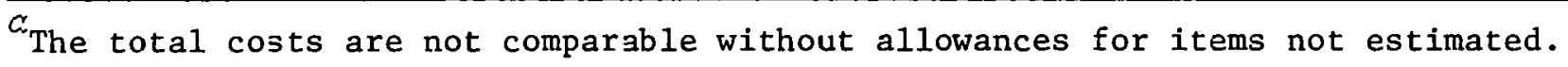


General Electric did not estimate the cost of electricity required to operate the plant. This cost is likely to be the same as the other estimates. Electricity costs are, of course, subject to rapid change in the present economy.

Fixed and variable maintenance are not estimated by GE or WANL. Based on recent experience with high temperature heat exchangers (see Sect. 2.5), maintenance costs are expected to be high. The GA/UE\&C estimate is conservative, but the costs are likely to be similar for all plants. (Note: The GA/UE\&C estimate includes maintenance of the reformer but no other process equipment.) 


\section{REFERENCES}

1. High-Temperature Nuclear Heat Source Study, Report GA-A13158, General Atomic Company, December 1974.

2. The VHTR for Process Heat, Report GEAP-14018, General Electric Company, December 1974.

3. The Very High Temperature Reactor for Process Heat, Report WANL2455-1, Westinghouse Astronuclear Laboratory, December 1974.

4. Ref. 2, Fig. 2.6.2.

5. HTGR Gas Turbine Fower Plant Control, Safety, and Maintenance Studies Seriannual Progress Report for Period Ending December 31, 1972, Report GA-A12503, General Atomic Company, February 22, 1973, pp. 11-13.

6. F. E. Schilling, B. Beine, H. Gross, The Prestressed Cast Iron Pressure Vessel: Its Applicability for Gas and Watercooled Nuclear Power Reactors and for Impact Load Protection, Paper G 2/8 (source unknown).

7. Ref. 3, Table 5.2.1, p. 5-7.

8. American Society of Testing and Materials Committee A-4, "Gray Iron Castings for Pressure-Containing Parts for Temperatures up to $650^{\circ} \mathrm{F}$," ASTM Designation A278-64 (Reapproved 1971), 1972 Annual Book of ASTM Standards, Part 2.

9. Ref. 3, p. 2-13.

10. Ref. 3, p. 2-16.

11. Ref. 3, p. 139 .

12. Ref. 3, p. 1-14.

13. Ref. 3, pp. 5-5 - 5-7.

14. American Society of Mechanical Engineers, ASME Boiler and Pressure Véssel Code, Sect. III, ASME Regulatory/Liccnoing Body.

15. Ref. 1, Appendix B.

16. R. A. Strehlow and H. C. Savage, "The Permeation of Hydrogen Isotopes through Structural Metals at Low Pressures and through Metals with Oxide Film Barriers," Nucl. Technol. 22(1): 127-137 (April 1974). 
17. Ref. 3, Fig. 2.2-10.

18. Ref. 3, p. 2-32.

19. Guide for Economic Evaluation of Nuclear Reactor Plant Design, Report NUS-531, United States Atomic Energy Commission.

20. Personal communication, W. E. Thomas to J. G. Delene, November 1974, Oak Ridge National Laboratory.

21. 77-MWe Central Station Power Plants Investment Cost Study - HighTemperature Gas-Cooled Reactor Plant, vol. V, Report WASH-1230, United States Atomic Energy Commission, January 1973.

22. Ref. 1, Fig. 4.3.

23. Ref. 19, Appendix A.

24. Ref. 1, pp. 4-19-4-42.

25. Kef. 1, p. 5-49.

26. Ref. 2, "Systems Concepts Topical Report," Sect. 2.1.1.

27. Ref. 2, "Systems Concepts Topical Report," Sects. 2.1.1.4 and 2.1.1.5.

28. Ref. 2, Sect. 2.1.7.

29. Ref. 2, Sect. 2.1.9.1.

30. Ref. 2, "Systems Concepts Topical Report," Fig. 2-16.

31. Ref. 2, vol. II, Fig. 6-4.

32. Ref. 2, vol. I, Table 4-1.

33. Ref. 2, Table 4-5.

34. Ref. 2, Table 4-3.

35. Ref. 3, Fig. 2.1.1.

36. Ref. 3, Table 3.2.2.

37. Ref. 2, Fig. 2-4.

38. Ref. 2, Table 4-2.

39. Ref. 2, Tables 3.2-2 and A-9. 
ATTACHMENT A - PROCESS PLANT INTERFACES

This attachment defines the detailed thermal, mechanical, and electrical interfaces between the General Atomic/UE\&C conceptual nuclear plant and the chemical process plant.

\section{A.1 Thermal Interfaces}

The nuclear plant supplies steam to the process plant in return for boiler feed water at required conditions. Steam and methane are supplied by the process plant to the reformer in the nuclear plant, and the reformer effluent is returned. Conditions for these interfaces are shown in Table A.1.

In the 40-MW(e) turbine plant option, $0.322 \times 10^{6} \mathrm{lb} / \mathrm{hr}$ of steam in the process plant are directed to the turbine and returned at $2.5 \mathrm{in}$. HgA, $108.7^{\circ} \mathrm{F}, 2.94 \times 10^{8} \mathrm{Btu} / \mathrm{hr}$. The heat balance diagram is shown in Fig. 23.

In the $100-\mathrm{Mw}_{\text {(e) }}$ turbine plant option, $0.805 \times 10^{6} \mathrm{lb} / \mathrm{hr}$ of steam in the process plant are directed to the turbine and returned at 2.5 in. HgA, $108.7^{\circ} \mathrm{F}, 7.34 \times 10^{8} \mathrm{Btu} / \mathrm{hr}$. The heat balance diagram for this case is shown in Fig. 24.

\section{A.2 Mechanical Interfaces}

\section{A.2.1 Equipment}

As discussed in Sect. 4.2.2, the reformer and all other primary coolant and auxiliary equipment are considered within the scope of the nuclear plant. All process equipment, excluding the reformers, but including the reformer feed effluent heat exchangers located within the intermediate loop buildings, is included in the scope of the process plant. All process plant support equipment is included with the process plant scope:

(1) cooling water equipment and cooling water makeup equipment,

(2) lubricating oil equipment,

(3) station air equipment,

(4) instrument air equipment,

(5) turbine effluent conditioning equipment (if required), and

(6) feedwater equipment. 
Table A.1. Thermal interfaces

\begin{tabular}{|c|c|c|}
\hline $\begin{array}{l}\text { Nuclear plant } \\
\text { configuration }\end{array}$ & To process plant ${ }^{a}$ & From process plant ${ }^{a}$ \\
\hline \multirow[t]{2}{*}{ Base plant } & $\begin{array}{l}\text { Steam: } \\
\quad 4.72 \times 10^{6} \mathrm{~W} \\
6.35 \times 10^{9} \mathrm{~B} \\
915 \mathrm{P} \\
720 \mathrm{~F}\end{array}$ & $\begin{array}{l}\text { Boiler feedwater: } \\
4.72 \times 10^{6} \mathrm{~W} \\
1.64 \times 10^{9} \mathrm{~B} \\
3115 \mathrm{P} \\
370 \mathrm{~F}\end{array}$ \\
\hline & $\begin{array}{l}\text { Reformer effluent: } \\
4.94 \times 10^{6} \mathrm{~W} \\
400 \mathrm{P} \\
1590 \mathrm{~F}\end{array}$ & $\begin{array}{l}\text { Reformer feed: } \\
3.75 \times 10^{6} \mathrm{~W} \text { steam } \\
1.19 \times 10^{6} \mathrm{~W} \mathrm{CH}_{4} \\
570 \mathrm{P} \\
1050 \mathrm{~F}\end{array}$ \\
\hline \multirow[t]{2}{*}{$\begin{array}{l}\text { Base plant with } \\
\text { intermediate } \\
\text { loop }\end{array}$} & $\begin{array}{l}\text { Steam: } \\
5.69 \times 10^{6} \mathrm{~W} \\
7.6 \times 10^{9} \mathrm{~B} \\
915 \mathrm{P} \\
705 \mathrm{~F}\end{array}$ & $\begin{array}{l}\text { Boiler feedwater: } \\
4.63 \times 10^{6} \text { W primary } \\
1.61 \times 10^{9} \text { B primary } \\
1.06 \times 10^{6} \text { W intermediate } \\
3.69 \times 10^{8} \text { B intermediate } \\
3115 \mathrm{P} \\
370 \mathrm{~F}\end{array}$ \\
\hline & $\begin{array}{l}\text { Reformer effluent: } \\
6.6 \times 10^{6} \mathrm{~W} \\
300 \mathrm{P} \\
1400 \mathrm{~F}\end{array}$ & $\begin{array}{l}\text { Reformer feed: } \\
5.41 \times 10^{6} \mathrm{~W} \text { steam } \\
1.19 \times 10^{6} \mathrm{~W} \mathrm{CH}_{4} \\
515 \mathrm{P} \\
1050 \mathrm{~F}\end{array}$ \\
\hline $\begin{array}{l}\text { Power generation, } \\
40 \mathrm{MW}(\mathrm{e})^{b}\end{array}$ & $\begin{array}{l}\text { Steam: } \\
0.322 \times 10^{6} \mathrm{~W} \\
2.94 \times 10^{8} \mathrm{~B} \\
1.23 \mathrm{P} \\
108.7 \mathrm{~F}\end{array}$ & $\begin{array}{l}\text { Steam: } \\
0.322 \times 18^{6} \mathrm{~W} \\
4.30 \times 10^{8} \mathrm{~B} \\
915 \mathrm{P} \\
705 \mathrm{~F}\end{array}$ \\
\hline $\begin{array}{l}\text { Power generation, } \\
100 \mathrm{MW}(\mathrm{e})\end{array}$ & $\begin{array}{l}\text { Steam: } \\
\quad 0.805 \times 10^{6} \mathrm{~W} \\
7.34 \times 10^{8} \mathrm{~B} \\
1.23 \mathrm{P} \\
108.7 \mathrm{~F}\end{array}$ & $\begin{array}{l}\text { Steam: } \\
0.805 \times 10^{6} \mathrm{~W} \\
1.08 \times 10^{9} \mathrm{~B} \\
915 \mathrm{P} \\
705 \mathrm{~F}\end{array}$ \\
\hline
\end{tabular}




\section{A.2.2 Piping}

Process piping is the responsibility of the process plant from the containment building outer wall. In the case of the intermediate loop, process piping will start at the reformer inlets and outlets and at the steam generator inlets.

\section{A.2.3 Space}

Control board space is provided in the control building for process plant control which is equal to the space allocated for turbine-generator controls in an 1160-MW(e) HTGR.

\section{A.3 Electrical Interfaces}

The switchgear, power cable, and wire to the switchgear of the process plant, and $30 \mathrm{MW}(\mathrm{e})$ power are provided to the process plant by the nuclear plant. The process plant will supply all instrumentation and control wire and equipment for the process systems and interfaces with nuclear plant systems.

Additional electric power over $30 \mathrm{MW}(\mathrm{e})$ must be provided by the process plant. 
THIS PAGE

\section{WAS INTENTIONALLY LEFT BLANK}


ORNL/ TM-5409

\section{INTERNAL DISTRIBUTION}

1. T. D. Anderson

2. J. H. Coobs

3. R. H. Cooper

4. F. L. Culler

5. J. G. Delene

6. J. R. Distefano

7. W. P. Eatherly

8. J. R. Enge1

9. G. G. Fee

10. E. C. Fox

11. L. C. Fuller

12. W. R. Gambill

13. M. J. Goglia

14. H. W. Hoffman

15. F. J. Homan

16. J. E. Jones, Jr.

17. P. R. Kasten

18. O. H. Klepper

19. C. C. Littlefield
20. R. E. MacPherson

21. A. P. Malinauskas

22. W. J. McCarthy, Jr.

23. J. P. Nichols

24. H. Postma

25. M. W. Rosenthal

26. T. H. Row

27. M. D. Silverman

28-170. I. Spiewak

171. J. J. Taylor

172. D. B. Trauger

173. G. D. Whitman

174. W. J. Wilcox

175. ORNL Patent Office

176-177. Central Research Library

178. Document Reference Section

179-181. Laboratory Records Department

182. Laboratory Records (RC)

EXTERNAL DISTRIBUTION

183. Director, Division of Fossil Energy Research, ERDA, Washington, D.C. 20545

184. Assistant Administrator for Fossil Energy, ERDA, Washington, D.C. 20545

185. Director, Division of Coal Conversion and Utilization, ERDA, Washington, D.C. 20545

186. Mayo Carrington, Division of Coal Conversion and Utilization, ERDA, Washington, D.C. 20545

187. R. E. Vener, Division of Coal Conversion and Utilization, ERDA, Washington, D.C. 20545

188. Fred Witmer, Division of Coal Conversion and Utilization, ERDA, Washington, D.C. 20545

189. Director, Division of Nuclear Research and Applications, ERDA, Washington, D.C. 20545

190. T. Beresovski, Division of Nuclear Research and Applications, ERDA, Washington, D.C. 20545

191. D. E. Erb, Division of Nuclear Research and Applications, ERDA, Washington, D.C. 20545

192. K. O. Laughon, Division of Nuclear Research and Applications, ERDA, Washington, D.C. 20545

193. J. C. Montgomery, Division of Nuclear Research and Applications, ERDA, Washington, D.C. 20545

194. R. G. Oehl, Division of Nuclear Research and Applications, ERDA, Washington, D.C. 20545

195. J. H. Swisher, Division of Conservation Research and Technology, ERDA, Washington, D.C. 20545 
196. A. T. McMain, General Atomic Co., P.0. Box 81608, San Diego, Calif. 92138

197. R. N. Quade, General Atomic Co., P.0. Box 81608, San Diego, Calif. 92138

198. G. H. Farbman, Westinghouse Electric Corp., Astronuclear Laboratory, P.O. Box 10864, Pittsburgh, Pa. 15236

199. A. R. Jones, Westinghouse Electric Corp., Astronuclear Laboratory, P.0. Box 10864, Pittsburgh, Pa. 15236

200. A. E. Kakretz, General Electric Co., Fairfield, Conn. 06431

201. 0. G. Woike, General Electric Co., P.0. Box 15132, Cincinnati, Ohio 45215

202. J. H. Crowley, United Engineers \& Constructors, 1401 Arch St., Philadelphia, Pa. 19105

203. J. B. Newman, United Engineers \& Constructors, 1401 Arch St., Philadelphia, Pa. 19105

204. D. J. Blickwede, Bethlehem Steel Corp., Bethlehem, Pa. 18016

205. T. F. Barnhart, U.S. Steel Corp., 125 Jamison Lane, Monroeville, $\mathrm{Pa} .15146$

206. H. W. Paxton, U.S. Steel Corp., 125 Jamison Lane, Monroeville, $\mathrm{Pa} .15146$

207. R. W. Wendes, Amoco Oil Co., Box 6110A, Chicago, I11. 60680

208. D. C. Azbill, Shell Oil Co., One Shell Plaza, P.o. Box 2463, Houston, Tex. 77001

209. F. M. Richmond, Universal-Cyclops, 650 Washington Rd., Pittsburgh, $\mathrm{Pa} .15228$

210. Derek Gregory, Institute of Gas Technology, 3424 South State St., Chicago, I11. 60616

211. R. J. Jiacoletti, Los Alamos Scientific Laboratory, P.0. Box 1663, Los Alamos, N.M. 87544

212. Donald Bogart, National Aeronautics and Space Administration, 6390 Nelwood Rd., Cleveland, Ohio 44135

213. D. R. Stone, National Aeronautics and Space Administration, Washington, D.C. 20546

214. Jack G. Connors, Battelle-Columbus Laboratory, 505 King Ave., Columbus, Ohio 43201

215. F. E. Faris, Interdevelopment, Inc., Suite 1014, Rutherford B. Hayes Bldg., 2361 S. Jefferson Davis Hwy., Arlington, Va. 22202

216. Seymour Alpert, Electric Power Research Institute, 3412 Hillview Ave., Palo Alto, Calif. 94304

217. A. Flowers, American Gas Association, 1515 Wilson Blvd., Arlington, Va. 22209

218. W. C. Helt, National Coal Association, 110317 th St., NW, Washington, D.C. 20036

219. W. W. Talley, Resource Analysis \& Management Group, 2500 First National Center, Oklahoma City, Okla. 73102

220. Don Crego, Gilbert Associates, 525 Lancaster Ave., Reading, $\mathrm{Pa} .19603$

221. M. Steinberg, Brookhaven National Laboratory, Upton, N.Y. 11973

222. Engineering Technology Division, ORO, Oak Ridge, Tenn. 37830

223. Research and Technical Support Division, ORO, Oak Ridge, Tenn. 37830

224-250. Technical Information Center, Oak Ridge, Tenn. 37830 